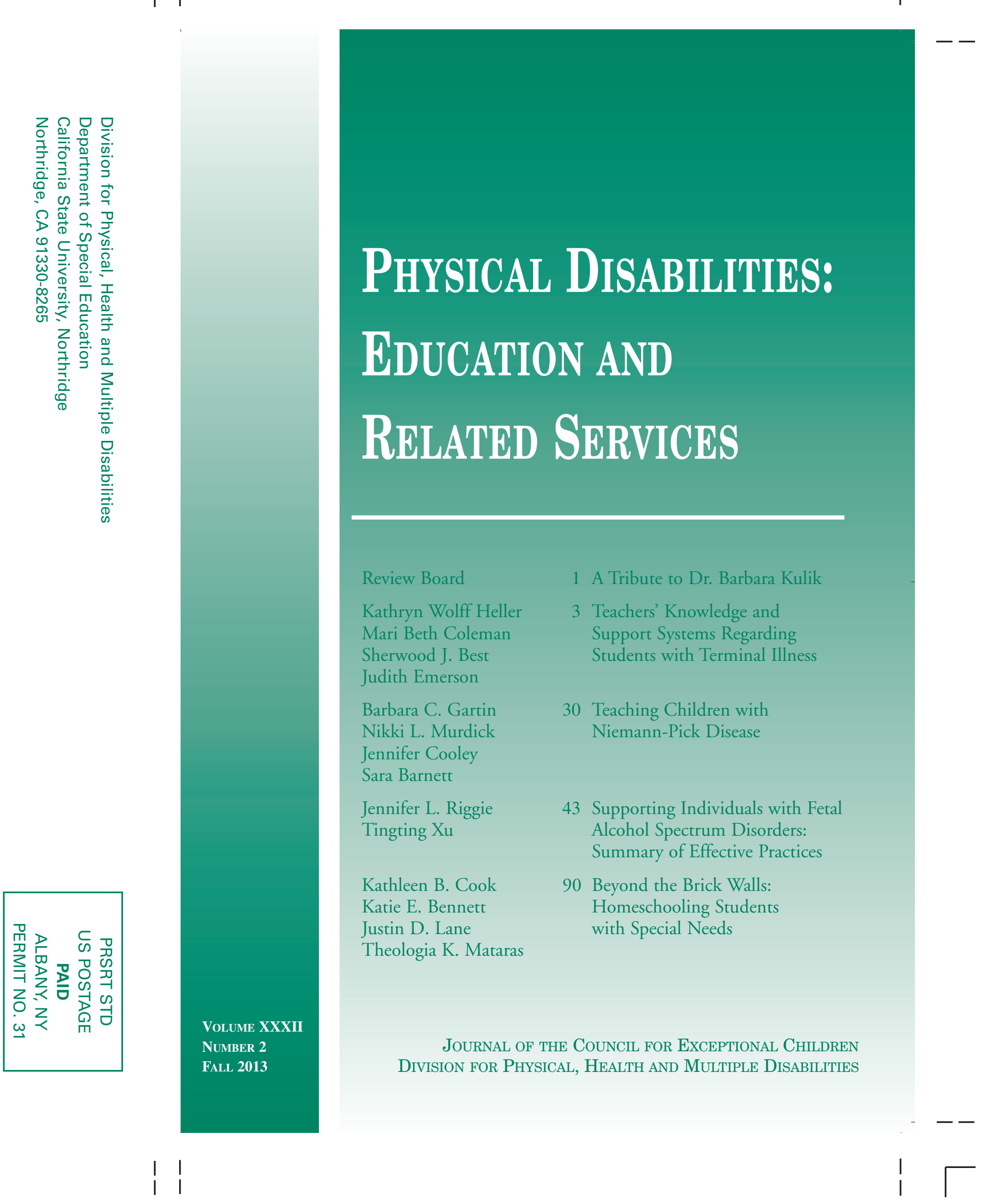




\section{Physical Disabilities: EDUCATION AND}

ReLated SERvices

Volume XXXII, No. 2

FALL 2013

Journal of THE COUNCIL FOR EXCEPTIONAL CHILDREN Division for Physical, Health and Multiple Disabilities 
Copyright (C) 2013

The Council for Exceptional Children

Division for Physical, Health and Multiple Disabilities 


\section{EDITOR}

Barbara J. Kulik, California State University, Northridge

\section{EDITORIAL BOARD}

Sherwood J. Best, California State University, Los Angeles

Mari Beth Coleman, University of Tennessee

Blanche Jackson Glimps, Tennessee State University

Kathryn Wolff Heller, Georgia State University

Robert Sandieson, University of Western Ontario

Gardner T. Umbarger, III, Saginaw Valley State University 


\section{DIVISION FOR PHYSICAL, HEALTH AND MULTIPLE DISABILITIES (DPHMD) 2013 OFFICERS AND COMMITTEE CHAIRS}

\author{
PRESIDENT \\ Kharon Grimmet \\ Indiana University-Bloomington \\ 8861 Kathleen St. \\ Indianapolis, IN 46234 \\ 317/670-8660 \\ kgrimmet@indiana.edu
}

\section{PRESIDENT ELECT}

Melissa Jasieniecki

SPEED Program for Adaptive

Learning

1125 Division St.

Chicago Heights, IL 60411

219/776-4915 (C)

mjasieniecki@comcast.net

\section{VICE PRESIDENT}

David S. Gordon

Wagner College

One Campus Rd.

Staten Island, NY 10301

718/390-3472

david.gordon@wagner.edu

\section{PAST PRESIDENT}

Lisa Pufpaff

Dept.of Special Education

Teachers College, Room 709

Ball State University

2000 W. University Ave.

Muncie, IN 47306-0002

765/285-5714 (O)

lapufpaff@bsu.edu

\section{TREASURER}

Margaret (Meg) Cooper

University of West Georgia

121 Oxford Sq

Carrollton, GA 30117-2456

678/839-6158 (O)

mcooper@westga.edu

\section{SECRETARY}

Kristin Joannou

516 Ohio St. \#A

Lawrence, KS 66044

785/760-5806

kjoannou@ku.edu

\section{STUDENT REPRESENTATIVE}

Vacant

\section{HISTORIAN}

Mark Oppenheimer

3001 Veazey Terrace NW,

Apt 1214

Washington, DC 20008-5407

202/431-5418 (C)

\section{JOURNAL EDITOR-Physical}

Disabilities: Education and Related

Services

Barbara Kulik

3380 Country Club Dr

Glendale, CA 91208-1718

818/541-0649 (O \& H)

barbara.kulik@csun.edu 


\section{NEWSLETTER EDITOR}

Linda Thomas

School District Hillsborough County

1006 Helmsdale Dr.

Wesley Chapel, FL 33543

813/975-7611x224 (O)

lthomas33@tampabay.rr.com

\section{CAN COORDINATOR}

Amanda Carter

7932 Montbridge Way

Powell, TN 37849

865/805-9100 (O)

wxc155@mocs.utc.edu

\section{MEMBERSHIP CHAIR}

Robert Hales

2965 W. Comstock Dr.

Chandler, AZ 85224

480/570-2916

rdhales79@yahoo.com

\section{CRITICAL ISSUES AND}

LEADERSHIP CO-CHAIRS

Kathryn Wolff Heller

Dept. of Educational Psychology \&

Special Education

Georgia State University

Box 3979

Atlanta, GA 30302-3979

404/413-8216 (O)

kwheller@aol.com

Mary Jane (Janie) Avant

220 Baywater Dr

Suwanee, GA 30024-4045

770/815-3645 (C)

jtavant@mindspring.com
CONSTITUTION \& BY-LAWS

CHAIR

Mari Beth Coleman

Dept. of Theory and Practice in Teacher Educ.

A416 Bailey Education Complex

University of Tennessee

Knoxville, TN 37996-3442

865/974-4456 (O)

mbc@utk.edu

\section{KNOWLEDGE AND SKILLS}

\section{COMMITTEE CHAIR}

Joni Baldwin

Department of Teacher Education

University of Dayton

800 Rockcreek Dr

Centerville, $\mathrm{OH} 45458$

218/234-9026 (C)

jbaldwin1@udayton.edu

\section{SEVERE/MULTIPLE DISABILITIES}

CHAIR

Emily Morrison

2479 Country Club Rd. \#200A

Spartenburg, SC 29302

302/757-6760

emorrison992@yahoo.com

\section{FINANCE CHAIR}

Alexandra Da Fonte

Dept. of Special Education

Box 228 GPC

Vanderbilt University

Nashville, TN 37203

615/322-8898 (O)

alexandra.dafonte@vanderbilt.edu 
CHRONIC MEDICAL CONDITIONS CHAIR

Megan Elam

3333 Burnet Ave.

MLC 2040

Cincinnati, $\mathrm{OH} 45229$

513/803-3272

megan.elam1@cchmc.org

POLICY \& ADVOCACY CHAIR

Amanda Carter (see CAN COORDI-

NATOR)

STRATEGIC PLAN CHAIR

Linda Thomas (see NEWSLETTER

EDITOR)

\section{CONVENTION CHAIR}

Joni Baldwin (see KNOWLEDGE \& SKILLS)

\author{
PROFESSIONAL DEVELOPMENT \\ CO-CHAIRS \\ Pamela Mims \\ Dept. of Human Dev. \& Learning \\ Box 70548 \\ East Tennessee State University \\ 807 University Parkway \\ Johnson City, TN 37614 \\ 423/439-7145 (O) \\ mimspj@mail.etsu.edu
}

Cynthia R. Chambers

Dept. of Human Dev. \& Learning

Box 70548

East Tennessee State University

807 University Parkway

Johnson City, TN 37614

423/439-7586 (O)

chamberc@mail.etsu.edu

\section{ADVISORY CHAIR}

Pamela DeLoach

6711 Spanish Moss Circle

Tampa, FL 33625

813/966-6197 cell

pdeloach@tampabay.rr.com

CEC-RA REPRESENTATIVES

Kharon Grimmet (see PRESIDENT)

Melissa Jasieniecki (see PRESIDENT

ELECT)

\section{CEC-IDC REPRESENTATIVES}

Kharon Grimmet (see PRESIDENT)

Lisa Pufpaff (see PAST PRESIDENT)

DPHMD WEB PAGE

http://web.utk.edu/ -dphmd 


\section{INFORMATION PAGE}

Goals of Physical Disabilities: Education and Related Services:

1. Support the goals of DPHMD

2. Provide a forum for presentation of current research in the field of physical, health, and multiple disabilities (PHMD)

3. Act as a vehicle for the dissemination of information important to practitioners in the field

4. Address the nature and characteristics of children and adults the PHMD, program development, assessment practices, and instruction from different perspectives

5. Supply valuable information for professionals providing related services to the population with PHMD

6. Stimulate thoughtful consideration of the future of education of individuals with PHMD

Physical Disabilities: Education and Related Services is published twice a year and is indexed in EBSCO as well as ERIC at http://www.eric.ed.gov

The Division for Physical, Health and Multiple Disabilities of the Council for Exceptional Children retains literary rights on the copyrighted articles in Physical Disabilities: Education and Related Services. Up to 100 copies of the articles in this journal may be reproduced for nonprofit distribution without permission from the publisher. All other forms of reproduction require written permission from the journal editor.

Any journal article is the personal expression of the author(s) and does not necessarily carry the endorsement of the Division for Physical, Health and Multiple Disabilities.

Physical Disabilities: Education and Related Services is sent to all members of the Division for Physical, Health and Multiple Disabilities (DPHMD) of 
the Council for Exceptional Children (CEC). Application for DPHMD membership can be made through CEC at 2900 Crystal Drive, Suite 1000, Arlington, VA 22202-3557 or (866)509-0218 or (703) 620-3660. Subscriptions are available through Boyd Printing Company, Inc., 595 Loudon Road, Ste. 117, Latham, NY 12110 or (518) 608-2565 or cjohnson@boydprinting.com. Cost is $\$ 35$ per year for individuals, $\$ 75$ per year for institutions. Back issues are available for $\$ 18$ each.

Visit the web site for the Division for Physical, Health and Multiple Disabilities at: http://web.utk.edu/ -dphmd 


\section{A TRIBUTETO}

\section{DR. BARBARA KULIK}

We would like to take this opportunity to express our appreciation to Dr. Barbara Kulik for all of her hard work and dedication to the field of Physical and Health Disabilities and over 50 years of service to the Council for Exceptional Children (CEC) and the Division for Physical, Health and Multiple Disabilities (DPHMD). When she was a student in 1962, Dr. Kulik became a member of CEC and DPHMD (or DOPHHH as it was known back then). She began her career as a teacher of students with physical disabilities in Whittier Cooperative School District in California. She added another dimension to her educational service when she obtained her Ph.D. at Texas Woman's University and became a Professor and Department Chair in the Department of Special Education at California State University, Northridge (CSUN). As a professor, she provided leadership to the credentialing program in Physical and Health Impairments at CSUN and was an active member in the state-wide consortium of California Professors in Physical and Health Disabilities (CPPHD).

Nationally, Dr. Kulik has made a profound impact in the field of Physical and Health Disabilities through her work as a Professor, and through her dedication and commitment to DPHMD. For over 50 years, she has been instrumental in addressing the critical issues in CEC and DPHMD and supporting the organization. In the 1970s, she served DPHMD as Vice President, President-Elect, President, and Past President. In 1982, Dr. Kulik became a member of the Editorial Board of DPHMD's journal, and, in 1994, she became the Editor of Physical Disabilities: Education and Related Services. As Editor, she has been the driving force in producing a very high quality journal that has published articles which are critical to the field of physical, health, and multiple disabilities. Dr. Kulik has had a major impact in lives of numerous professionals by providing ongoing encouragement and mentorship to assist them in producing high quality articles. She has maintained a strong editorial board throughout the years that have assured a rigorous referee process. She was also instrumental in having Physical Disabilities: Education and Related Services become part of the ERIC system to enhance dissemination efforts of the journals' articles. Professors have used articles from the journal to assist with teacher preparation efforts and support evidence-based educational programming for infants, children, and youth with physical, health, and multiple disabilities. Individuals who receive the journal have frequently commented on the usefulness of the articles in assisting teachers and related service staff in better serving children with physical disabilities. 
2 PHYSICAL DISABILITIES: EDUCATION AND RELATED SERVICES

Barbara's tireless efforts throughout the years have made a profound impact on professors, teachers, and children and she is greatly appreciated. Thank you Dr. Kulik! 


\title{
TEACHERS' KNOWLEDGE AND SUPPORT SYSTEMS REGARDING STUDENTS WITH TERMINAL ILLNESS
}

\author{
KATHRYNWOLFF HELLER \\ Georgia State University \\ MARI BETH COLEMAN \\ University of Tennessee, Knoxville \\ SHERWOOD J. BEST \\ California State University, Los Angeles \\ JUDITH EMERSON \\ Georgia State University
}

\section{Author Note}

Kathryn Wolff Heller, Department of Educational Psychology and Special Education, Georgia State University; Mari Beth Coleman, Department of Theory and Practice in Teacher Education, University of Tennessee; Sherwood J. Best, Division of Special Education, California State University, Los Angeles; Judith Emerson, Department of Educational Psychology and Special Education, Georgia State University.

We acknowledge and thank the following organizations for allowing their membership lists to be data sources for this research: Division of Physical, Health, and Multiple Disabilities of the Council for Exceptional Children; National Association of School Nurses; Georgia Orthopedic Impairment Consortium; and California Association of Physical and Health Impairments.

Correspondence to: Kathryn W. Heller, Dept. Educational Psychology and Special Education, P.O. Box 3979, Georgia State University, Atlanta, GA 30302-3979. E-mail: kheller@gsu.edu 


\section{ABSTRACT}

This study examined teachers' knowledge and support when working with students with terminal illness or having experienced a student death. One hundred and ninety teachers of students with physical or multiple disabilities responded to a 40 item questionnarionnaire that was distributed nationally. Results indicated that teachers have greater knowledge and support in this area than 21 years ago, although there continues to be deficits. For teachers receiving support, the school nurse was identified as their primary source of support, as well as the primary source to answer questions, and discuss the teachers' role. School counselors were identified as the primary support for classmates (in addition to receiving support from their teacher). Teachers identified several areas in which they wanted assistance and support which have implications for future research and training.

Death is an inevitable and universal experience for all living things. However, death and dying remains a topic that is regarded by many as uncomfortable and even inappropriate for public discussion (Harrawood, Doughty, \& Wilde, 2011; Horridge, 2011; Mak, 2011). It is especially difficult to contemplate the death of a child. Although approximately 2.5 million people die in the United States every year, slightly over 50,000 of these are infants or children (Heron, Sutton, Xu, Ventura, Strobino, \& Guyer, 2010). Evaluation of these statistics suggests that experiencing the death of a school-age child is not a highly probable event for teachers. However, with the increasing inclusion of children and adolescents with terminal illnesses or special health care needs into public schools, coupled with advances in medical technology that allow children with vulnerable health to live longer, the likelihood that teachers will encounter student death increases. It also magnifies the need for teachers who can sensitively and effectively meet these student's health and emotional challenges, as well as support classmates, parents and themselves when faced with students who are dying. Unfortunately, teachers typically do not receive formal training on how to support a student who is dying, nor how to support classmates, parents, or themselves (Lazenby, 2006). This deficiency, added to factors such as anxiety and personal fear of death, complicate the dynamic and may reduce the ability of teachers to effectively and compassionately support students, their families, and themselves.

Historically, family members were integrally involved in many aspects of the death process. Currently, physical caregiving, preparation of the body after death, and internment, previously provided by family members, have been supplanted by professionals who assume these roles and responsibilities. Children, who might have witnessed many of these activities at younger ages, 
may not experience them until they are much older (if at all). Added to the physical distance placed between the living and the dead in contemporary Western society are views that children must be "sheltered" from the emotional impact of death and a belief that children cannot comprehend the meaning of death, which may lead parents to discourage discussion about illness, dying, and death (Holland, 2008). These prohibitions create additional barriers to communication and understanding. At a time when we have more students in the school with severe medical conditions and terminal illness who will die before they graduate, the need for informed professional support is essential.

The development of concepts about death and reactions to death are highly influenced by variables such as age, intellectual function, culture, media, religion/spirituality, communication opportunities, and personal experience (Clute, 2010; Cox, Garrett, \& Graham, 2005; Hunter \& Smith, 2008; Mak, 2011; Niemiec \& Schulenberg, 2011; Smith, Alberto, Briggs, $\&$ Heller, 1991). Speece and Brent $(1984 ; 1992)$ note that a mature concept of death is attained by most children by the time they are 9 or 10 years old, although children approach their understanding of death at different rates. Eventually, most children will understand the five major concepts of death: 1) inevitability (everything dies), 2) universality (nothing is exempt), 3) irreversibility or finality (not coming back), 4) cessation or nonfunctionality (body does not work); and 5) causality (something in the body prevents it from functioning) (Corr, 2010; Slaughter \& Griffiths, 2007; Walker, 2010). Once they comprehend these characteristics of death, children begin to understand the emotions that accompany the realization of death.

The child's ability to understand the concept of death will parallel the child's general cognitive development; hence, children who are very young or have developmental disabilities will not understand abstract concepts of death (Walker, 2010). These children may repeatedly ask when a classmate is coming back or believe that the body will start working again. Children between the ages of five and seven often associate nonphysiological reason for death, such as punishment or wishing the person dead. Death is often personified as an entity (e.g., ghost) from which one can escape (Corr, 2010; Walker, 2010 ). Teachers instruct students at all ages and levels of understanding and without understanding the developmental nature of the concept of death, teachers may be unable to effectively assist students with terminal illness, parents, or classmates.

When students have a terminal illness, their death is differentiated from a sudden death (such as from accident, suicide, homicide) in that there is 
the element of time. When there is a child with a terminal or life-limiting condition, teachers and school staff have time to determine the parents' feelings about the impending death, important cultural considerations, ways to address the dying child's questions and concerns, and how they prefer classmates' concerns be addressed (Rice \& Gourley, 2003). Parents often need support and suggestions as well. They may turn to the teacher for information about the condition, and necessary school adaptations. Teachers need to be prepared to provide this information or find out how to obtain it.

School-age children with terminal or life-limiting conditions often are aware of the seriousness of their illness. If they are able, continuing in school is important, even if it is for short periods of time since it allows them to participate in purposeful activities. In addition, when students with terminal illness realize their future is shortened, they often adapt and shift their focus to the more immediate future, such as the next significant event (e.g., holiday, school event) (Beale, Baile, Aaron, 2012). Sometimes these children will seek out a teacher to talk about their concerns and wishes or just have someone listen to them. Teachers will need to use reflective listening skills and help provide needed adaptations or supports to allow students with terminal illness to participate in significant events they have identified as important. Teachers need to have supports in place to assist their interactions with students with terminal illness that not only help them understand the students' particular condition, but provide ways of assisting students with terminal illness.

Some students with terminal illness will receive pediatric hospice services to address physical, psychological, social, and spiritual aspects of care when death is expected to occur within six months. The purpose is to enhance the quality of life of the child, focus on comfort rather than cure, provide support to the entire family through an interdisciplinary team (e.g., nurse, social worker, physician, chaplain, nursing assistant), and deliver hospice services in the student's environment (Wolfe, Hinds, \& Sourkes, 2011). It also includes emphasis on family-centered practice, cultural sensitivity, continuing education, and awareness of community resources (Crozier \& Hancock, 2012). Hospice care may also extend to the school setting. In one example, "school staff worked together with a hospice team to help a dying child remain involved with his class he was attending while attending school and as he declined at home. Support for students continued after their classmate's death, individually and school wide." (RamerChrastek, 2000, p. 52).

Classmates of all ages will need support when they experience the death of a classmate. Grief reactions can vary greatly between having the appear- 
ance of no reaction to a death to having reactions of intense longing, experiencing an inability to concentrate, asking multiple questions, exhibiting a range of emotions, and having physical symptoms. Each student will grieve in his or her own way and new grief reactions may occur long after the death (Cowan, 2010; Koehler, 2010). Having open discussions and finding ways to express grief in a safe environment is important (Cowan, 2010).

Teachers and counselors may use several approaches to support students who have lost a classmate such as: 1) using children books that have death and dying themes; 2) participating in rituals (such as attending funerals, drawing pictures, writing cards); 3) memorializing (such as planting a tree, making a memory box, making a collage of photographs); 4) creating legacies (such as scholarships, charity drives, dedicating an activity); and 5) creating peer support groups (Cowan, 2010). Teachers, school counselors, and other members of the educational team will need to have a good knowledge base in place to address classmates' concerns. Local hospices may provide occasional or ongoing support to school systems on how to help grieving children, including finding appropriate activities and assisting in helping bridge "the discomfort zone" where teachers struggle to find the right words when talking to grieving students (Naierman, 1997). In order for teachers to effectively help grieving children, it will be important that they also find ways to address their own grief (Lazenby, 2006).

The need to address issues of death and dying in schools has never been more critical. Teachers are typically more accessible to family members than doctors or social workers. In addition, daily contact with their students makes them a logical and pivotal source of information and comfort. They are an important part of a team that includes nurses, counselors, administrators, school psychologists, and others in the educational workplace. However, their effectiveness to support children's learning and emotional development begins with their own knowledge and self-competence (Chan $\&$ Tin, 2012).

The purpose of this study was to examine teachers' knowledge and support when working with students with terminal illness or having experienced a student death. This included examining the types of supports they had in place as well as determining the types of supports they would like to have in the future. Results of this study were also compared to results from the original questionnaire taken 21 years ago to examine any changes that have occurred over time. In addition, participants were also asked to respond to two areas not included in the original study, pain management and hospice, to determine knowledge and support in these areas. 


\section{METHOD}

\section{PARTICIPANTS}

The questionnaire targeted special education teachers who worked with students with physical disabilities and multiple disabilities (including students with severe and profound intellectual disabilities) since they were more likely to have experienced a student death and have students with terminal conditions. The questionnaire was also sent to school nurses. Two national organizations were targeted: the Division for Physical, Health and Multiple Disabilities (DPHMD) of the Council for Exceptional Children (which is the only national teacher organization in physical, health and multiple disabilities) and the National Association of School Nurses (NASN) (which is the national organization specifically for school nurses). In addition, since students with physical disabilities are more likely to have conditions that are terminal or life-limiting, two states that had teacher certification in Physical and Health Disabilities and consortia specifically for these teachers were targeted. These were the Georgia Orthopedic Impairment Consortium and the California Association of Physical and Health Impairments.

An email was sent to members of these groups explaining that the purpose of the questionnaire was to better understand the training, knowledge, experiences, and supports of teachers and school nurses who have experienced a student death or who have worked with students with terminal conditions. The letter contained a link to the questionnaire. Several weeks after the initial email letter was sent, a second reminder e-mail letter was distributed. In addition, an explanation of the research and link to the questionnaire was posted twice electronically in the National Association of School Nurses Weekly Digest. In the consortia and DPHMD meetings, an identical paper copy of the questionnaire was available if the participants preferred this to the electronic copy.

\section{QUESTIONNAIRE}

The questionnaire was comprised of 40 questions divided into 5 sections: a) demographics, b) terminal illness, c) death of a student, d) pain management, and e) hospice. The first three sections of the questionnaire were based on the original 1991 questionnaire in order to makes some comparisons in responses over time. The last two sections were new. The demographics section included information on employment, state the respondent worked, number of years teaching or practicing as a school nurse, and amount of training they had in the area of death and dying.

The section of the questionnaire on terminal illness had questions pertaining to: availability of support; availability of a source to answer questions; 
source to discuss respondents' role with student, family or classmates; desired support; and willingness to teach another student with a terminally illness. A question not included on the original questionnaire inquired about how knowledgeable respondents felt about their student's terminal illness.

The section of the questionnaire on the death of a student, questions pertained to: availability of support to the teacher or nurse following a student death; availability of support to the student's classmates; desired support; and attitudes regarding whether continuing in school as in the best interest for the student. Added to this section was a question about how knowledgeable respondents felt about the student's medical or health condition.

The two new sections of the questionnaire addressed the issues of pain and hospice. The pain section contained a background question to ascertain if the respondents had students who experienced pain and the number of these students. Other questions then dealt with ability to recognize pain, how knowledgeable the respondent felt about the student's pain medication, and who assisted them in assessing or managing student pain. The hospice section also started with a background question identifying if the respondent had any students receive hospice services. Topics in the hospice section included: how knowledgeable respondents were about hospice, if they wanted support or information from hospice personnel, and if they wanted to learn more about hospice.

\section{DATA ANALYSIS}

Two versions of the questionnaire were created: online and print. Questions on both versions were identical. Several types of questions were used in the questionnaire. Some multiple-choice questions required the respondent to choose one single answer (e.g., level of knowledge options from very knowledgeable to no knowledge at all) while other questions allowed multiple responses (e.g., check all sources of support that apply). Three questions about hospice were set up using a Likert-type rating scale. The remaining questions were open-ended and required respondents to type into an answer field (e.g., list questions classmates had about a student's death).

The online questionnaire was created using IBM Statistical Package for the Social Sciences (SPSS) Data Collection Web Interviews software. This software allows researchers to create various types of questions (e.g., single and multiple response multiple choice questions, Likert-type scales) which are answered online. Data are stored on a server and must be downloaded into SPSS Statistics software for analysis. When respondents clicked the link, they were taken to the consent page which explained the purpose of the questionnaire, described the voluntary and confidential nature of the questionnaire, 
and provided contact information of the researchers.. If they consented to participate, they were routed to the first question in the Demographic and Training section. SPSS Data Collection Web Interviews software saved respondents' data after each response; however, if participants closed the browser window prior to completing the last question, they were considered to be "incompleters" and their data were not included in the analyses. Most questions were displayed one question at a time on the screen. If the responder did not have a student with a pain, a terminal illness, or death, the rest of the section would be skipped. When respondents indicated they had a student in one of these areas, the software provided a reminder on the screen if respondents missed answering a question. The questionnaire was tested for proper construction.

The print questionnaire was created in Microsoft Word and was 8 pages in length. It was identical to the on-line questionnaire and also contained a consent page for the participants to sign. Data from print questionnaires were entered into the SPSS Data Collection Software so that all data were available for analysis.

Once all responses were collected, data were downloaded and analyses were completed using SPSS. For the purpose of this study, teachers' responses were separated from the original data set. This study used descriptive statistics including frequencies, percentages, valid percentages, and cumulative percentages. Valid percents of this current questionnaire were compared to the valid percent data in the original questionnaire.

Data were compared to the original questionnaire to find any general differences in responses. With over two decades between the two questionnaires, and increasing awareness of a need for greater teacher support, it was hypothesized that supports and knowledge bases would have changed over time.

\section{RESULTS}

A total of 1,723 questionnaires were sent by the researchers (although those receiving the email letter could forward it to other special education teachers or school nurses). Of these , 65 email addresses were returned with an error delivery message, making the total number distributed by the researchers as 1,658. A total of 589 questionnaires were returned for a return rate of $35.5 \%$.

Although the larger data set included school nurses, this article examines the smaller data set of special education teachers to determine teacher's current knowledge and support in the area of terminal illness and death as well as compare it to teacher responses from about 20 years ago. Of these returned questionnaires, 190 questionnaires were from special education teachers with: 
74 from teachers of students with physical and health disabilities; 110 from teachers of students with moderate, severe, profound intellectual disabilities or multiple disabilities; and 6 from hospital/ home bound teachers. This closely compares to the earlier study which had a return rate of 189 responses with: 74 teachers of students with physical and health disabilities; 96 teachers of students with moderate, severe, profound intellectual disabilities; and 19 other such as hospital/homebound. The 190 respondents in the current study were from 22 states and $70 \%$ had been teachers for longer than 10 years.

\section{KNOWLEDGE BASE OF TEACHERS}

In reporting their training, $33.2 \%$ of the respondents said they had no prior preparation in the area of death and dying, $47.4 \%$ had the topic discussed in university/college courses, $21.1 \%$ had in-services or workshops on death and dying, and $13.2 \%$ had training from other sources (e.g., hospice, life experiences). Respondents were asked four questions about their knowledge of students' terminal illness, medical condition of students who died, pain medication, and hospice (see Table 1).

On a 5-point Likert-type scale with 5 being very knowledgeable and 1 having no knowledge; respondents reported a mean of 3.78 regarding knowledge of

Table 1.

Teacher's Reported Knowledge Level Reported as Percentages

\begin{tabular}{|c|c|c|c|}
\hline & $\begin{array}{c}\text { Very knowledgeable/ } \\
\text { Knowledgeable }\end{array}$ & $\begin{array}{c}\text { Somewhat } \\
\text { knowledgeable }\end{array}$ & $\begin{array}{c}\text { Not very } \\
\text { Knowledgeable/ } \\
\text { No Knowledge }\end{array}$ \\
\hline $\begin{array}{l}\text { How knowledgeable do } \\
\text { you feel about students' } \\
\text { terminal illness? }(n=165)\end{array}$ & 64.2 & 29.7 & 6.1 \\
\hline $\begin{array}{l}\text { How knowledgeable do } \\
\text { you feel about medical } \\
\text { condition of the student } \\
\text { who died? }(\mathrm{n}=157)\end{array}$ & 70.7 & 26.1 & 3.1 \\
\hline $\begin{array}{l}\text { Do you feel knowledgeable } \\
\text { about the pain medication } \\
\text { your students receive? } \\
(\mathrm{n}=124)\end{array}$ & 44.3 & 41.1 & 14.5 \\
\hline $\begin{array}{l}\text { How knowledgeable are } \\
\text { you about hospice? } \\
(\mathrm{n}=190)\end{array}$ & 32.1 & 41.1 & 26.9 \\
\hline
\end{tabular}


their student's terminal illness. Stated in another way, only $64.2 \%$ rated themselves as very knowledgeable or knowledgeable about student's terminal illness. Respondents reported a mean of 3.87 regarding knowledge of medical conditions of students who had died. In this case, $70.7 \%$ rated themselves as very knowledgeable or knowledgeable about the medical conditions of students who had died. In rating their knowledge of the pain medications their students received, there was a mean of 3.43 with $44.3 \%$ of respondents reporting as being very knowledgeable or knowledgeable. When asked about hospice, there was a mean of 3.14 with only $32.1 \%$ indicating they were very knowledgeable or knowledgeable about hospice.

\section{TERMINAL ILLNESS}

Of those who responded to the questionnaire, $86.8 \%$ reported that they had at least one student with a terminal illness. The majority of respondents (25.8\%) reported having 2 or 3 students with a terminal illness. This was followed by $20 \%$ having 4 to 7 students with terminal illnesses, $4.2 \%$ having more than 12 students with a terminal illness, and $14.2 \%$ having 1 student with a terminal illness.

\section{Teachers' Source of Support When Students Have Terminal Illness.} Respondents were asked if they had a source of support available to them in working with students with terminal illnesses. As seen in Table 2, 14.5\% answered that they had no such source of support. Of those who answered that they had a source of support, the school nurse $(62.4 \%)$, coworkers $(60.6 \%)$ and supervisor/administrator $(26.1 \%)$ were the three most frequent sources of support within the school system. The top three sources outside the school system were family (47.9\%), reading/internet (37\%), and friends $(26.1 \%)$. The $15.8 \%$ who identified "other" as a source of support primarily identified nurses (not with the school system) and parents of the student.

In the original 1991 questionnaire, 32\% of the teachers reported having no source of support in working with students with terminal illnesses. For those who had support, $49 \%$ identified school counselors and/or school psychologists as being the greatest source of support within the school system, followed by co-workers (25\%), and social workers and nurses tied for third $(12 \%)$. The most frequent sources of support outside the school system were physicians (36\%), organizations (17\%), and clergy (14\%).

Available Sources to Answer Teachers' Questions. In the current study, respondents were asked if they had a source available to answer questions about the student's terminal illness or condition. Only $2.4 \%$ reported they had no source of support. Of those that had a source of support, the school nurse $(77 \%)$, co-worker (33.9\%) and school psychologist (17.6\%) were the 
Table 2.

Source of Support When Teaching a Student with a Terminal Illness Reported as Percentages (with 1991 Questionnaire in parentheses)

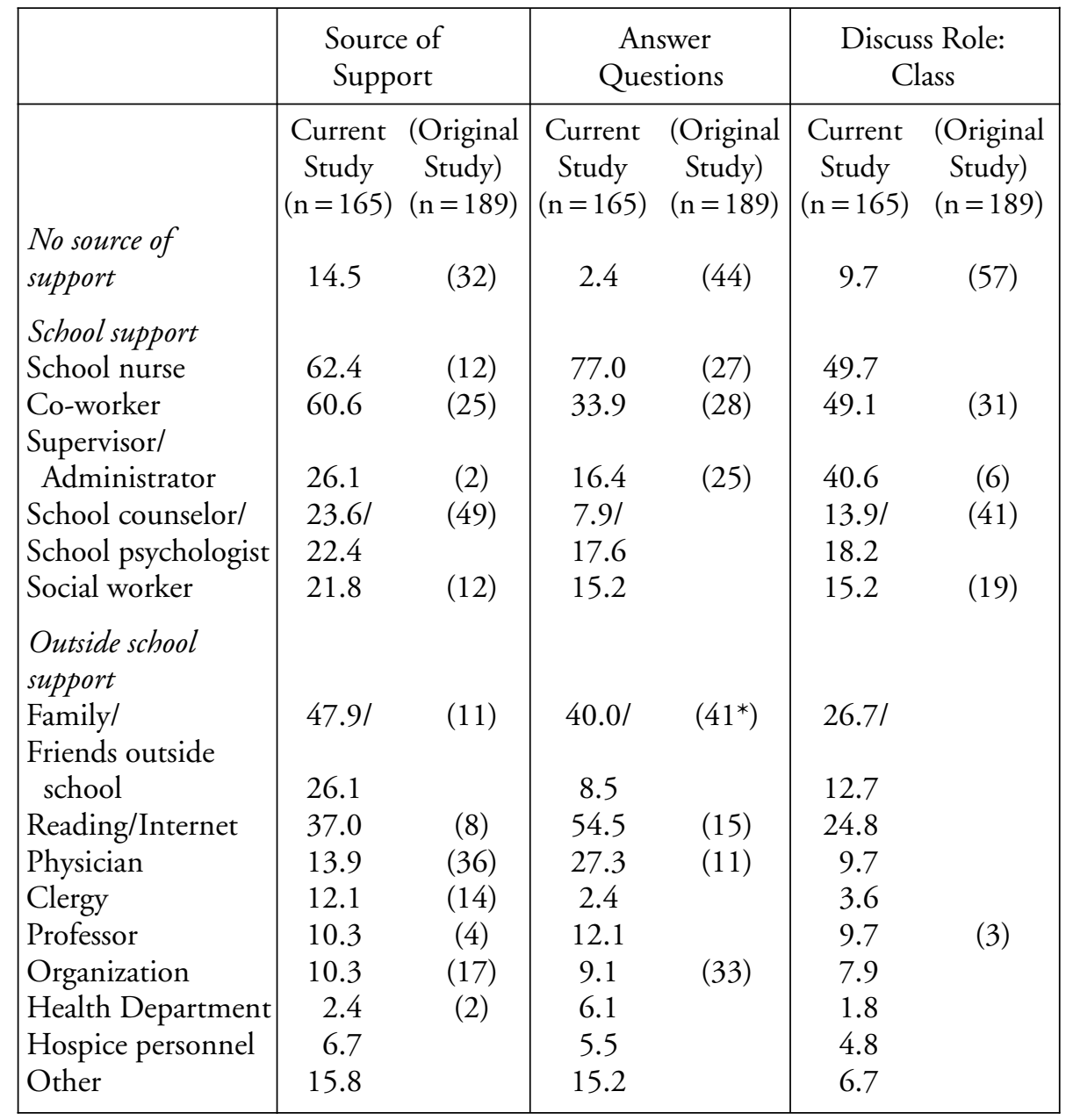

*The term family was not differentiated in the current study, whereas in the original study this percentage referred to the student's family.

three most common sources within the school system. Outside of the school system, the most common sources of support to answer questions about the terminal illness or student condition were reading/internet (54.5\%), family (40\%), and physician (27.3\%). The $15.2 \%$ who selected the category of other, primarily identified nurses (not associated with the school system), physical therapists, students guardians as their source of information. 
In the original study, $44 \%$ of the teachers responded that they had no support to answer questions about the terminal illness. For those who had a source of support, co-workers (28\%), school nurse (27\%) and supervisor/administrator $(25 \%)$ were the leading responses. Outside of the school system, the students' parents $(41 \%)$ were the most common source of support, followed by organizations (33\%) and reading/internet (15\%).

Available Support to Discuss Teachers' Role. In the current study, $9.7 \%$ responded that they had no source of support to discuss their role in interacting with the student, family or classmates. Of those that had a source of support, the school nurse (49.7\%), co-worker (49.1\%) and school psychologist $(18.2 \%)$ were the three most common sources in the school system. Outside of the school system, the three most common sources of support were family (26.7\%), reading/internet (24.8\%), and friends outside school (12.7\%).

In the original 1991 questionnaire, $57 \%$ of the teachers responded that they had no source of support to discuss their role in interacting with the student, family or classmates. The top three sources of support in the school were identified as the school counselor and/or school psychologist (41\%), coworker (31\%) and social worker (19\%).

Providing Support When Students Have Terminal Illness. Respondents reported providing support to students with terminal illness, their parents, and their classmates.

Supporting Students with Terminal Illness. Respondents reported that they provided support to students with terminal illness by answering their questions about terminal illness. Although $38.2 \%$ of respondents reported that students were unable to ask questions due to cognitive issues, $17 \%$ had students asked them questions. There were four major categories of inquiries from students with terminal illness: a) condition and prognosis, b) faith-based questions, c) school adaptations, and d) family concerns. The majority of questions (52\%) dealt with the students' condition and prognosis, such as: "Am I going to die," "Will I get better," "How fast do they [brain tumors] grow," and "How long will I live?" The next most common type of question asked was faith-based (28\%) where students asked such question as: "Do you believe in heaven," and "How does God decide who dies?" Some students asked about adaptations (12\%), such as one student wanting a different assignment from one dealing with financial planning for old age and another student was concerned about how to get the teacher's attention when he can no longer raise his hand. Family concerns (8\%) included the parent not wanting the student to know about his condition, and questions about how to help the family deal with medical expenses. Some respondents reported trying to be supportive and encouraging and also utilizing other members of the educational team to help with these questions. 
Supporting Parents of Students with Terminal Illness. Twenty percent of parents who had children with a terminal illness asked teachers questions that were divided into five major categories: a) school issues, b) prognosis or student condition, c) resources, d) discussions with the child about terminal illness, and e) effective transition between home and hospital. The majority of questions (43.7\%) pertained to school issues. These included: "How does their illness affect the educational process," "How long can they keep the child in school," and "How much emphasis should be placed on academics; how much should they push a student to achieve?" There were also questions pertaining to Do Not Resuscitate (DNR) orders.

The next most frequent category of questions pertained to prognosis or questions about the students' condition (21.9\%). Families asked such questions as: "How long do you think they have," "Is there a cure," and "What happened to a child with a similar diagnosis?" Parents also wanted to know about resources $(18.7 \%)$ with some questions pertaining to the type of help hospice can give, as well as questions regarding alternate treatments or suggestions of alternate doctors.

The last two categories respondents identified as questions from parents dealt with discussing the illness (9.4\%) and effective transitioning (6.3\%). Respondents reported questions regarding how to tell the student about his terminal illness, and questions about the classmates understanding of the student's condition. Respondents also reported questions regarding having an effective transition between home and hospital settings.

Supporting Classmates with a Student who has a Terminal Illness. Respondents found themselves supporting classmates with $46.7 \%$ reporting that they talked with the classmates about the child with a terminal illness. Other people who talked with classmates were: parents $(8.5 \%)$, students with terminal illness, themselves $(6.1 \%)$, and other $(12.7 \%)$ which consisted primarily of school nurses, psychologists, school counselors. Several respondents reported that the student was receiving services at home, so they had limited peer contact. Many respondents also reported that peers who had cognitive impairments did not seem to understand what was happening. However, one respondent reported that that although the peers had cognitive challenges and could not verbally ask, their behaviors and communication attempts made obvious their sense of situation and their concern and care.

For those respondents who had students who were verbal, peer questions divided into six main categories: a) condition and medical equipment, b) prognosis, c) contagious, d) dying issues, e) how to help, and f) adaptations. The majority of questions (34.9\%) asked by peers dealt with the condition of the student and any medical equipment they might have, such as: "What is that in their neck [tracheostomy tube]," "What kind of cancer 
does he have," "Why is there an oxygen tank," "What's wrong with him," and "Why is he in a wheelchair?" One respondent elaborated upon the struggle with finding simple answers without violating Health Insurance Portability and Accountability Act (HIPPA) and staying respectful of religious beliefs.

Many questions also dealt with prognosis (27\%) and dying issues $(11.1 \%)$. The respondents encountered such questions as, "Is the student going to be OK," "Is he coming back to school," and "How long does [my] friend have to live?" Some respondents remarked about the difficulty of explaining the outcome of the condition and in some instances explain what death meant. Discussions often led to questions pertaining to dying, such as. "Where will he go when he dies," "What is it like, and "Why him?" Respondents reported peers became very upset and some peers questioned the fairness of the situation. Many students (15.9\%) asked if the student's terminal illness was contagious and if they would get it. This topic also raised concern for students with various medical conditions as to whether their own condition was also terminal.

Several students wanted to help (9.5\%) and directly asked "Can we help him?" Other questions dealt with providing support as peers, such as: "Can we still be friends," "Will I hurt her," and "Can he go to the home of a classmate?" Some students found ways of helping by assisting with adaptations such walking to class with the student, carrying the student's books, or getting lunch for the student. Some students asked about helping the student with schoolwork such as typing a paper. However, sometime adaptations raised questions $(1.69 \%)$ such as why the student does not have homework

Future Supports for Teachers with Students with Terminal Illness. Respondents were asked if they would be comfortable teaching another student with a terminal illness. The majority of respondenets (53.9\%) answered yes with no changes. However $39.4 \%$ answered yes with changes to the support system. The $6.7 \%$ who answered that they would not be comfortable teaching another student with a terminal illness, gave such reasons as they are not qualified, do not have enough training, and find it is very hard emotionally.

Respondents were asked what supports they would like if they were to work with another student who has a terminal illness. As seen in Table 3, $55.8 \%$ answered they would like support from the school nurse, followed by $26.7 \%$ from the school counselor and $25.5 \%$ from the social worker. Outside of the school, $52.1 \%$ of respondents answered that they would like help from parents and $26.7 \%$ help from hospice staff. This is in contrast to the original study in which the majority of teachers (29\%) wanted support from either the school counselor or psychologist. 
Table 3.

Supports Wanted by Teachers in the Future When Having a Student with a Terminal Illness Reported as Percentages

\begin{tabular}{|l|c|c|}
\hline & $\begin{array}{c}\text { Current Study } \\
(\mathrm{n}=165)\end{array}$ & $\begin{array}{c}\text { Original Study } \\
(\mathrm{n}=189)\end{array}$ \\
\hline Inside of school & 55.8 & 4 \\
School nurse & $26.7 /$ & $29^{*}$ \\
School counselor/ & 20.6 & 5 \\
Psychologist & 25.5 & \\
Social worker & & 3 \\
Outside of school & 52.1 & $\mathrm{~N} / \mathrm{A}$ \\
Help from parents & 26.7 & \\
Hospice staff & & 34 \\
Delivery and type & 70.3 & 14 \\
More medical information & 47.3 & $11^{* *}$ \\
Inservices & 18.8 & \\
Other & & \\
\hline
\end{tabular}

* This number reflects a combination of school counselor/psychologist ** This number reflects a support group

In terms of delivery and type, $70.3 \%$ wanted more medical information and $47.3 \%$ would like it delivered as in-services. For respondents who selected "other," $18.8 \%$ of the respondents identified wanting support from school administrators, support from physicians, communication among team members regarding the illness, and support to classmates.

\section{STUDENT DEATH}

The majority of respondents surveyed (82.6\%) reported that they experienced student death; $26.8 \%$ reported 2 or 3 deaths, $17.9 \%$ reported 1 student death, $15.8 \%$ reported 4 to 7 student deaths, and 5.3\% reported more than 12 student deaths. Respondents were also asked if continuing in school was in the student's best interest. In this study, $78.3 \%$ responded with positively, $16.6 \%$ responded that they don't know and $5.1 \%$ responded no. In the original study, 92\% responded that continuing in school was in the student's best interest, while $8 \%$ were unsure.

Teachers' Source of Support When a Student Dies. Respondents were asked about sources of support available to them when a student died. As seen in Table 4, $21 \%$ of the respondents answered that they had no source 
Table 4.

Source of Support When a Student Dies Reported as Percentages (with 1991 Questionnaire in parentheses)

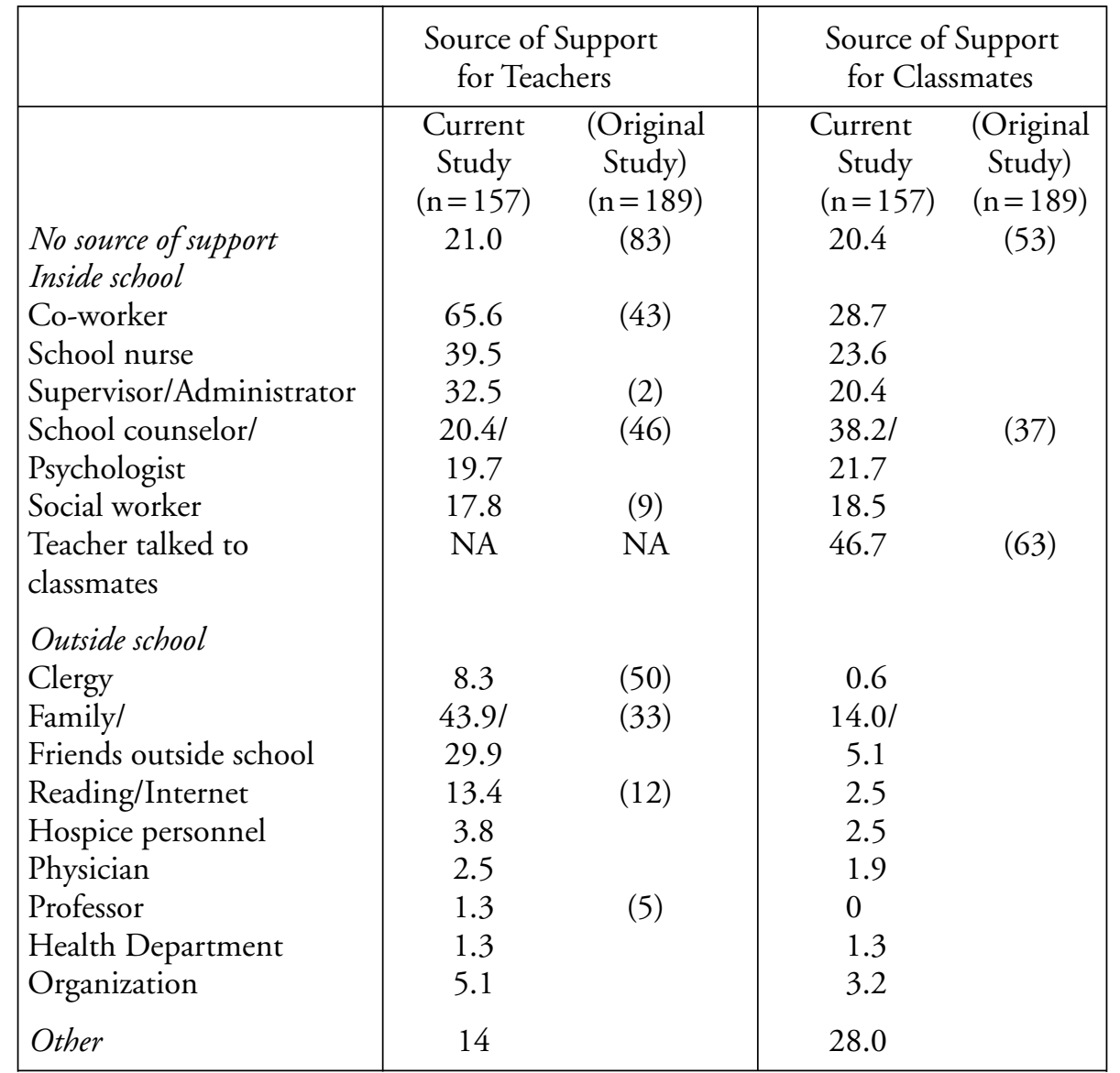

of support. Those who had a source of support named co-workers (65.6\%), school nurses (39.5\%) and supervisor/administrators (32.5\%) as the three most frequent sources within the school system. The top three sources of support outside the school system were family (43.9\%), friends outside of school (29.9\%), and reading/internet (13.4\%). The $14 \%$ of respondents who had other sources of support primarily identified nurses (who were associated with hospitals or agencies such as student's own nurse), and private counseling and grief support groups. One respondent reported receiving support from the crisis team while another had access to an employee assistance program. 
In the original 1991 questionnaire, $83 \%$ of the teachers reported having no support when a student died. Of those with support, $46 \%$ identified school counselors and/or school psychologists have being the greatest source of support within the school system, followed by co-workers (43\%) and social workers $(9 \%)$. The most frequent sources of support outside the school system were clergy (50\%), family/friends outside of school (33\%) and reading/internet $(12 \%)$.

Providing Support to Classmates When a Student Dies. Although no source of support was available to classmates as reported by $20.4 \%$ of respondents, $46.7 \%$ of respondents identified themselves as talking to students about terminal illness and death. Other sources of support for classmates were: school counselors $(38.2 \%)$, co-workers $(28.7 \%)$, and school nurses $(23.6 \%)$. Outside support was primarily from the family (14\%). The "other" category was selected by $28 \%$ of the respondents; they identified additional sources as hospital personnel, paraprofessionals, or administrators. The majority of comments in the "other" sections were comments of there either there being no classmates (due to homebound status) or "just me." Respondents reported such activities as: discussing student death with the class, making butterflies, and reading books pertaining to death and dying. In the original article, 53\% of the teachers reported they had no support. When support was provided, the persons identified were the teacher (63\%) and school counselor/ psychologist (37\%).

Respondents were asked to list questions the classmates had about death. Questions were divided into six main categories: a) information about death, b) painful death, c) difficulty understanding death issues, d) if it will happen to them, e) faith-based, and f) how to help. Several respondents reported that their students who were unable to verbalize due to cognitive impairments, showed a behavior change (e.g., appeared sad). Of those students who were able to ask questions, 30.5\% asked information about the death, such as, "What made him die," "Where did his things go" and "Why is he dead?" An addition 11.1\% asked specifically if death was painful and if the student suffered.

Some students were reported as having experience with pets or other classmates dying. The older students had an understanding of death; however, younger children or students with intellectual disabilities (30.1\%) had difficulty comprehending death issues, as seen by such questions as: "Why did he die at a young age," and "Why can't he turn into a superhero?"

Although one respondent reported that some of her students became analytical regarding the death and asked many questions to obtain specific information, other students became fearful. $17.5 \%$ of the respondents reported they had students asking it if would happen to them or their family members. Young students without the same diagnosis were reported as becoming fearful due to focusing on the effects of the disability (e.g., my friend used a power chair and 
he died, I use a power chair so I'm going to die [even though the friend had muscular dystrophy and the student had cerebral palsy]). One respondent commented she had students learn about their conditions before they are high school age, if they are cognitively able and parents provide permission.

Several questions regarding death were faith-based questions (7.9\%) and mostly dealt with the topic of heaven. One respondent reported that the students believed in an afterlife where the child was free of cancer and no longer had disabilities.

The last category of questions and comments dealt with helping (3.2\%). Some students asked about going to the funeral and one student with moderate intellectual disability was reported as attending the funeral. Some respondents had classmates make cards for the family, write letters, make picture boards, write articles in school newspapers about the student, and cook food to be available after the funeral service.

Future Supports for Teachers When a Student Dies. Respondents identified several areas of support they would like in the future: help assisting family members of students who died (59.2\%), help assisting classmates with the loss of a student (58.6\%), and help to support themselves cope with loss of a student (36.9\%) (see Table 5). Many respondents wanted more information surrounding student death $(39.5 \%)$ and many respondents wanted inservices $(35.7 \%)$ on issues surrounding student death. Also, respondents reported that they wanted additional support from supervisor/administration (21\%), school nurse (19.1\%), and other teachers (16.6\%). One respondent commented that she wanted release time to go to funerals, and discussed the need to allow teachers involved with the student to come together to support each other. It was also commented that it is acceptable for the crisis teams to check up later with others who are involved with the death. In the original questionnaire, support from school counselors/school psychologists (27\%) was the highest ranking area.

Respondents identified five categories of questions at the time of a student death: a) supporting classmates, student's family, and staff; b) obtaining more information; c) dealing with emotions; d) worrying if enough support was provided; and e) resolving school conflicts and issues.

The majority of questions (44.1\%) dealt with providing support to classmates, student's family, and staff. Respondents asked how to talk with classmates, how to share information within the bounds of confidentiality and how to handle differing belief systems of students with varying backgrounds (e.g., responding in a supportive manner to students' religious beliefs about heaven, while also responding in a supportive manner for those students who do not believe in heaven). Respondents also questioned how to best address fears of students with the same disability. Questions for family support pertained 
Table 5.

Type of Additional Support Wanted by Teachers Concerning Student Deaths Reported as Percentages

\begin{tabular}{|l|c|c|}
\hline & $\begin{array}{c}\text { Current } \\
\text { Study } \\
(\mathrm{n}=157)\end{array}$ & $\begin{array}{c}\text { Original } \\
\text { Study } \\
(\mathrm{n}=189)\end{array}$ \\
\hline $\begin{array}{l}\text { Support wanted by teachers } \\
\text { Support help me assist family members of }\end{array}$ & 59.2 & 12 \\
$\quad$ student who died & 58.6 & 12 \\
Support help me assist classmates & & \\
$\quad$ with loss of student & 39.5 & \\
More information on issues & 36.9 & \\
$\quad$ surrounding student death & & 25 \\
Support help me cope with loss of student & 35.7 & 3 \\
Desired added support & 19.1 & \\
Inservice & 10.2 & \\
Support group with others who & & \\
$\quad$ have lost a student & 21.0 & \\
Funeral home visit & 19.1 & \\
Added support from individuals & $12.1 /$ & \\
Support from Supervisor/Administrator & 10.8 & \\
Support from School nurse & 16.6 & \\
Support from School counselors/ & 12.1 & \\
School Psychologists & 8.4 & \\
Support from Other teachers & & \\
Support from Hospice staff & & \\
Other & & \\
\hline
\end{tabular}

to how to help the family, and if they should maintain contact with the student's family.

Many respondents (23.7\%) felt that they should have more communication and information surrounding student's death. Some of them expressed surprise by the sudden decline or sudden death and wanted more information about how the disability impacted the life span or the exact reason of death. One respondent commented that during the beginning of her career there was less information and support, but now teachers have received additional training. She added that her school has two nurses serving 250 students, and she asked her nurses questions and received updated information from them. One respondent commented how difficult it is when the family does not communicate the details of the death. 
Some respondents wanted more support and resources from the school. This included release time for funerals as well as ways to address conflicts with coworkers who felt it was not in the best interest of the student to be at school. One respondent commented that it was difficult to balance the benefits of having the dying student attend school with new testing/accountability regulations and negativity from administrators when dying students perform poorly. Another respondent questioned if she should have brought up the topic of death at meetings (even though it seemed taboo) so decisions could be made about issues related to students' decline and impending death.

Respondents also had concerns over their own emotional response $(10.2 \%)$, such as, "What is my role and where do I put these feelings?" One respondent commented that," My student's death was one of the hardest experiences that I have had as a teacher." Emotional responses also included struggling with questions as to why some children have to die while others have long life and how the death helps us all to grow. In addition to these, respondents were concerned if they provided sufficient care to the dying student, and asked such questions ass: "Did I do all that I could for the student?" and "Did I do all that I could do to make the student comfortable?," There were also comments that their student was loved.

\section{PAIN MANAGEMENT}

There were $95.8 \%$ of respondents who reported that they taught students who experienced pain. The majority of respondent reported that they had more than 12 students experiencing pain $(27.4 \%)$ or had between 4 to 7 students experiencing pain (24.7\%). Only $44.7 \%$ of respondents answered that they were able to recognize pain in their students, with $37.9 \%$ being uncertain of recognizing pain in one or more students; $15.8 \%$ finding it difficult to recognize pain in one or more students and $1.6 \%$ being unable to recognize pain.

Respondents reported that $65.3 \%$ of students experiencing pain received pain medication at school. Medication was administered by the following personnel: $85.5 \%$ by the nurse, $27.4 \%$ by the teacher, $25.0 \%$ by the teacher's aide, $9.7 \%$ by the secretary, and $12.1 \%$ by other (e.g., student self administered, nursing assistant, private duty nurse, and clinic worker). When asked if the respondent felt knowledgeable about the pain medication, $15.3 \%$ responded very knowledgeable, $29.0 \%$ knowledgeable, $41.1 \%$ somewhat knowledgeable, $12.9 \%$ not very knowledgeable, and $1.6 \%$ no knowledge at all. $30.2 \%$ of the respondents answered that they disagreed or strongly disagreed that all of the students who had pain appeared to have the pain under control. 


\section{HOSPICE}

In the hospice section of the questionnaire, $26.8 \%$ of the respondents answered that they had students who were in the process of receiving or who had received hospice services. Ten percent of the respondents answered that they were very knowledgeable about hospice, $22.1 \%$ were knowledgeable, $41.1 \%$ were somewhat knowledgeable, $25.3 \%$ were not very knowledgeable, and $1.6 \%$ reported no knowledge at all (mean 3.14 on 5-point Likert type scale with 5 being very knowledgeable). Upon asking if the respondent would like hospice personnel to provide support to school personnel when a student dies, $36.8 \%$ strongly agreed and $33.2 \%$ agreed (mean 4.01 ). In regard to having hospice personnel to provide information on terminal illness, $46.3 \%$ strongly agreed and 30\% agreed (mean 4.16).

Sixty-seven respondents wrote in comments about hospice, with many having experience with hospice due to their own family or friends. All of the comments praised their hospice experience (e.g., fabulous support), except for one respondent who questioned some hospice policies. All comments from respondents who had students on hospice were positive, such as, "Hospice was helpful and accommodating with one of my students," "Hospice was wonderful! They gave me support and helped me support my ill student and my other students," and "Hospice was able to help with having the class come visit the dying child at home during school hours."

Respondents also commented on specific ways hospice could be beneficial, such as: providing information on terminal illness and realistic expectations at child's level, supporting school staff, , training in hospice care, and finding ways that hospice and school staff can work together to approach the family about this. Some respondents brought up issues of confidentiality and having hospice personnel in the classroom, while others discussed the training and support roles. Several comments indicated an unfamiliarity with hospice as well as misconceptions about its services. These included being unaware of hospice for children and thinking that hospice is a place rather than a philosophy and form of care that can occur in any location.

\section{DISCUSSION}

Special education teachers of students with physical, health and multiple disabilities often are educating students with terminal illness and life limiting conditions. This places the teacher in the unique position of providing support to the student, classmates, family, and self. The need for support also continues after the student has died. The results of this study indicate that teachers play a primary role in providing information and support, but do not 
always have the tools and support that they need. Ninety-three percent of teachers are willing to have another student with a terminal illness and assume this role, but $39.4 \%$ want changes to the support system.

The amount of training teachers have had in the area of death and dying issues has increased vastly over the years, from $75 \%$ having no prior training in 1991 to $33.2 \%$ having no training in 2012 . But this means that approximately one third of the respondents have no training in this area and lack an appropriate knowledge base. They have students with terminal illnesses or students who have died and are faced with providing appropriate information and support to others. In addition, some of these students with terminal conditions will have pain. The lack of training regarding pain medications, coupled with the majority of teachers being unable to recognize pain in students, can create an unsafe environment for the student. It is disconcerting that of those who could recognize pain, $30.2 \%$ disagreed or strongly disagreed that all of their students with pain appeared to have pain under control. Further research is needed as to determine why students are having uncontrolled pain in the school settting and to examine the training and procedures that need to be put in place regarding proper pain management in the classroom.

For those teachers who received training on death and dying issues, slightly under half had the topic discussed in university and college courses. With teachers encountering students with terminal illness and their deaths, it is critical that universities provide the information needed to assist teachers with this difficult topic. This study has identified several crucial skills that teachers should acquire in these courses: understanding children's developmental concept of death; learning effective methods to support the student, classmates, parents, and self; learining how to conduct discussions with classmates voicing differing religious beliefs and in complicance with HIPPA; identifying pain in students with multiple disabilities and knowing what actions to take; understanding terminal illnesses and their prognosis and management; and knowing how to identify and form support networks. For teachers who are no longer in a university setting, in-services should be offered, as requested by $47.3 \%$ of the respondents. This could be given by individuals who have the appropriate knowledge base (e.g., certain university professors, nurses trained in this area, trained teachers, counselors, and personnel associated with hospices).

The vast majority of teachers reported having support with students with terminal illness $(85.5 \%)$ as opposed to 21 years ago (68\% reporting having support). However, a lack of support still exists for some teachers, which can impact their ability to effectively respond to the student with a terminal illness, as well as to classmates, and the student's parents. Unlike the prior study which had most support coming from school counselors/ school psychologist, 
there has been a major shift where the school nurse has been identified as the primary source of support, as well as the primary source to answer questions and discuss the teacher's role (although co-workers were almost equal in providing support in role discussions). The school nurse was also the leading source of support teachers wanted if they had another student with a terminal illness.

This shift of having the school nurse as the teacher's primary source of support may have occurred due to the increased number of students who have complex health care needs included in school setting. They often need more complex care that requires the training and skills of a school nurse. In addition to being involved in these students' care, the school nurses' role includes clairifying students' health status, explaining their impairments, and interpreting medical and other health information (NASN, 2012). School nurses are often in an ideal position to provide information and support to teachers due to their knowledge base and training and teachers should be encouraged to seek them out as a source of support. However, not all school nurses are able to fulfill this role due to high workloads and/or having deficits in this area. Further investigation is needed to examine nurses' expertise, supports, and challenges.

Other sources of major support identified by teachers included co-workers, counselors, as well as reading and the internet. The finding that co-workers (fellow teachers) are a major support and continue to be the primary support for teachers when a student dies is consistent with the literature (Lazenby, 2006). In terms of helping classmates with a student death, school counselors also continue to be the primary source of support for classmates (besides the teacher). Although school nurses are the most frequent source of support for questions about terminal illness, the present study shows a significant increase in reading and the Internet as additional sources of information. This is not surprising due to the growth of the Internet. However, Internet research may not be accurate and teachers should be cautioned about the sources they consult. Teachers should be encouraged to use people with whom they are comfortable for support, but should consider utilizing the school nurse, counselors, crisis teams (when available for the death of a child with physical, health, or multiple disabilities), or other staff who have knowledge and skills in this area.

The majority of teachers identified the school nurse as the person they wanted to receive support from in the future if they again have students with terminal illness. Many commented that they were content with the support they had in place, which tends to indicate that the school nurse is fulfilling the support role well. However, when asked about additional future supports wanted by teachers concerning student deaths, the supervisor/administrator 
was the individual who was identified the most. Comments about letting teachers go to funerals and discussions regarding having more support in meetings, tend to indicate that some teachers want administration to do more. Administrators will need more information on how to be supportive, as well as the best ways to utilize members of the educational team.

This study was able to identify several categories of questions that teachers encountered from students with terminal illness, parents, and classmates, as well as questions the teachers had themselves. Students with terminal illnesses and their families often turned to the teacher for information about the condition and prognosis. Teachers will need to work closely with the school nurse, family, and team to know how to best address this type of information. Also, it should be noted that sometimes these types of questions may be more directed towards having someone listen to their concerns or find adaptations or solutions to problems, rather than providing concrete information. Teachers should learn techniques to be supportive listeners and provide appropriate adaptations and resources.

Classmate questions often reflected difficulties understanding death or terminal illness, especially young classmates or classmates with developmental disabilities. Some classmates reacted to a student's death with fear over their own mortality, whether they have the same diagnosis or not. This aligns with the literature on the various developmental stages of understanding death (Walker, 2010). The majority of teachers expressed concern over how to support classmates who don't have a mature understanding of death, as well as those who are older. In addition, teachers had questions about finding appropriate ways to talk with classmates, addressing differing belief systems, and upholding confidentiality. In order to address these difficult areas, teachers will need to continuing to utilize the school counselor for classmates concerns, as well as the school nurse, and other members of the interdisciplinary team for information and support.

Teachers provided several activities and interactions to address student concerns. Several utilized activities for classmates that have support in the literature (e.g., making cards) (Cowan, 2010). Knowing the most effective words to say in a situation is more difficult and it is important that they have the knowledge base of how to do this effectively. Teachers' reflection on if they did the right thing with their interactions indicate that they need need to support themselves to mediate doubt and guilt. This is an important need with 36.9\% of teachers responding that they need to have support to cope with the loss of a student.

Over a fourth of the teachers taught students who had hospice services. A lack of sufficient knowledge exists among teachers regarding these services and the majority of teachers would like assistance from hospice personnel as 
well as more information about hospice. Hospices have grief counselors, nurses, educators, social workers, and others who have a strong knowledge base in such areas as terminal illness, dying process, grief reactions, and providing support. They can assist school teachers. Although some hospices have outreach programs to schools, more dissemination of information and support is needed.

This study provided important and insightful information, but it has some limitations. Readers should be cautioned when comparing the original study to the current one since the original study used teachers from a single state, while the current study had respondents from across the nation. (The current study did examine the data from the single state used in the original study to the rest of the country and found the same trends). Also, readers need to consider that in the questionnaire, the term "family" did not differentiate between the teacher's family and the student's family. Therefore, when family was selected as a response, it is not clear if teachers' meant their own family or their students' family. A final consideration pertains to the Internet information since our study did not explore what types of Internet sources were used so perhaps future research could examine this area.

Teaching students with terminal illness or facing student death will likely occur to teachers who have students with physical, health, or multiple disabilities. Many are able to find information and support with their school nurse, school counselors, co-workers and others, although there are still many teachers who lack resources. Universities and school districts need to provide information and strategies to teachers in these fields to assist them in these difficult situations. Hospices may also be a tremendous resource and more education about hospice services is needed. Examining the issues that teachers have described in this study will hopefully assist in promoting further training in these areas and promote effective support systems that will assist teachers and their students and families.

\section{REFERENCES}

Chan, W. C. H. \& Tin, A. F. (2012). Beyond knowledge and skills: Selfcompetence in working with death, dying, and bereavement. Death Studies, 36, 899-913.

Clute, M. A. (2010). Beveavement interventions for adults with intellectual disabilities: What works? Omega, 61(2), 163-177.

Corr, C. (2010). Children's emerging awareness and understandings of loss and death. In C. Corr \& D. Balk (Eds.), Children's encounters with death, bereavement, and coping (pp. 21-37). New York: Springer. 
Cowan, D. (2010). Death of a friend during childhood. In C. Corr \& D. Balk (Eds.), Children's encounters with death, bereavement, and coping (pp. 219-236). New York: Springer.

Cox, M., Garrett, E., \& Graham, J. A. (2005). Death in Disney films: Implications for children's understanding of death. Omega: The Journal of Death and Dying, 50(4), 267-280.

Crozier, F. \& Hancock, L. (2012). Pediatirc palliative care: Beyond the end of life. Pediatric Nursing, 38(4), 198-203, 227.

Harrawood, L. K., Doughty, E. A., \& Wilde, B. (2011). Death education and attitudes of counselors-in-training toward death: An exploratory study. Counseling and Values, 56, 83-95.

Heron, M., Sutton, P. D., Xu, J., Ventura, S. J., Strobino, D. M., \& Guyer, B. (2010). Annual summary of vital statistics: 2007. Pediatrics, 125(4), $4-15$.

Holland, J. (2008). How schools can support children who experience loss and death. British Journal of Guidance and Counseling, 36(4), 411-424.

Horridge, K. A. (2011). Dying, death, disabled children and young people: How might we be better prepared? Child: Care, Health, and Development, 38(1), 3-5.

Hunter, S. B. \& Smith, D. E. (2008). Predictors of children's understanding of death: Age, cognitive ability, death experience and maternal communicative competence. Omega, 57(2), 143-162.

Koehler, K. (2010). Helping families help bereaved children. In C. Corr \& D. Balk (Eds.), Children's encounters with death, bereavement, and coping (pp. 311-336). New York: Springer.

Lazenby, R. B. (2006). Teachers dealing with death of students: A qualitative analysis. Journal of Hospice and Palliative Nursing, 8(1), 50-56.

Mak, M. H. J. (2011). Quality insights of university students on dying, death, and death education-A preliminary study in Hong Kong. Omega, 62(4), 387-405.

National Association of School Nurses. (2012). Position Statement: Chronic Health Conditions Managed by School Nurses. Retrieved from: http://www.nasn.org/PolicyAdvocacy/ PositionPapersand Reports/ NASNPositionStatementsFullView/tabid/462/ArticleId/17/ChronicHealth-Conditions-Managed-by-School-Nurses-Revised-January-2012.

Naierman, N. (1997). Reaching out to grieving students. Educational Leadership, 55, 62-65.

Niemiec, R. M. \& Schulenberg, S. E. (2011). Understanding death attitudes: The integration of movies, positive psychology, and meaning management. Death Studies, 35, 387-407. 
Ramer-Chrastek, J. (2000). Hospice care for a terminally-ill child in the school setting. Journal of School Nursing, 16, 52-56.

Rice, C. \& Gourley, J. (2003). Preparing classroom teachers with impending death of a student with terminal illness. Physical Disabilities: Education and Related Service, 22, 25-36.

Slaughter, V. \& Grittiths, M. (2007). Death understanding and fear of death in young children. Chilincal Child Psychology and Psychiatry, 12, $525-535$.

Smith, M., Alberto, P., Briggs, A., \& Heller, K. (1991). Special educator's need for assistance in dealing with death and dying. DPH Journal, 12(1), $35-44$.

Speece, M. W. \& Brent, S. B. (1984). Children's understanding of death: A review of three components of a death concept. Child Development, 55, 1671-1686.

Speece, M. W. \& Brent, S. B. (1992). The acquisition of mature understanding the concept of death. Death Studies, 16, 211-219.

Walker, A. (2010). Ethics, research, and dying or bereaved children. In C. Corr \& D. Balk (Eds.), Children's encounters with death, bereavement, and coping (pp. 61-79). New York: Springer.

Wolfe, J., Hinds, P., \& Sourkes, B. (2011). The language of pediatric palliative care. In J. Wolfe, P. Hinds, \& B. Sourkes (Eds.), Textbook of interdisciplinary pediatric palliative care (pp. 3-6). Philadelphia: Elsevier. 


\title{
TEACHING CHILDREN WITH NIEMANN-PICK DISEASE
}

\author{
BARBARA. C. GARTIN \\ University of Arkansas, Fayetteville \\ NIKKI L. MURDICK, JENNIFER COOLEY, \\ AND SARA BARNETT \\ Saint Louis University
}

\begin{abstract}
Author Note
Barbara C. Gartin, Curriculum and Instruction, University of Arkansas; Nikki L. Murdick, Department of Education, Saint Louis University; Jennifer Cooley, Department of Education, Saint Louis University; Sara Barnett, Department of Education, Saint Louis University.

Correspondence should be addressed to Barbara C. Gartin, Department of Curriculum and Instruction, University of Arkansas, Fayetteville, Arkansas 72701. E-mail: bgartin@uark.edu
\end{abstract}

\begin{abstract}
Niemann-Pick Disease (NPD) is a group of rare inherited disorders that are both systemic and degenerative. Knowledge of the disease, its characteristics, and its progression are essential for the teacher and related service personnel to provide an appropriate educational experience for the student. For the teacher who has a student with $\mathrm{NPC}_{1}$ in his/her classroom, the focus is two-fold: first to provide a supportive academic environment for the student with $\mathrm{NPC}_{1}$ and her/his classroom peers; and, second, to provide emotional support for the student and the family. Included in this manuscript are suggested accommodations for the teacher and other therapists and related service personnel to use in providing an appropriate education for a student with $\mathrm{NPC}_{1}$.
\end{abstract}


Niemann-Pick Disease (NPD) is a group of rare autosomal, recessive disorders that is fatal (Knox \& Ramsey, 1932). Recent research (Bergamin et al., 2013; Heath, 2008; Rodriguez-Pascau et al., 2012; Tagermo et al., 2011; Wraith, Guffon, et al., 2009) indicates that all forms of NPD are a result of a spontaneous genetic mutation on chromosomes 11, 14, or 18 (Wraith, Guffon, et al., 2009). In NPD, lipids or fats collect in the cells of the spleen, liver and brain resulting in skin, eyes, musculoskeletal, nervous system, liver, and lymphoid organ disorders (Bi \& Liao, 2010; Lloyd-Evan et al., 2008; Santos et al., 2008; Xu et al., 2012). NPD occurs in all ethnic groups and in both males and females (Greer et al., 1997; Wraith, Guffon, et al., 2009). Early onset can occur anytime from prenatal through age two, but onset is more likely to occur during childhood between 4 and 10 years old (Crocker $\&$ Farber, 1958; Tang, Li, \& Liu, 2010; Winsor \& Welch, 1978). Therefore, children with NPD may be identified during the school years and will be attending school at onset and during the degeneration of involved systems. Classroom teachers and supporting personnel become an integral part of the team that observes and documents changes in student health and behaviors that impact student learning (National Neiman-Pick Disease Foundation [NNPDF], 2009). Therefore, a review of NPD and its characteristics is in order.

\section{DEFINITION}

The first written reports of NPD were by Albert Niemann in 1914 and Ludwig Pick in 1927. Both doctors described cases of infants who had "rapidly progressive neurodegeneration that subsequently led...to ...death" (Heath, 2008, p. 2). In 1958, Alan Crocker and Sidney Farber reviewed cases of 18 individuals with characteristics of this disease and, in 1961, proposed that NPD be divided into four groups or subtypes: A, B, C, and D (Tang, Li, \& Liu, 2010). Each of these subtypes was based on the time of onset and disease path. Interestingly, this action expanded the category of Niemann-Pick disease by applying the diagnosis to all patients with lipid storage issues and led to the inclusion of older, less severely affected individuals than those originally described by Niemann and Pick (National Organization for Rare Disorders [NORD], 2006). Regardless of the subtype, symptoms include "yellow discoloration of the skin, eyes, and/or mucous membranes (jaundice), progressive loss of motor skills, feeding difficulties, learning disabilities, and an abnormally enlarged liver and/or spleen (hepatosplenomegaly)" (NORD, 2006, p. 1). NPD is always fatal with many individuals dying before age 10 
Table 1.

Subtypes of Niemann-Pick Disease

\begin{tabular}{|l|l|}
\hline Subtype & Prognosis \\
\hline NPA: Classic or Severe Infantile Form & Death as an infant or toddler \\
\hline NPB: Visceral or Chronic Form & $\begin{array}{l}\text { Death by late childhood or early } \\
\text { adulthood depending on severity of } \\
\text { symptoms }\end{array}$ \\
\hline $\mathrm{NPC}_{1}$ : Sub acute or juvenile form & $\begin{array}{l}\text { Death within } 6 \text { to } 10 \text { years of diag } \\
\text { nosis; no later than } 15 \text { years old }\end{array}$ \\
\hline $\mathrm{NPC}_{2}$ : Nova Scotia variant & Same prognosis as $\mathrm{NPC}_{1}$ \\
\hline NPE: Adult onset & Unknown \\
\hline
\end{tabular}

and the majority dying before age 20 (Vanier, 2010; Wraith, Baumgartner, et al., 2009). See Table 1 for an overview of the NPD subtypes.

NPD is also divided by symptoms as well as by severity. NPA (classic form or severe infantile form) includes the earlier identified version wherein infants had neurodegenerative disease leading to death before age one. Those individuals with NPB (visceral or chronic form) have no brain or nervous system involvement, such as loss of motor skills, but may have respiratory problems. Both A and B are relatively rare subtypes with an approximate total of 1200 cases worldwide for both with the majority being those with NPB (NNPDF, 2010). Individuals with $\mathrm{NPC}_{1}$ (subacute or juvenile) have neurodegeneration (Bi \& Liao, 2009), but it occurs in a slower progression than it does in children with NPA. Approximately 500 cases of individuals with $\mathrm{NPC}_{1}$ have been identified worldwide, but this number is considered to be low as many other children may be under diagnosed or misdiagnosed (Wraith, Guffon, et al., 2009). Often $\mathrm{NPC}_{1}$ is initially diagnosed as "learning disability, mild retardation, 'clumsiness', and delayed development of fine motor skills" (NNPDF, 2010). NPD type D (Nova Scotia variant or Crocker-Farber syndrome) is a variant of $\mathrm{NPC}_{1}$ and has been found only in one area of Nova Scotia. It is now often called $\mathrm{NPC}_{2}$. The various forms of NPD are found throughout the world, thus affecting all ethnic groups, although there has been a higher incidence found in some populations worldwide, e.g., Ashkenazi Jewish families (NPA), the Maghreb region of Northern Africa (NPB), and Spanish-American families in New Mexico and Colorado (NPC 1 ) (Heath, 2008; NNPDF, 2010; Patterson, Vanier, et al., 2001; Winsor \& Welch, 1978). More recent research supports that $\mathrm{NPC}_{1}$ and $\mathrm{NPC}_{2}$ have different causation (Goldman \& Krise, 2010). 


\section{CHARACTERISTICS AND ACCOMMODATIONS}

Children with NPA and NPC both exhibit signs of neurodegeneration; however, children with NPC show a slower rate of neurodegeneration than children with NPA that often results in death before age one. Children with NPB exhibit only respiratory issues and seldom exhibit neurodegeneration. Consequently, only children with $\mathrm{NPC}_{1}$ may encounter classroom issues (Greer et al., 1997; Patterson, Vanier, et al., 2001). Therefore, this discussion will focus on symptomology of, and accommodations for, children with $\mathrm{NPC}_{1}$. According to Yanjanin et al. (2010), clinical signs can be noted "in nine major (ambulation, cognition, eye movement, fine motor, hearing, memory, seizures, speech and swallowing) and eight minor (auditory brainstem response, behavior, gelastic cataplexy, hyper reflexive, incontinence, narcolepsy, psychiatric, and respiratory problems) domains" (p. 132). Issues in the domains represented in the previous quote (physical health, fine and gross motor, speech and language, and cognition) are important educational domains and, therefore, important to the student's educational program, either in the IEP-related documents or in the Section 504 plans. Based on reviews of the extant literature on NPC, the authors developed this discussion of possible educational accommodations for classroom use. The authors based the selected accommodations on their extensive experience in the field of education of children with disabilities and how the characteristics of children with NPC could impact their educational experience. Thus, suggestions for working with these issues follow and are summarized in Table 2.

\section{HEALTH ISSUES}

The physical health of the child is often the first indicator of the presence of NPD (Patterson, Vanier, et al., 2001). This is compounded, though, with the fact that it is an exceptionally variable condition. Symptoms of the disease are shared by other lysosomal disorders and the rate of disease progression is variable. These two factors make it difficult to conclusively diagnosis $\mathrm{NPC}_{1}$ (NNPDF, 2011). One of the first physical signs is an enlarged abdomen along with an enlarged spleen. In addition, liver disease may occur (Tangermo et al., 2011). Children with $\mathrm{NPC}_{1}$ often have respiratory issues and an insufficiency in respiration that may lead to reoccurring bouts of respiratory infections.

As a result of the physical health issues, many of these student will be absent from school and the school will need to identify the student as in need of special education services under the regulations identifying students with Other Health Impairments. Based on the student's needs the school may need to have hospital/homebound services available to maintain the continuity of 
the student's education program. When in attendance at school, students may need to be observed by the teacher or an identified classroom adult so that parents may be contacted about the possible onset of respiratory or other health issues. Care should be taken to reduce exposure to classroom sources of respiratory infections. Universal precautions should be observed to reduce the spread of infection. For example, frequent hand washing and equipment disinfection should be the rule.

\section{MOTOR ISSUES}

Teachers may notice the presence of issues with delay or regression in either or both fine and gross motor development. With the onset of the disease, delayed performance of motor milestones may occur. Gait problems, perhaps seen as clumsiness, will emerge. The gait issues seem to be compounded by balance issues, hypotonia (decreased muscle tone), and resultant ataxia (frequent falls) (Tangermo et al., 2011). As the disease progresses, dysphagia (difficulty swallowing) may be noticed during lunch time. In addition, some children experience hand tremors, backward head thrust, and seizures (Patterson, 2009; Patterson, Vanier, et al., 2001). For those activities that are impacted by the student's increasing problems with motor coordination, the teacher can provide a number of changes to the classroom. Within the classroom, teachers should clear walkways and position backpacks, tables, chairs, desks, objects, etc., so that they are not an impediment to the student. The student's desk should be placed close to materials and the work areas for easier access. As the disease progresses, a personal assistant may need to help the student to move about the classroom and the school and to provide other personal services as needed. It is the responsibility of the teacher to provide a physically safe environment for the student. As a result not only the classroom teacher but the occupational therapist may need to be involved in developing appropriate activities for the student.

A request for assistance from the Occupational Therapist (OT) should be made when the teacher needs additional strategies for meeting the fine motor challenges of students. The OT can provide information and materials to support the student who is having hand, grasp, and finger issues. As a member of the student support team, OTs can choose appropriate adaptive equipment and teach the student, teacher and family members in its correct use. Also, OTs can support the student and teachers by modifying classroom equipment and providing strategies to help students participate as fully as possible in school activities.

In response to the fine motor issues, the classroom teacher may need to adapt student assignments that would usually be completed in written format 
and allow them to be submitted using a word processing program or an audio recorder. If the student is willing, a scribe can be identified who will write the student's answers. When this is not a possibility, a non-written assignment can be substituted. Copying homework assignments and various written language activities from the board is often used in classrooms. For children who are experiencing Vertical Supranuclear Gaze Palsy (VSGP), or the inability to voluntarily raise and lower their eyes, this is extremely difficult. A substitute activity could be provided or a copy of any homework assignments given to the student in lieu of requiring the copying activity.

For a student who has issues with balance and gait, a request for a Physical Therapist evaluation is appropriate. Also, the student may benefit from the services of an Adaptive Physical Education (APE) instructor who can provide information and training on physical education and recreational activities that will allow the student to physically participate in school activities as long as possible.

\section{SPEECH AND LANGUAGE ISSUES}

Parents and teachers will often begin to notice a change in the speech and language ability of children with $\mathrm{NPC}_{1}$. One of the first symptoms is the delayed language acquisition, as some parents note that their children's language has not only slowed but, in fact, is decreasing. In addition, children may exhibit dysarthria, wherein the muscles that help with speech begin to lose the ability to form words, resulting in word slurring and speech that is difficult to understand. As the disease progresses many children begin to exhibit aphasia, wherein they forget the words to use for objects. Teachers should be aware of ways to assist students with continuing to participate in classroom activities and interacting with peers.

Preserving language and speech communication are essential to prevent the student from becoming prematurely isolated. For some children, one of the first language losses they may encounter is an inability to find words to use in conversation or to answer questions. A photo/picture board with the student's most used words or activities can be prepared to help. There are a number of computer programs that can be used to print pictures or that can be used on a tablet, personal computer, or smartphone. Because of memory issues, the student may have difficulty with time awareness or be unable to remember when to move to a new activity. The teacher and student may develop verbal cues or physical signals as a prompt. One method using visual cues is to use a digital camera to make an individualized schedule board for the student's daily activities.

As the disease progresses, the student will need to have support and assistance from the Speech and Language Pathologist (SLP) because of the 
presence of language delay, dysarthria, and aphasia issues associated with $\mathrm{NPC}_{1}$, as well as the issues related to eating and swallowing. The SLP can provide the teacher with information and strategies for the management, intervention, and treatment of both language and swallowing issues.

\section{COGNITIVE ISSUES}

One of the most difficult groups of characteristics for teachers revolves around changes in the brain. This group of symptoms is the reason that this disease is often called "childhood dementia" or "childhood Alzheimer's disease" (Imrie, Jacklin, \& Mathieson, 2009; NNPDF, 2011). One of the early neurological indicators is when the child begins to have difficulty with voluntarily raising his/her eyes in a vertical motion, known as Vertical Supranuclear Gaze Palsy (VSGP) (Patterson, 2009; Patterson, Vanier, et al., 2001; Tang, Li, \& Liu, 2010; Tangermo et al., 2011). A second indicator is when the child begins to exhibit cataplexy, which is a sudden loss of muscle tone and falling, often triggered by some emotion. For children with $\mathrm{NPC}_{1}$, this has been noted as occurring when activities arouse emotional responses or laughter (Patterson, 2009; Patterson, Vanier, et al., 2001).

The most significant characteristic for the school age child, though, is the gradual loss of mental ability; i.e., the onset of dementia (Imrie, Jacklin, \& Mathieson, 2009). Children begin to lose their ability to concentrate on academic activities. They no longer have the ability to remember information, especially information in short-term memory. Additionally, their ability to learn new material begins to decrease. For children who reach adolescence, psychosis may appear in the form of paranoid delusions, auditory or visual hallucination, and interpretative thoughts (NNPDF, 2011; Tangermo et al., 2011). Episodes of depression and aggressive behavior may also begin to appear (Patterson, 2009; Patterson, Vanier, et al., 2001).

To assist students in being successful during the classroom day, transitional class routines should be established. This consistency in change-up times will help the student who has difficulty with time considerations and memory. When memory loss occurs, children may forget the location of their desks, materials, and books. To reduce the anxiety or behavioral outbursts that may result when the student is unable to find his/her materials, the student's name can be attached to his/her desk, cubby, books, tables, etc. As the student's memory continues to deteriorate, schematic drawings or flow charts with photos can be used as memory cues for daily activities allowing the student, peers, or aide to more easily locate his /her place in the classroom. 
Table 2 .

Accommodations for Individuals with NPD

\section{Health Accommodations}

- Know and use Universal Precautions within the classroom

- Thoroughly disinfect desks and equipment at least once a day

- Have disinfect wipes available for student use in the classroom

- Keep infectious students at a distance from the student with NPD

- Notify parents of student with NPD if the child becomes ill or if others are ill in the classroom

- Implement a system to send homework to student when he/she is absent (computers can be used)

- Implement a system where students at school can visit the student with NPD when student is absent perhaps using skype or facetime or other electronic or digital avenues

- Arrange for hospital/homebound services before they are needed

\section{Fine Motor Accommodations}

- Use word processor or tape recorder in place of written assignments

- Ask a peer to serve as a scribe

- Assign non-written assignment options

- Provide a substitute activity for copying from the board

- Request Occupational Therapist support for hand, grasp and finger issues

\section{Gross Motor Accommodations}

- Keep walkways clear

- Place student desk close to materials or work area

- Provide personal assistant

- Request Physical Therapist support for gait \& balance

- Utilize services of Adaptive Physical Education instructor for Physical Education and recreational activities

\section{Speech and Language Accommodations}

- Provide student with a digital camera to make a schedule board to cue activities 


\section{Table 2. (Continued)}

- Use a photo/picture board for language starters

- Utilize speech/language pathologist support for speech and swallowing concerns

\section{Cognitive Accommodations}

- Establish transitional class routines

- Use schematic drawings or flow charts as memory cues for daily activities

- Provide pre-transition warnings \& cue activities with music

- Label items when word memory fails

- Use text to speech applications

- Provide a quiet work area

- Provide peer support

- Prepare a photo or video daily school/home diary

Reading textbooks for information access or for relaxation can become difficult as children begin to lose their ability to remember and understand written words. The use of a text-to-speech application can be useful. The provision of peer support or a peer buddy to assist the student throughout the day can be very helpful. The peer can ensure that the student has his/her materials and is cued for the correct activity. More so, a peer can offer a feeling of comfort or assurance to the student.

Peers, as well as the student, can use a digital camera (still or video) to provide a daily diary that can be taken home. This can be a used as a communication tool by the parents as well as a memory tool to assist the student in telling about his/her day. The parents can then do the same at home with the student bringing the photo/video to school each morning. Over time, this diary can provide a diagnostic observational tool to track the change in the student's abilities.

To decrease the chances of behavioral outbursts and/or occurrences of cataplexy, pre-transition warnings should be given to the student. These can be in oral or visual format. Music is one of the last items to be forgotten so pairing certain musical phrases with specific activities can assist the student in remembering what the activity is and what he/she should do. A quiet work or relaxation area may be needed to provide the student an environment with less stimulation since she/he may become anxious or over stimulated with the noise and activity in a typical school classroom. In addition, the child often recognizes the loss of ability, especially early on in the disease progression, and this may result in anxious moments and/or depression. 


\section{EMOTIONAL ISSUES}

A significant concern for the student's family and teacher is that the deterioration of language and physical skills may result in social isolation for the student. Therefore, as the disease progresses, teachers will need a variety of accommodations to allow the student to continue to participate both educationally and socially in the classroom. A Counselor may be added to provide emotional support to the student with $\mathrm{NPC}_{1}$ and his/her family, the student's classmates, and the teachers and support staff involved with the student.

Thus, for the teacher who has a student with $\mathrm{NPC}_{1}$ in the classroom, the focus becomes two-fold. Support for both the family and the student must occur. To assist the family in knowing how the student is doing physically, emotionally, and educationally during the school day, daily notes can be sent home to the parents. The manner of submission will depend on the family and their wish to receive notes in written or digital format. In addition, online or written information about current and future assignments, and activities such as field trips should be provided to the parents so that they can prepare and assist their student.

Identification and connection with community or national support groups is essential for the parents of a student with a progressive, fatal disease such as $\mathrm{NPC}_{1}$. In addition, teachers "will need to develop, within their own establishments, a support system to help each other deal with the emotional feelings often experienced when working with people who have a terminal condition" (NNPDF, 2011). Of course, the teacher can use many of the

Table 3 .

\section{Informational and Support Groups}

\begin{tabular}{|l|l|}
\hline $\begin{array}{l}\text { National Niemann-Pick Disease } \\
\text { Foundation }\end{array}$ & www.nnpdf.org \\
\hline Niemann-Pick Disease Group (UK) & www.niemannpick.org.uk \\
\hline National Library of Medicine & ghr.nlm.nih.gov/condition/niemann-pick \\
\hline NIH: Office of Rare Diseases & rarediseases.info. \\
\hline Medline Plus & nlm.nih.gov/medlineplus \\
\hline $\begin{array}{l}\text { Ara Parseghian Medical Research } \\
\text { Foundation }\end{array}$ & www.parseghian.org \\
\hline Race for Adam & www.raceforadam.org \\
\hline Mayo Clinic & www.mayoclinic.org/niemann-pick \\
\hline Rare Disease Network & $\begin{array}{l}\text { rarediseasesnetwork.epi.usf.edu/ } \\
\text { stair/NPC }\end{array}$ \\
\hline
\end{tabular}


activities noted above within the classroom during the early stages of the disease progression. Teachers will need to check the student's records and then seek further assistance from the personnel described previously. In order to use the skills of all suggested support personnel, a request for special education and subsequent IEP or Section 504 plan development should occur. A student with Niemann-Pick Disease, Type C, will require the combined skills of a team of educators and related support personnel.

\section{SUMMARY}

Niemann-Pick Disease, Type C, is a disease that presents many issues for the student, the parents, and the student's teacher. Knowledge of the disease, its characteristics, and its progression is essential for the teacher to provide an appropriate educational experience for the student. The team approach in developing IEP or Section 504 plans is essential because of the complexity of the disease. Teachers play a key role in coordinating the therapeutic programs recommended by the health professionals. For the teacher who has a student with $\mathrm{NPC}_{1}$ in his/her classroom, the mission is two-fold: first to provide a supportive academic environment for the student with $\mathrm{NPC}_{1}$ and classroom peers; and, second, to provide emotional support for the student and the family. Identification and connection with community or national support groups may be helpful to both parents and others in the school community. Teachers and service providers may also need to develop a support system to help each other deal with the feelings accompanying a student's illness and death. The steps identified by the authors of this manuscript can provide teachers with a prototype for the steps to use when a student with a rare syndrome or another unfamiliar disorder can use to identify characteristics which may impact on the student's educational success and will need classroom revisions and/or request for related personnel support.

\section{REFERENCES}

Bergamin, N., Darchis, A., Beltrami, A., Cesselli, D., Rigo, S., et al. (2013). A human neuronal model of Niemann-Pick C disease developed for stem cells isolated from patient's skin. Orphanet Journal of Rare Disorders, 8, 34.

Bi, X. \& Liao, G. (2007). Autophagic-lysosomal dysfunction and neurodegeneration in Niemann-Pick type C mice: Lipid starvation or indigestion? Autophagy, 3, 646-648. 
Bi, X. \& Liao, G. (2010). Cholesterol in Niemann-Pick type C disease. Subcellular Biochemistry, 51, 319-335.

Crocker, A. C. \& Farber, S. (1958). Niemann-Pick disease: A review of 18 patients. Medicine, 37, 1-95.

Goldman, S. D. B. \& Krise, J. P. (2010). Niemann-Pick C1 functions independently of retrograde transport of membrane-impermeable lysosomal cargo. Journal of Biological Chemistry, 285, 4983-4994.

Greer, W. L., Riddell, D. C., Byers, D. M., Welch, J. P., Girouard, G. S., Sparrow, S. M., Gillan, T. L., \& Neumann, P. E. (1997). Linkage of Niemann-Pick disease type D to the same region of human chromosome 18 as Niemann-Pick disease type C. American Journal of Human Genetics, 61, 139-142.

Heath, J. (2008). Clinical characteristics of Niemann Pick type C in New Mexican patients. SOM Medical Student Research Papers. Albuquerque, NM: University of New Mexico. Retrieved from http://hdl.handle.net/1928/9763

Imrie, J., Jacklin, E., \& Mathieson, T. (2009). Dementia in children, teenagers and young adults: A guide for parents, teachers and care professionals. Stirling, Scotland, UK: University of Scotland.

Knox, R. A. \& Ramsey, G. W. (1932). Niemann-Pick's disease: (Essential lipoid histiocytosis). Annals of Internal Medicine, 6, 218-226.

Lloyd-Evan, E., Morgan, A. J., He, X., et al. (2008). Niemann-Pick disease type $\mathrm{C} 1$ is a sphingosine storage disease that causes deregulation of lysosomal calcium. Nature Medicine, 14, 1247-1255.

National Niemann-Pick Disease Foundation (NNPDF). (2009). General information on educational management for young people with Niemann-Pick type C. Retrieved from http://www.nnpdf.org/familyservices_13.html

National Niemann-Pick Disease Foundation (NNPDF). (2010). NiemannPick disease overview. Retrieved from http://www.nnpdf.org/npdisease_01.html

National Niemann-Pick Disease Foundation (NNPDF). (2011). The Niemann-Pick Disease Foundation brochure. Fort Atkinson, WI: NNPDF.

National Organization for Rare Disorders (NORD). (2006). Niemann Pick Disease. Retrieved from https://myhealth.alberta.ca/Health/Pages/

Patterson, M. C. (2009). Niemann-Pick disease type C-The challenge of diagnosis and treatment. European Paediatrics, 3, 10-13.

Patterson, M. C., Vanier, M. T., Suzuki, K., Morris, J. A., Caresta, E., Neufeld, E. B., Blanchette-Mackie, J. E., \& Pentchev, P. G. (2001). NiemannPick Disease type C: A lipid trafficking disorder. In C. R. Scriver, 
A. L. Beaudet, W. E. Sly, \& D. Valle (Eds.), The metabolic and molecular bases of inherited disease (8th ed.) (pp. 3611-3634). NY: McGrawHill.

Rodriguez-Pascau, L., Coll, M. J., Casas, J., Vilageliu, L., \& Grinberg, D. (2012). Generation of a human neuronal stable cell model for Niemann-Pick C disease by RNA interference. Journal of Inherited Metabolic Disorders Reports, 4, 29-37.

Santos, M. L., Raskin, S., Telles, D. S., Lohr, A. J., et al. (2008). Treatment of a child diagnosed with Niemann-Pick disease type $\mathrm{C}$ with miglustat: A case report in Brazil. Journal of Inherited Metabolic Disorders, 2, S357-S361.

Tang, Y., Li, H. \& Liu, J. (2010). Niemann-Pick disease type C: From molecule to clinic. Clinical \& Experimental Pharmacology \& Physiology, 37, 132-140.

Tangermo, C., Weber, D., Theiss, S., Mengel, E., \& Runz, H. (2011). Niemann-Pick type $\mathrm{C}$ disease: Characterizing lipid levels in patients with variant lysosomal cholesterol storage. Journal of Lipid Research, 52, 813-825.

Vanier, M. T. (2010). Niemann-Pick disease type C. Orphanet Journal of Rare Diseases, 5, 1-18.

Winsor, E. J. T. \& Welch, J. P. (1978). Genetic and demographic aspects of Nova Scotia Niemann-Pick Disease (Type D). American Journal of Human Genetics, 30, 530-538.

Wraith, J. E., Baumgartner, M. R., Bembi, B., Covanis, A., Levade, T., Mengel, E., Pineda, M., Sedel, F., Topcu, M., Widner, H., Vanier, M. T., Wijburg, F. A., \& Patterson, M. C. (2009). Recommendations on the diagnosis and management of Niemann-Pick disease type C. Molecular Genetics and Metabolism, 98, 152-165.

Wraith, J. E., Guffon, N., Rohrbach, M., Hwu, W. L., Korenke, G. C., Bembi, B., Luzy, C., Giorgino, R., \& Sedel, F. (2009). Natural history of Niemann-Pick disease type $\mathrm{C}$ in a multicentre observational retrospective cohort study. Molecular Genetics and Metabolism, 98, 250-254.

Yanjanin, N. M., Velez, J. L., Gropman, A., King, K., et al. (2010). Linear clinical progression, independent of age of onset in Niemann-Pick disease, type C. American Journal of Medical Genetics Part B: Neuropsychiatric Genetics, 153B, 132-140.

Xu, M., Liu, K., Swaroop, M., Porter, F. D., Sidhu, R., Fimkes, S., et al. (2012). d-Tocopherol reduces lipid accumulation in Niemann-Pick type $\mathrm{C} 1$ and Wolmen cholesterol storage disorders. Journal of Biological Chemistry, 287, 39349-39360. 


\title{
SUPPORTING INDIVIDUALS WITH FETAL ALCOHOL SPECTRUM DISORDERS: A SUMMARY OF EFFECTIVE PRACTICES
}

\author{
JENNIFER L. RIGGIE AND TINGTING XU
}

Florida State University

\section{Author Note}

Jennifer Riggie, School of Teacher Education, Florida State University; Tingting Xu, School of Teacher Education, Florida State University.

Correspondence concerning this article should be addressed to Jennifer Riggie, School of Teacher Education, Florida State University, 1114 West Call Street, Stone Building, G107 Tallahassee, FL 32306. E-mail: jlr09c@my.fsu.edu

\begin{abstract}
Fetal alcohol spectrum disorder (FASD) is a lifelong condition that significantly affects the individual's learning, development, behavior, family, and quality of life. Diagnosing children with this condition and providing effective supports is challenging for professionals because little intervention research has been performed with the population. This is frustrating for caregivers who often take an active role in their child's life to ensure that needs are met. This article summarizes quantitative and qualitative studies that have targeted learning and behavioral interventions that aim to support children with FASD and their families. Research suggests that practices accommodating children's neurocognitive and neurobehavioral deficits are likely to produce positive outcomes. Interventions that include the family are also promising in their effectiveness. Extra attention needs to focus on early intervention for infants and toddlers and interventions that can promote the self-determination of adults with FASD. Additional directions for future research are provided along with policy and practice implications.
\end{abstract}

Fetal Alcohol Spectrum Disorders (FASD) is an umbrella term for a group of conditions impacting individuals whose mothers consumed alcohol during their pregnancy (Center for Disabilities, 2008; Center for Disease 
Control and Prevention [CDCP], 2011). Prevalence estimates for children with FASD could be a much as 2-5\% in the United States (May et al., 2009). The main clinical diagnoses associated with FASD in the US are Fetal Alcohol Syndrome (FAS), Alcohol-Related Birth Defects (ARBD), and AlcoholRelated Neurodevelopmental Disorder (ARND) (CDCP, 2011). Fetal Alcohol Effects (FAE) was a term previously used but replaced; other terms like Partial Fetal Alcohol Syndrome (pFAS) are still used to describe conditions on the spectrum (CDCP, 2011). Individuals with FASD can have physical, neurological, and/or developmental challenges that vary greatly from one person to another (CDCP, 2011), depending on the amount of consumption, the duration of use, and the patterns of alcohol exposure (Day et al., 2013; Streissguth, 1997).

Diagnosing children with one of the FASD conditions is difficult because currently there are only assessments for FAS and not the other diagnostic categories (CDCP, 2010b). A diagnosis for one of the other conditions is based upon the extent of characteristics in the following four key areas: facial abnormalities, decreased pre/post-natal growth, impairments in the central nervous system, and prenatal alcohol exposure. The National Task Force on FAS and FAE recommends steps be taken to allow for early diagnosis, diagnosis criteria for all FASD conditions, and the addition of FASD as a disability under federal guidelines (Olson et al, 2009a).

Results from the 2010 National Survey on Drug Use and Health indicate that over $10 \%$ of pregnant women between the ages of 15 and 44 reported current alcohol usage (Substance Abuse and Mental Health Services Administration, 2011). Further, over 3\% of pregnant women reported binge drinking and $1 \%$ heavy drinking. Although these percentages are drastically lower than women who are the same age and not pregnant (54\%,24\%, and $5 \%$ respectively), the CDCP (2010a) report that, "There is no known safe amount of alcohol to drink while pregnant" (para. 1). The effects of prenatal alcohol exposure for the estimated 40,000 children born each year in the United States could be prevented if women refrained from alcohol consumption during their pregnancy (CDCP, 2010a; Lupton, Burd, \& Harwood, 2004).

Per child with FAS, it is estimated that 16,800 dollars are spent each year on medical expenditures; this is nine times greater than the average cost per year of children without this condition (Amendah, Grosse, \& Bertrand, 2011). There is no cure for FASD and the challenges associated with this developmental disability persist throughout the individual's lifespan. Current data on the lifetime cost for an individual with FASD are unavailable; data from about a decade ago indicate that the costs associated with care for all 
individuals with FAS in the United States exceeds four billion dollars each year (Lupton, Burd, \& Harwood, 2004).

About half of all individuals with FASD need support across at least two developmental areas (Dumaret, Cousin, \& Titran, 2010). Individual and family characteristics and risk factors tend to result in children with FASD having disrupted school experiences, failing a grade of school, receiving special education services, and/or needing separate school placements for individuals with severe medical or learning needs (Dumaret et al., 2010). These challenges in school are often outcomes of deficits in cognition, information processing, and challenging behaviors (Kodituwakku, 2007; Riley \& McGee, 2005). Behavioral and emotional challenges do not stop at school, however. About half of those with FASD have problems with the law and/or regular inappropriate sexual behaviors, while a third experience drug or alcohol problems (Streissguth et al., 2004).

Even with these alarming data, little attention has been given to the diagnosis and educational interventions for this population (Coles \& Black, 2006). Three research summaries were conducted in the past decade describing the effects of prenatal alcohol exposure on children (Dixon, Kurtz, \& Chin, 2008; Kalberg \& Buckley, 2007; Kodituwakku, 2007). An additional six studies focused on methods educators (Caprara, Nash, Greenbaum, Rovet, \& Koren, 2007; Green, 2007; Kodituwakku, 2010; Peadon, RhysJones, Bower, \& Elliott, 2009), caregivers (Rowbottom, Merali, \& Pei, 2010) and nurses (Caley, Kramer, \& Robinson, 2005) could take to meet the needs of children with FASD. Four researchers focused their recommendations on the classroom, specifically, assessment (Caprara et al., 2007; Kalberg \& Buckley, 2007), learning interventions (Green, 2007), and behavioral interventions (Kodituwakku, 2010). One review targeted each of the following for its recommendations: medicine (Peadon et al., 2009), positive caregiving experiences (Rowbottom et al., 2010), and prevention of FASD (Caley et al., 2005).

Although researchers have come to a general agreement on the physical and neurological challenges associated with this population (Mattson et al., 2013), minimal studies have researched the effects of interventions for individuals with FASD, or other supports to enhance the quality of life for the children and their families. Many problems remain to be examined. The primary purpose of this article is to summarize the research targeting individuals with FASD and their families to gain a holistic view of practices that show promise of effectiveness with this population. Secondary purposes of this article are to present implications for professionals in the field and future directions for researchers and policymakers. 


\section{METHODS}

Quantitative and qualitative studies were included in the research synthesis if they targeted educational, behavioral, or social interventions for individuals with FASD and/or their families. Studies were identified using PsycINFO and ERIC databases without date restrictions using the identifiers of fetal alcohol spectrum disorder OR fetal alcohol syndrome AND instruction OR intervention. A total of 391 studies were found with PsycINFO and 64 with ERIC. Of these studies, 21 met the inclusion criteria. Over half of these studies used experimental or quasi-experimental methods (Bertrand, 2009; Coles, Kable, \& Taddeo, 2009; Engle, 2008; Kable, Coles, \& Taddeo, 2007; Keil, Paley, Frankel, \& O’Connor, 2010; Kerns, Macsween, Wekken, \& Gruppuso, 2010; Loomes, Rasmussen, Pei, Manji, \& Andrew, 2008; O'Connor et al., 2006; O'Connor et al., 2012; Roebuck-Spencer \& Mattson, 2004; Vernescu, 2007; Wells, Chasnoff, Schmidt, Telford, \& Schwartz, 2012). Qualitative studies used purposeful sampling (Carpenter, 2011) and included a case study (Duquette, Stodel, Fullarton, \& Hagglund, 2006) and pilot study (Grant et al., 2004). Other qualitative studies were explored using ethnography (Edmunds $\&$ Crichton, 2008), grounded theory (McGregor, 2009), and contextual comparison (Ryan \& Ferguson, 2006). The remaining studies used either reversal (Kurtz, Chin, Rush, \& Dixon, 2008) or multiple baseline (Padgett, Strickland, \& Coles, 2006; Timler, Olswang, \& Coggins, 2005) single-case designs.

Results are organized by the type of development targeted for the participants. The three main sections are cognitive development, social-emotional development, and contextual factors. This organization guides the reader through the characteristics of individuals with FASD as the specific interventions are described in each section. Participants, interventions, and results about the intervention studies are summarized in the Appendix.

\section{RESULTS}

\section{COGNITIVE DEVELOPMENT}

Many children with FASD have a cognitive impairment or have below average intelligence (Howell, Lynch, Platzman, Smith, \& Coles, 2006; McGee, Bjorkquist, Riley, \& Mattson, 2009). A recent study examining medical differences between children with and without FAS suggests that while only $1 \%$ of the population without FAS had a cognitive impairment, it was exhibited in 12\% of the children with FAS (Amendah et al., 2011).

In 2009, McGee et al. found that the intelligence level of individuals with FASD affects their abilities in a variety of areas, such as reading, spelling, and 
communication. McGee and colleagues' research on the expressive and receptive communication skills of children with FASD indicates that although these children have poorer language skills than that of children without prenatal alcohol exposure, their abilities are no worse than expected given their cognitive levels. Similarly, children's reading abilities are comparable to what is expected given their intelligence (Rasmussen \& Bisanz, 2009). This research suggests that children with FASD develop normally in each of these areas, but that development occurs at a slower rate than that of children with average intelligence (McGee et al., 2009). This developmental trend does not extend to mathematics; even when intelligence was controlled children with FASD had poorer performance in mathematics than children who were not prenatally exposed to alcohol (Howell et al., 2006).

Executive Functioning. Executive functioning is a complicated construct that encompasses a series of cognitive processes such as planning (Kalberg \& Buckley, 2007; Skogerbø et al., 2012), inhibition, working memory, and task switching (Davis, Gagnier, Moore, \& Todorow, 2013). It also includes behavioral skills such as "sequencing behavior to efficiently achieve a goal" (Kalberg $\&$ Buckley, 2007, p.279), measures of self-control (Skogerbø, et al., 2012), and using stimulus-reward associations to serve the plan for problem solving (Davis et al., 2013). Overall, executive functioning has been recognized as a central deficit for individuals with FASD (Kodituwakku, 2009; Mattson, Riley, Gramling, Delis, \& Jones, 1998; Rasmussen, 2005;). Challenges in complex working memory, flexibility in cognition, concept formation, and reasoning, highlight some specific difficulties in executive functioning (Kodituwakku, Kalberg, \& May, 2001; Mattson, Goodman, Caine, Delis, \& Riley, 1999). Individuals with FASD usually struggle shifting their attention from one topic to another and are confused by changes in their routine (Coles, Platzman, Raskin-Hood, Brown, Falek, \& Smith, 1997). Therefore, these individuals are challenged and can become frustrated while learning new information, retaining the information, and applying it to new situations.

Neuropsychological profiles for children with FASD identify areas of deficit in intellectual functioning, information processing and integration, attention, and memory (Green et al., 2009; Kodituwakku, 2009). These individuals have substantial difficulties in organization (Pei, Job, Kully-Martens, $\&$ Rasmussen, 2012) and focusing and engaging attention (Mattson, Calarco, $\&$ Lang, 2006). They struggle shifting their attention from one topic to another and are confused by changes in their routine (Coles et al., 1997). For these individuals, the more complex a task becomes, the worse their cognitive functioning performance (Kodituwakku, 2009). However, a recent study has shown improvements in executive functioning skills (e.g. memory, cause and effect, and problem solving) for children with FASD (Wells et al., 2012). 
In a study of younger (aged 4-6) and older children (aged 7-9) with FASD, Rasmussen (2006) found that both age groups struggled with tasks of executive functioning and that working memory was a central weakness. These challenges were correlated with performance on many of the math measures given to the children, indicating that limitations in executive functioning may impact other areas of development and may occur across various developmental stages.

Children with FASD have challenges generalizing learned information to other contexts (Duquette et al., 2006). Some research targeting functional skills has found success generalizing safety skills from virtual reality to realworld contexts (Coles, Strickland, Padgett, \& Bellmoff, 2007; Padgett et al., 2006), but no research was found which specifically explored interventions to ameliorate the limitations children with FASD exhibit in generalization. Further, very few have targeted strategies to improve executive functioning deficits in children with FASD.

Promising Practices: Neurocognitive Habilitation. To lessen the impact of executive functioning limitations, Wells and colleagues (2012) and Bertrand (2009) studied the effectiveness of a neurocognitive habilitation program on the behavior and mathematics functioning of children (aged 6-11) with FASD. Randomly assigned children and families in the intervention group received 12 -weeks of instruction lasting 75 minutes for each of the weekly sessions. Content of the program consisted of group learning activities, transition facilitation, and goodbye rituals (Wells et al., 2012). Review of content was conducted at the end of each week to promote children and caregiver's memory of the practices (Wells et al., 2012). Children in intervention groups demonstrated significant improvements compared to those in the control group, who received no intervention $(\mathrm{p}<01)$ (Bertrand, 2009; Wells et al., 2012). These data suggest that neurocognitive habilitation can improve executive functioning (Bertrand, 2009; Wells et al., 2012), problem solving skills (Wells et al., 2012), and selfregulation (Bertrand, 2009).

Acquisition and Information Processing. Individuals with FASD experience deficits in both the quantity and the quality of the information they process (Burden et al., 2009; Kully-Martens, Pei, Job, \& Rasmussen, 2012). When presented with the same number and type of learning opportunities, children with FASD are likely to learn less information than children without prenatal alcohol exposure (Mattson \& Roebuck, 2002; Roebuck-Spencer \& Mattson, 2004), as well as those with Attention Deficit Hyperactivity Disorder (ADHD) (Crocker, Vaurio, Riley, \& Mattson, 2011). Further, when increasing amounts of visual stimuli are provided, a significant positive linear effect is 
observed for children with FASD in the quantity of time required to process the growing amounts of information (Simmons, Thomas, Levy, \& Riley, 2006). This research is consistent with findings of Engle (2007) suggesting that children with FASD can successfully acquire new information; they just tend to learn at a slower speed than children without prenatal alcohol exposure, especially when large amounts of information are provided.

Promising Practices: Semantic Clustering. Semantic clustering is one learning strategy that may support children with FASD's ability to acquire new knowledge (Kodituwakku et al., 2006; Roebuck-Spencer \& Mattson, 2004). Semantic clustering can be used to group words into categories; for example, apple, banana, and orange could be taught under the cluster of fruit. This grouping may help students with FASD form connections between the words and their meanings, and may make retrieval of the information easier when prompted with the clustering category. Although children with FASD learned less verbal information when presented in a standard format, when the information was presented using semantic clustering, there were no differences exhibited in the learning or memory between children with and without FASD (Aragon et al., 2008b; Kodituwakku et al., 2006; Roebuck-Spencer \& Mattson, 2004).

Promising Practices: Individualizing Instruction. In addition to the research by Roebuck-Spencer and Mattson (2004), Duquette and colleagues (2006) shared tips for teachers that were provided by adolescents with FASD. These individuals indicated that they learn new information better when concepts are taught and re-taught in small amounts and when procedures are given one at a time and repeated. In addition, the adolescents reported that they learn better when opportunities are provided for hands-on learning and concepts are modeled by the teacher. These strategies allow the students more time to process each piece of given information before going on to further learning; the strategies help to ensure that instruction is provided at an appropriate pace so that comprehension can occur. They practices are also consistent with data describing the cognitive profile of individuals with FASD suggesting that teachers should slow the pace that instruction is delivered (McGee et al., 2009) and provide supports to enhance concept formation (Kodituwakku et al., 2001).

Retention. It is well documented that children with FASD have memory deficits (Kully-Martens et al., 2012; Manji, Pei, Loomes, \& Rasmussen, 2010), that generally impact their verbal, visual and working memories (Manji et al., 2010). However, the memory deficits may be less prominent when controlling for initial learning (Mattson \& Roebuck, 2002; Willford, Richardson, Leech, \& Day, 2004). Research indicates that children's memory functioning 
varies according to the degree of prenatal alcohol exposure. For example, children with moderate prenatal alcohol exposure have demonstrated deficits in short-term and long-term memory (Willford et al., 2004), while children with heavy prenatal alcohol exposure have exhibited poor recognition and retention of information previously taught (Crocker et al., 2011).

One aspect of memory that has been rarely investigated in children with FASD is source monitoring (Kully-Martens et al., 2012). Source monitoring is defined as the ability to differentiate internal versus external sources of memory. It is one type of episodic memory that inputs the sensory experience of an important daily function into long-term storage (Johnson, Hashtroudi \& Lindsay, 1993). Research conducted by Kully-Martens and colleagues (2012) examined the overall source monitoring abilities in children (aged 6-12) with FASD by asking them to recall the source of auditory words which were previously presented. Results revealed that children with FASD performed poorly in all source monitoring tasks.

Promising Practices: Rehearsal Training. In their study of a strategy to accommodate children's limitations in memory, Loomes et al. (2008) examined the effectiveness of verbal rehearsal training on the working memory in children (aged 4-11) with FASD. Children in the experimental group received rehearsal training, where they were given instructions to whistle the name of items and numbers repeatedly in their minds, while the control group received no instructions. All children were tested on a digit span task three times (one pretest and two posttests), with only children receiving the rehearsal training significantly increasing in their test scores across the three tests. The results suggest that rehearsal training may help individuals with FASD retain some information previously taught to them.

Mathematics. The amount of prenatal alcohol exposure is positively correlated with the severity of math deficits in children with FASD (Rasmussen \& Bisanz, 2009). Additionally, children with FASD are likely to experience deficits in mathematics, more than other content areas (Carpenter, 2011; Rasmussen, 2006; Rasmussen \& Bisanz, 2009). Therefore, it seems necessary to determine children's intrapersonal strengths and weaknesses in math and to explore interventions to facilitate learning in this content area; to date, several socio-cognitive and neurocognitive practices, as well as modified math curriculum, have been successful.

Promising Practices: Socio-cognitive Habilitation. Kable, Coles, and Taddeo (2007) and Bertrand (2009) examined the impacts of a socio-cognitive habilitative program using modified mathematics curricula. These studies both aimed to improve behavior and mathematics in children (aged 3-10 years) with FASD through the program. Their math intervention program resulted in 
children significantly improving their math knowledge and maintaining the improvements after six months (Coles et al., 2009). All families attended workshops where they were provided information about FASD, advocacy, and behavior regulation and all children received psycho-educational care. The children in the intervention group also received six weeks of tutoring services using modified High Scope Curriculum Series (Kable et al., 2007) or the Math Interactive Learning Experience (Bertrand, 2009). Caregivers in the math intervention groups were instructed to support math learning at home. Results showed a high level of satisfaction for the caregivers and significant gains in their knowledge of FASD, advocacy, and behavior regulation $(\mathrm{p}<.05)$. Both groups of children gained in their math knowledge, with gains for the treatment groups significantly higher than gains in the control groups $(p<.01)$ (Bertrand, 2009).

Functional Skills. It has been well documented that children with FASD have poor adaptive skills (Padgett, Strickland, \& Coles, 2006), sensory processing (Carpenter, 2011; Carr, Agnihotri, \& Keightley, 2010), sensory regulation (Brown, Olson, \& Croninger, 2010; Carpenter, 2011), daily living skills (Crocker, Vaurio, Riley, \& Mattson, 2009), and vocational skills (Spohr, Willms, \& Steinhausen, 2007). In 2008, Edmunds and Crichton found that individuals with FASD struggle finding their place within society. Howell and colleagues (2006) suggest, however, that some functional limitations are the result of prenatal alcohol exposure in combination with contextual factors; their data highlight the possibility that the functional challenges seen in individuals with FASD may be assuaged given high quality home and school environments. Along with the promising practices described below, sensory integration and exercise programs have been identified by teachers as practices that should be considered for individuals with FASD (Carpenter, 2011).

Promising Practices: Virtual Reality Programs. One method used to teach functional skills to individuals with FASD is computer assisted instruction. In 2003, Hamilton and colleagues' research indicated that children with FASD have the visual, motor, and motivational qualities necessary to successfully complete virtual learning tasks. In addition, in 2008, individuals in Edmunds and Crichton's study all had positive experiences with computer programs, and participants mentioned that the computer was less distracting and very enjoyable to use.

Virtual reality programs have been successful in teaching children with FASD fire safety (Padgett et al., 2006) and street safety (Cole et al., 2007). A virtual reality program used to teach children with disabilities safety skills was modified to meet the characteristic needs of children with FASD; these adaptations were additional verbal instructions, visual cues, background music, and 
instruction in navigating the virtual world (Padgett et al., 2006). Children were taught how to perform the assigned task with help from an animated character before they were expected to complete it independently (Coles et al., 2007; Padgett et al., 2006). When the children made correct decisions, the program reinforced them verbally and visually and when an incorrect decision was made, the screen would go black, the danger explained, and they would start from the beginning. In both studies (Coles et al., 2007; Padgett et al., 2006) children learned at least some of the steps of their safety skill, were able to generalize them in a real world simulation, and maintained the learned steps one week later.

In 2007, Strickland, McAllister, Coles, \& Osborne conducted a series of studies using a virtual reality computer based program to train fire and street safety skills. They started with children who had been diagnosed with autism spectrum disorders and then worked with children who had FASD. They changed participants and varied the training content and assessments for five groups of children, but the majority of children who participated demonstrated gains in fire and safety skills and retained their knowledge during a one-week follow-up (Strickland et al., 2007).

Although no research has been completed in the past five years using virtual reality programs with individuals with FASD, it has been effective in promoting the functional skills of individuals with other types of disabilities. Lotan, Yalon-Chamovitz, and Weiss (2010) used a virtual physical fitness program to improve the physical health and heart rates of adults with severe intellectual disabilities. Then, in 2011, Bart et al.'s research improved the attention and self-care abilities of children (aged 6-11) with brain injury. Most recently, Yuen et al.'s (2013) research improved social anxiety, depressive symptoms, and the quality of life for 14 adults with a social anxiety disorder.

Promising Practices: In Vivo Instruction. In vivo instruction is a method in which students are taught and coached on a particular skill in the context of the students' natural environment. In this manner, students have the opportunity to apply skills they have learned in the contexts that have direct application to their lives. The goal of this type of instruction is to enhance the functional use of skills by the participants in their everyday lives.

Adolescents with FASD have indicated that they learn well from interesting hands-on lessons (Duquette et al., 2006; Edmunds \& Crichton, 2008). This suggests that offering participation from among a choice of functional courses or topics may increase students' engagement in the activities and be more meaningful for their future. For example, students working on laundry skills are permitted to choose whether to sort clothes, use the machines, or fold the clothes to practice these functional skills, while giving them input and the opportunity to become invested in the activity. 
Students with FASD have found success in vocational high schools that focus on job skills or other post-secondary training (Duquette et al., 2006). These programs often offer students the opportunity to learn a skill by directly practicing that skill. Supports are often provided by trained staff and then gradually faded to promote students' independence in the task.

In a pilot study of 19 women with FASD, Grant, Huggins, Connor, Pedersen, Whitney, and Streissguth (2004) found success in their community outreach supporting women with FASD with the goal of meeting their identified needs and preventing another generation of prenatally exposed children. The project helped women find housing, enroll in substance abuse treatment programs, receive consistent health care services, and use some method of family planning. Even with this success, the women were still not able to independently function and the advocates in the program emphasized the importance of ongoing supports (Grant et al., 2004).

\section{SOCIAL EMOTIONAL DEVELOPMENT}

Prenatal alcohol exposure negatively effects children's post-natal behavior (Dixon, Kurtz, \& Chin, 2008), even while controlling for confounding variables, such as socioeconomic status and children's intelligence (Mattson $\&$ Riley, 2000). In 2004, Bailey and colleagues' research indicated that prenatal binge drinking was associated with children's behavior problems, but the amount of prenatal alcohol exposure was unrelated to their behavioral outcomes. Day et al. (2013) arrived at a different conclusion indicating that the average daily volume of alcohol consumption during pregnancy and the duration of drinking throughout pregnancy were both predictors of behavioral problems.

Children with FASD have poor social cognition and emotional processing (Greenbaum, Stevens, Nash, Koren, \& Rovet, 2009). They often display deficits in social skills (Carpenter, 2010; Kodituwakku, 2007; Rasmussen, Becker, McLennan, Urichuk, \& Andrew, 2010; Whaley, O'Connor, \& Gunderson, 2001) and are at risk for a variety of social-emotional challenges (Dixon, Kurtz, \& Chin, 2008; Drotar, Aylward, \& Beebe, 2012; Greenbaum et al., 2009). These challenges are exhibited as both internalizing and externalizing behaviors (Graham et al., 2012; Greenbaum et al., 2009; O'Connor \& Paley, 2006; Sood et al., 2001) and are observed by both parents and professionals across environments (Schonfeld, Paley, Frankel, \& O'Connor, 2006).

Internalizing Behaviors. Internalizing behaviors are behaviors that are directed at the individual exhibiting them. These behaviors are more-likely to cause harm to the person performing them rather than others in the environment 
because the individual's emotions are directed inwardly (Rasmussen et al., 2010). Common internalizing behaviors for children with FASD include depression (O'Connor \& Paley, 2006), lack of persistence, forgetfulness, confusion (Graham et al., 2012), and lack of energy (Carr et al., 2010; Edmunds \& Crichton, 2008).

Some internalizing behaviors create specific learning challenges for children with FASD. For example, young children prenatally exposed to alcohol exhibit a more negative affect which in turn impacts the type of interactions between them and their caregivers (O'Connor \& Paley, 2006). Additionally, many school-age children struggle recalling instructions provided orally and following them (Carpenter, 2011). Research also indicates that individuals with FASD experience difficulties meeting learning and behavioral expectations when there are changes in the routine and variations in the tasks presented (Aragon et al., 2008b; Hamilton, Kodituwakku, Sutherland, \& Savage, 2003; Kodituwakku et al., 2001). Teachers have reported success through the use of consistent routines, visual schedules, pairing short concrete directions with visual cues, and repeating instructions and rules as needed (Carpenter, 2011).

Externalizing Behaviors. Externalizing behaviors, directed outwardly, are likely to be disruptive to the learning environment and likely to draw attention to the person performing them and/or cause harm to others. Individuals with FASD have been found to perform a variety of these behaviors, such as hostility (Keil et al., 2010), non-compliance (Ware et al., 2012), mood swings (Carpenter, 2011), lying and stealing (Nash et al., 2006), substance abuse (Burd et al., 2003; Edmunds \& Crichton, 2008), inappropriate sexual behaviors, and trouble with the law (Burd et al., 2003; Streissguth et al., 2004).

Research suggests that children with FASD lack guilt when they misbehave (Caprara et al., 2007; Duquette et al., 2006; Janzen, Nanson, \& Block, $1995)$ and are more likely to lie about their misbehavior when compared with children without prenatal alcohol exposure (Caprara et al., 2007; Rasmussen, Talwar, Loomes, \& Andrew, 2008). Further, Rasmussen et al.'s research indicates that elementary children with FASD are more skilled in telling lies than they were at preschool age. These findings suggest that children with FASD may understand that they can fabricate a story in an attempt to prevent negative repercussions associated with their actions.

Promising Practices: Reinforcement Learning. Although Burd and colleagues' (2003) research highlights the difficulties that may be encountered motivating and rewarding children with FASD, research supports the use of reinforcement as a behavioral support tool for families and professionals (Carpenter, 2011; Engle, 2008; Kurtz et al., 2007) provided that the expectations and rewards remain consistent (Carpenter, 2011). In 2007, a child in Kurtz and colleagues' research decreased in challenging behaviors when 
reinforcement was used as a part of his program. Engle (2008) was able to teach children with and without FASD to select an item from a pair that was more likely to provide a positive response using reinforcement learning. If children selected the correct response, they were likely to receive positive feedback $70 \%$ of the time and negative for $30 \%$. When children selected an incorrect response they received positive feedback $30 \%$ of the time and negative feedback for 70\%. Engle's (2008) research suggests that children with FASD are able to learn from consistent reinforcement, but that the learning may take longer than it does for children who are not prenatally exposed to alcohol. Therefore, to support children with FASD learning with these methods, it is essential that consistent repetition of reinforcement and consequences be provided for behaviors to aid students in learning about the positive or negative effects of their behaviors (Duquette et al., 2006; Engle, 2008).

Promising Practices: Function-Based Interventions. Functional behavioral assessments and behavioral intervention plans are research based methods for determining why children are exhibiting challenging behaviors and determining how to resolve the problem. In 2008, Kurtz and colleagues used these methods to intervene with two toddlers with prenatal exposure to alcohol, cocaine, and heroine who exhibited aggressive and self-injurious behaviors. In their study, Kurtz and colleagues first determined the function of the challenging behaviors to be obtaining attention or tangibles or avoidance of demands. One child was taught to request a preferred item as a replacement for the challenging behaviors. This strategy was effective for the child in two out of three of the conditions presented. The other child was provided reinforcement non-contingently of his behavior every 30 seconds lasting $10 \mathrm{sec}-$ onds; this was paired with ignoring challenging behaviors. This was not effective enough for the child given the dangerous nature of his behaviors, so the ignoring was replaced with a 30 second time-out each time a challenging behavior was exhibited. The combined intervention of non-contingent reinforcement and time-out was effective at decreasing the challenging behaviors for the child.

Attention, Hyperactivity, and Impulsivity. The amount of alcohol consumed prenatally is related to the degree of distractibility and the reaction times for children on performance tasks (Kodituwakku, 2007). Children with FASD are likely to have poor attention spans (Aragon et al., 2008a) and act impulsive and restless (Carpenter, 2011; Janzen et al., 1995; Rasmussen, Becker, McLennan, Urichuk, \& Andrew, 2010). Many also meet the diagnosis requirements for ADHD (Fryer, McGee, Matt, Riley, \& Mattson, 2007), although many professionals rate the social skills of children with FASD as significantly worse than children with ADHD (Greenbaum et al., 2009). The multiple challenges associated with those who have a dual diagnosis may 
compound the social-behavioral limitations and create a unique developmental profile for the population (Ware et al., 2013). For example, individuals with FASD experience challenges focusing their attention and regulating their behaviors which parents and professionals believe may interfere with the learning process (Carpenter, 2011; Kodituwakku, Handmaker, Cutler, Weathersby, \& Handmaker, 1995), leading to poorer social skills, increased problem behaviors (Schonfeld et al., 2006), and interrupted school experiences (Spohr $\&$ Steinhausen, 2008).

Impulsivity is also a struggle for children with FASD (Rasmussen et al., 2010). Parents have reported that their children's impulsive nature is so extreme that they fear for their children's safety (Burgess \& Streissguth, 1992). Although interventions can be used to teach safety skills, if impulsivity is the cause of some safety concerns, it cannot be overlooked. Interventions need to be investigated to determine methods to assist children in managing their impulsiveness and regulating their behaviors.

Both parents and professionals report that children with FASD have more behavioral problems and poorer social skills than children without FASD (Greenbaum et al., 2009). Although research suggests that these problems persist throughout the lifespan for individuals with FASD (O'Connor, 2001; Streissguth, Barr, Kogan, \& Bookstein, 1996), additional research shows that by providing instruction on the rules of social behaviors, modeling appropriate behaviors, and giving home assignments, children can improve their knowledge of appropriate social behaviors and act in more socially appropriate ways (O'Connor et al., 2006).

Promising Practices: Attention Process Training. In 2008, Vernescu randomly assigned 20 children with FASD (aged 6-12) into attention process training and control contact sessions. Materials from the Pay Attention! training protocol were used to teach children the following types of attention: sustained, selective, alternating, and divided. During 12 daily sessions lasting about 30 minutes each, children were provided visual and auditory stimuli to attend. Results show that the attention processing intervention significantly improved children's ability to sustain attention, selection the focus of attention, and alternate attention between sources (Vernescu, 2008).

Computerized Progressive Attention Training (CPAT) is an intervention that targets three neuro-cognitive attention networks responsible for alertness, sensory input, and resolving conflicts (Kerns, Macsween, Wekken, \& Gruppuso, 2010). Ten children (aged 8-15) with FASD completed the 16-hour training program. An average of 30.5 training sessions, lasting about 30 minutes each, were completed one-on-one with a research assistant or teacher. From pre to post testing, children significantly improved their ability to remain focused with distractions present, as well as their sustained and divided 
attention (Kerns et al., 2010). Further, children's reading and mathematics fluency improved.

Friendships. Many children with FASD desire friendships but lack the skills necessary to form and maintain meaningful relationships (Carpenter, 2011). The social emotional challenges (Burgess \& Streissguth, 1992) of children with FASD coupled with their limitations with social skills (CDCP, 2010b) and communication (Kully-Martens, Denys, Treit, Tamana, \& Rasmussen, 2012) propose challenges in establishing friendships. Additionally, children with FASD struggle to identify the emotions of others based upon their facial expressions and to effectively communicate their thoughts (Greenbaum et al., 2009). The interpersonal communication limitations create difficulties in both structured and unstructured situations (KulleyMartens et al., 2012).

Overall, children with FASD perform significantly worse than children without disabilities as well as those with ADHD on measures of socialization (Crocker et al., 2009). These weaknesses also result in the children acting younger than their age, selecting younger friends, being taken advantage of, and not identifying social dangers (e.g. strangers) (Burd et al., 2003; Greenbaum et al., 2009; Janzen et al., 1995). Adolescents and adults with FASD also struggle with relationships, feeling socially accepted, and developing deeper relationships (Duquette et al., 2006). Crocker and colleagues' research in 2009 indicates that performance on socialization tasks for individuals with FASD decrease as children age into adolescence; the authors hypothesized this to be the result of the increasingly complex social demands as children age. Research suggests that individuals with FASD may benefit from counseling and discussions about life or social challenges (e.g. bullying) (Duquette et al., 2006; Edmunds \& Crichton, 2008) or from the use of social stories and scripts (Carpenter, 2011).

Promising Practices: Social Skills Training. In 2005, Timler, Olswang, and Coggins conducted a case study using social-communication interventions with one nine year old girl who was diagnosed with a FASD. The subject received two, one-hour weekly individual intervention sessions, followed by four weeks of group sessions occurring for two hours, three days a week with the subject and two other children with prenatal alcohol exposure. During the individual sessions, the child created a social checklist and a book with socially appropriate behaviors for different situations. The group intervention entailed role playing of social situations, using a checklist as a guide through the social routine, modeling appropriate responses, and an adult reading a social script to the children (Timler et al., 2005). When data were examined across study phases, the subject participated more in the social situation, produced more mental-state verbs, and used more social strategies to resolve conflicts. 
Project Bruin Buddies is a social skills training program aimed at improving peer friendships among children with FASD (Bertrand, 2009). This program was used to teach children (aged 6-12) how to have a conversation with peers, join a play group, participate in at-home play dates, and negotiate to avoid conflict (Bertrand, 2009). This content was the focus of Bertrand's (2009) program; however, the methods of intervention delivery were modified from the original training to account for the children's neurocognitive impairments. In addition to the typical methods, modeling, rehearsal, and performance based feedback were used during play sessions. Each of the 12 sessions lasted 90 minutes and occurred once a week; concurrently, parents attended training sessions for instruction on key social skills and issues related to FASD. At the conclusion of the program, the children had made significant improvements in their knowledge of social behavior $(\mathrm{p}<.0001)$; these findings were aligned with parent data indicating that the child's social skills had improved $(\mathrm{p}<.03)$ and problem behaviors lessened $(\mathrm{p}<.05)$. Further, at post-intervention follow-ups, not only did the children maintain their learned skills, but they continued to improve upon them $(\mathrm{p}<.002)$

The child friendship training (CFT) is another type of social skills training and was examined in three studies with children (aged 6-12) with FASD and their caregivers (Keil et al., 2010; O'Connor et al., 2006; O'Connor et al., 2012). In the studies from 2006 and 2010, children were assigned to either the CFT or delayed treatment control (DTC). The CFT group attended 12 sessions over 12 weeks, lasting 90 minutes in length, while the DTC group would wait to receive the intervention later. The essential social rules being taught to the children were also instructed to the parents using modeling, rehearsal, and performance feedback during the intervention sessions; then, parents were to rehearse the skills at home and coach their child when playing with a peer. In O'Connor and colleagues' study (2006), children in both groups were assessed before and after the treatment, and children receiving the CFT demonstrated gains in knowledge of social behaviors $(\mathrm{p}<.001)$ and actual social skills $(\mathrm{p}<.03)$ as well as reductions in problem behaviors $(\mathrm{p}<.05)$ compared to children in the delayed treatment control (DTC) group. In Keil and colleagues' research, CFT was effective in decreasing children's hostile behaviors for peer group entry $(\mathrm{p}<$ $.05)$, but not for provocation scenarios $(\mathrm{p}=.88)$. Results were maintained at comparable levels in both studies at a three month follow-up.

O'Connor's research from 2012 compared children's social skills before and after receiving the CFT or standard of care (SOC) intervention. The SOC intervention was another social skills training group that taught and discussed a variety of social behaviors; however, the topics were not empirically predictive of peer acceptance, nor was there any parental participation. Comparisons between pre and post testing of the two groups indicated that 
children who received the CFT intervention improved significantly better than children in the SOC on their knowledge of social skills $(\mathrm{p}<.001)$, their self-concept $(p<.05)$, and parental reports of children's assertion $(p<.05)$ and responsibility $(\mathrm{p}<.05)$, but not cooperation $(\mathrm{p}=.59)$ or self-control $(\mathrm{p}=.39)$. These results confirm previous findings that CFT positively impacts children's social knowledge and skills, but that a modification to the intervention may be necessary to target some of the specific social-behavioral needs of children with FASD.

Promising Practices: Social-Behavioral Therapies. In Bertrand's (2009) comparative study of parent-child interaction therapies, families received either the Parent-Child Interaction Therapy (PCIT) or the Parenting Support and Management (PSM) program across 14 weeks, with each weekly session lasting 90 minutes. Two of these sessions included in vivo coaching using bug-in-ear (BIE) technology for the PCIT group. BIE is a method of coaching in which performance based feedback is provided to a parent (or professional) through an earpiece while he/she is interacting with a child. Feedback from Bertrand's study focused on teaching parents behavioral management skills. The other 12 sessions entailed both the parent and child interacting with one another. Children in both groups improved on their behaviors with non-significant differences favoring the PCIT group $(\mathrm{p}=.14)$. In addition, caregivers in both groups found their program favorable and $80 \%$ indicated that they would recommend the program to others (Bertrand, 2009).

Another behavioral study compared the Families Moving Forward (FMF) program with families receiving standard community care (Bertrand, 2009). The FMF program lasted 9-11 months with families receiving sessions in their home lasting 90 minutes every other week. Each session focused on improving attitudes about children's challenging behaviors and empirically based methods caregivers could use to manage them. Results indicate that families' needs were better met $(\mathrm{p}<.01)$ and children's behaviors improved significantly $(\mathrm{p}<.05)$ for families in the FMF group compared to children receiving standard comminity care (Bertrand, 2009).

Other intervention studies that have shown significant results in child skills and performance also had involvement of parents or caregivers as one component. For example Kable and colleagues (2007) provided training to parents and caregivers to increase their knowledge about characteristics of FASD, as well as providing methods to support their children's learning in mathematics. Additionally, Coles, Kable, and Taddeo (2009) focused on teaching parents methods for enriching the home environment to support their children's learning of math skills. These studies suggest that involving peers and parents in the intervention can positively impact the social, behavioral, and/or cognitive learning in children with FASD. 


\section{CONTEXTUAL FACTORS}

In the United States, approximately $50 \%$ of pregnancies are not planned (CDCP, 2011). Even if a woman has the knowledge that she should not drink alcohol while she is pregnant, she may go weeks without learning of her pregnancy and drink during that time. In documented instances of this phenomenon, many women report feelings of grief and shame upon learning that their child's challenges may have been prevented had they not consumed alcohol during their pregnancy (Hope for Women in Recovery Summit, 2005). For children with FASD, there are a combination of biological and environmental factors that interplay and impact the children's development and learning (Kully-Martens et al., 2012).

When families have a child with a developmental delay, typically, the entire family is significantly affected (Bailey, Golden, Roberts, \& Ford, 2007; Skinner \& Weisner, 2007). Caregivers of children with FASD have reported this impact on their family (Rowbottom et al., 2010). Parents are frustrated with the lack of supports and services available to them and their child (Ryan $\&$ Ferguson, 2006). They often experience heightened stress and financial strain as a result of conditions associated with the disability (Olson, Oti, Gelo, $\&$ Beck, 2009b). The greatest challenge for these parents is dealing with their child's behaviors (Ryan \& Ferguson, 2006). Families have also reported adverse experiences with professionals; therefore, parents often must become directly involved in their child's services to ensure that they receive the attention they need (Olson et al., 2009b). Since the family environment impacts a child's development, it is essential to include the family in intervention planning (Olson et al., 2009b).

Home Environment. High quality, structured caregiving and a positive home environment are among the best protective factors for children with FASD (Streissguth, 1997; Streissguth, Bookstein, Barr, Sampson, O’Malley, \& Young, 2004). Unfortunately, “...a positive and stable environment during childhood is not typical for this population" (Olson, 2009b, p. 237). In fact, children with FASD are likely to experience additional risk factors such as exposure to other tetragons prenatally (O'Connor \& Paley, 2006; Streissguth et al., 2004), postnatal trauma (Coggins, Timler, \& Olswang, 2007), poverty and poor nutrition (May et al., 2009), and multiple living placements (Greenbaum et al., 2009) that increase the likeliness of lifelong challenges. Although family support services are valuable for all children with FASD, Jirikowic, Gelo, and Astley (2010) found that it may be even more important for children birth through two years of age, compared with children three years and older $(\mathrm{p}=.01)$.

Children with FASD often live with individuals who are not their biological parents (Jirikowic et al., 2010). These environments are typically more 
stable for the children and support healthy growth and development (Rowbottom et al., 2010). But many non-biological caregivers face challenges associated with raising a child with a FASD that negatively affect their emotional well-being and home environment (Rowbottom et al., 2010). Little research has specifically targeted adoptive or foster families in research; practices need to be investigated about methods that can better prepare these families for FASD and the challenges the family may incur as a result of the disability (Rowbottom et al., 2010).

Support Groups. Participation in family support groups may be particularly important for parents who have a child with FASD. Johnston and Mash (1989) found that the number one unmet need identified by caregivers of children with FASD was the opportunity to talk with other individuals who have gone through similar experiences. This need for support has not changed over the years; in 2009, parents were still reporting this need (Olson et al., 2009b).

The two primary types of support groups for families are parent support networks and FASD specific parent support organizations (Olson et al., 2009b). Parent support networks are broad groups that can include caregivers of children who have any type of disability or challenging condition, while FASD specific organizations are for caregivers who have a child with a FASD. Both types of support groups are helpful in providing information and resources from other parents or professionals and they serve as socialemotional networks that allow for families to give and receive support from one another (Olson et al., 2009b). The support groups are centered on family needs; discussion tends to focus on solutions to problems and parents often improve upon their advocacy skills after participation in support groups (Olson et al., 2009b).

Although support groups are highly recommended by professionals, research has not examined the impact of support groups on family and child outcomes. These studies could be an appropriate avenue to include siblings' perspectives and supports to gain knowledge about the impact of FASD on family members other than caregivers. It could also provide all family types (e.g. biological, foster, and adoptive) with strategies on effective child rearing methods that can aid in stress management (Olson et al., 2009a), challenging behaviors (Ryan \& Ferguson, 2006), and positive relationships (Olson et al., 2009b).

\section{IMPLICATIONS}

A plethora of research data exists describing the characteristics and challenges of individuals with FASD (Ware et al., 2013). These data are valuable given that adolescents with FASD have identified their best teachers as those who are 
knowledgeable about the disability and its impacts on learning and behavior (Duquette et al., 2006). Therefore, an important implication of this research is to increase the awareness of FASD and to develop more effective methods to disseminate knowledge and resources to professionals working with these individuals. These professionals will be more likely to acquire effective interventions and evidence based practices to meet the needs of children with FASD. The following aspects of assessment and planning are considered: the child's developmental portfolio, the environmental and task structure, self-determination, and caregiver involvement.

\section{ASSESSING THE CHILD'S DEVELOPMENTAL PORTFOLIO}

This research review has documented the cognitive (Mattson et al., 2013), functional (Crocker et al., 2009), sensory (Carr et al., 2010), and social emotional (Ware et al., 2013) limitations of individuals with FASD. It has also identified interventions that target these areas in an effective manner for the population (Green, 2007; Kodituwakku, 2010). This is beneficial because children with FASD have a unique set of strengths and weaknesses that, when considered through assessment and planning, maximize the effectiveness of an academic program (Burd et el., 2003; Carpenter, 2011; Janzen et al., 1995).

For children with FASD, the impact of prenatal alcohol exposure on their thoughts and actions need to be examined in the context of their developmental profile (Janzen et al., 1995; Mattson et al., 2013). Although this is not a novel recommendation the validity lies in the research suggesting that families are still under a great deal of stress because of their children's behavioral difficulties, and professionals continue to lack in their knowledge of FASD (Olson et al., 2009b). For children with FASD:

Effective interventions must consider the interplay between behavioral symptoms and the neuropsychological effects of prenatal alcohol exposure...instead of viewing a child's difficulties or behavior problems as a result of the child being defiant, lazy, intentional, or manipulative, these behaviors should be viewed as symptoms of neurocognitive deficits. (Green, 2007, p.106)

If children with FASD are viewed in such a manner, professionals who work with them and their families are more likely to provide instruction and behavioral supports in a positive manner (Green, 2007). This could be one factor that improves the services families receive from professionals (Olson et al., 2009b; Ryan \& Ferguson, 2006). In order for this to occur, improvements are warranted in how children with FASD are diagnosed and assessed (Brown et al., 2010). 
Screening. Over the past decade professionals have used a variety of screening measures to identify children who may have prenatally been exposed to alcohol (Poitra et al., 2003; Zelner et al., 2012). These screening methods have begun as early as prenatal (Chang, 2004) and extended as late as kindergarten enrollment (Poitra et al., 2003).

The T-ACE is a four-item questionnaire that physicians can ask pregnant mothers during prenatal appointments to gauge prior alcohol usage and red flags for current alcohol use during pregnancy (Chang, 2004). T-ACE is an acronym for the questions asked relating to the mother's tolerance, annoyance, cutting-down, and eye-opening experiences with drinking alcohol. Women can receive between zero and five points on the T-ACE with scores of two or higher indicating the mother may be at risk for alcohol consumption during pregnancy. Research suggests that when mothers were given a brief intervention after receiving a two or higher, women were more likely to refrain from alcohol use or decrease their consumption throughout the pregnancy (Chang, 2004). Mothers received the following four steps of intervention: 1) assessment and direct feedback, 2) goal setting, 3) usage of behavioral modification techniques, and 4) resources on self-help and reinforcement.

One challenge that arises with the T-ACE screening is the reliability of mothers' responses (Chang, 2004). The Timeline Followback calendar (TLFB) is another screening measure that uses the date of conception and the date the woman realized she was pregnant to assess the frequency and amount of alcohol consumed during pregnancy (Caprara et al., 2007) Caprara et al. suggest combining the T-ACE with the TLFB to increase the accuracy and effectiveness of screening for alcohol consumption during pregnancy. A flaw with prenatal screening is that women who do not visit a physician during pregnancy would not be evaluated using these methods.

Another method of screening for prenatal alcohol exposure is neonatal screening (Hopkins et al., 2008; Zelner et al., 2012). This method uses maternal biomarkers from the fatty acid ethyl esters (FAEE) in the newborn's meconium, earliest stools (Zelner et al., 2012). Although this method does not detect alcohol consumption for the entire pregnancy, it provides an accurate history for the second and third trimesters (Caprara et al., 2007). The early screening of FASD would have significant cost benefits to society if the majority of children were identified (Hopkins et al., 2008). However, Zelner et al.'s research suggests that if the meconium screening measure is optional, many women who have consumed alcohol during their pregnancy are likely to opt out of the procedure; this is problematic because the children most likely to test positive are likely to be the ones not screened. Methods should be considered to encourage more women to consent to screening (Zelner et al., 2012) or to make neonatal screening more universal (Hopkins et al., 2008). 
A third method used to screen for FASD is adding a test form to the additional assessments for early intervention (Watson et al., 2011) or kindergarten screening (Poitra et al., 2003). The benefits of this screening are that it only takes 10 minutes to administer, it is feasible to add into the other assessments, and it is cost efficient. The downsides are the relative lateness of the screening, the diminished growth delays with the child's age, and the increased likeliness that the child lives with non-biological parents and relevant information unknown by the current caregivers (Burd, Klug, Li, Kerbeshian, \& Martsolf, 2010). Overall, adding an FASD screening can be helpful in raising awareness of FASD and identifying children at risk for it (Watson et al., 2011).

Regardless of the screening method utilized, it is imperative that families and professionals know that screening positive does not mean that child has FASD. A screening is merely a tool to identify children at risk for FASD who may or may not have a diagnosis after further testing (Caprara et al., 2007).

Diagnosis. The authors agree with the National Task Force on Fetal Alcohol Syndrome and Fetal Alcohol Effects that modifications are necessary in the diagnostic process for children with FASD (Olson et al., 2009a). One change should occur at the policy level so that children with any diagnosis on the fetal alcohol spectrum can be eligible for services, if needed (Brown et al., 2010). Current diagnostic practices for FAS should be evaluated to determine if they could be adapted for the other FASD conditions, since there is "no definitive test for FASD" (Pei \& Rinaldi, 2004, p.126). Currently, about $75 \%$ of children are accurately diagnosed with FASD or evaluated as non-FASD (Mattson et al., 2013). FASD measures need to be validated so that children can be understood appropriately with one of the FASD conditions without going unrecognized or misidentified (Olson et al., 2009a) even if other conditions exist that may confound some characteristics of FASD (Bishop et al., 2007). This may entail improving current diagnostic methods (Ware et al., 2013) or exploring new methods of diagnosis, such as brain imaging (Wozniak, et al., 2011) and using Telehealth for FASD assessments (Ens, Hanlon-Dearman, Millar, \& Longstaffe, 2010).

Complete Assessments. Children with FASD are often diagnosed from symptoms and then the specific areas of atypical development are examined further to better understand the children's unique profiles (Pei \& Rinaldi, 2004). Individuals with FASD experience challenges in multiple developmental areas and therefore, to develop a thorough child profile, a variety of assessments should determine the child's strengths and limitations (Pei \& Rinaldi, 2004). A thorough assessment will shed light on the neurocognitive and neurobehavioral development of the child (Mattson et al., 2013), as well as identify any adaptive or sensory needs (Burd et al., 2003). This will help professionals understand the impact of the child's prenatal alcohol exposure on their learning and behavior, and equip them with the skills to provide services for children with FASD and their families (Brown et al., 2010). Since instruc- 
tional accommodations are more likely to be necessary as children increase with age ( $\mathrm{p}=.009)$, it is probable that complete assessments for children with FASD should occur routinely to guarantee that the information is current and relevant for the child's academic and/or behavioral plan (Jirikowic et al., 2010).

\section{PLANNING THE ENVIRONMENTAL AND TASK STRUCTURE}

Early Intervention. Research highlights the importance of interventions throughout the lifespan (Fagerlund et al., 2006; Spohr \& Steinhausen, 2008). In 1994, Williams and Howard reported the necessity for interventions to meet the needs of children with FASD; 20 years later, this is still an imperative need (Goodlett, 2010). Although intervention research for school age children with FASD is limited (18 studies), it is even scarcer for very young children (1 study) and adults ( 2 studies). It is well documented that children with developmental delays or disabilities benefit from early intervention (Burgess \& Streissguth, 1992; Goodlett, 2010). For children with FASD, early intervention is a protective factor that increases the likeliness of positive outcomes (Streissguth, Barr, Kogan, \&Bookstein, 1996). If screening and diagnosis practices improve for this population, then early identification is more likely and child and family services can begin at a younger age (Goodlett, 2010).

Since family resources are especially valuable for children birth through two years, research targeted family-centered interventions may be particularly meaningful for this population (Belcher et al., 2005; Jirikowic et al., 2010). For example, providing home-based and/or center-based services for families of children with pre-natal drug exposure has resulted in improvements for both caregivers and children (Belcher et al., 2005). Caregivers improved in responsive interactions (Lowe, Handmaker, \& Aragon, 2006; O'Connor \& Paley, 2006), increased their parenting knowledge, decreased corporal punishment, and reduced stress and depression (Belcher et al., 2005). Targeted interventions for children beginning at a younger age provide supports for aspects of the disability that emerge early in life, such as growth deficiencies (Belcher et al., 2005), information processing (Stephen et al., 2012), negative affect, and emotional regulation (Lowe et al., 2006; O'Connor \& Paley, 2006).

Individualization. For school aged children Ryan and Ferguson's (2006) research suggests that experienced teachers are better equipped to meet the needs of students with FASD, compared to novice ones. Their research indicates that experienced teachers differentiate instruction while novice teachers struggle to do so. In 2010, Blackburn and Whitehurst's study demonstrated that teachers are more successful educating children with FASD when their instruction is visual and concrete (Blackburn \& Whitehurst, 2010). One teacher highlighted the importance of repetition in both teaching and rules/directions when she indicated that for her students it is "Here today, gone tomorrow!" (Carpenter, 2011, p. 39). 
Individualization is not only important for academic tasks, but also for behavior modification. Students excel behaviorally when interventions are consistent (Engle, 2008) and opportunities are provided for students to self-monitor their behaviors (Green, 2007). Although numerous practices are available for professionals to implement, Bertrand (2009) found that these interventions could be more effective for individuals with FASD if they are personalized to the children's neurocognitive and behavioral characteristics. For example, since many individuals with FASD have difficulties with sensory processing, planning ongoing activities that allow them to integrate their senses can be beneficial in preventing sensory related challenging behaviors (Carpenter, 2011).

Structure. Routines and consistency cannot be overlooked when working with individuals with FASD. Researchers have documented the unpredictable nature of the population (Carpenter, 2011) and the challenges they face switching between concepts and expectations (Mattson et al., 2012). The difficulties experienced with changes in activities impact these individuals both academically and behaviorally, because they struggle adjusting to the new demands (Burd et al., 2003). Having clear structure, physical or visual boundaries, and set schedules can greatly aid children with FASD in navigating their environment and learning from it (Burd et al., 2003; Carpenter, 2011).

Transition. As adolescents transition into adulthood their need for support does not diminish (Fagerlund et al., 2006), yet the resources available to them may (Clark, Minnes, Lutke, \& Ouellette-Kuntz, 2008). Adults with FASD often struggle finding and keeping employment and housing, and remaining drug free (Edmunds \& Crichton, 2008; Grant et al., 2004). Adolescents may need a stronger emphasis on functional skills while in school and additional functional and vocational supports into adulthood (McGregor, 2009; Spohr \& Steinhausen, 2008). These findings are derived from exploratory qualitative studies; they highlight many challenges associated with adolescents and adults with FASD, but, with the exception of the community intervention pilot study (Grant et al., 2004), they do not offer interventions that could be effectively implemented with the population to improve their independence as an adult. Researching these practices is imperative to improve the quality of life for adults with FASD (McGregor, 2009) and to help prevent the cycle of prenatal alcohol exposure (Grant et al., 2004).

\section{PLANNING FOR SELF-DETERMINATION}

While certain aspects of self-determination can be targeted while children are young (e.g. choice making, safety, and reinforcement skills), these skills become increasingly more important as children reach adolescence and adulthood (McGregor, 2009). Although adults with FASD are at an increased risk 
to attempt suicide, having the responsibility to care for a child or to mentor others may diminish the likelihood of this irreversible action (McGregor, 2009). Improving self-determination can affect an individual's quality of life and lead to better life-long outcomes.

Independence. Individuals with FASD are likely to need assistance in their daily living. Whether targeting academic or functional skills, the individual's independence can be promoted if professionals provide the supports required and then fade the supports when they are no longer necessary. For older individuals, one method to assist them in feeling like adults is to allow them to make their own decisions (McGregor, 2009). Teaching individuals with FASD to problem solve and make their own choices and decisions can be helpful in promoting their independence and improving their quality of life.

Self-regulation. Individuals with FASD have diminished abilities to selfregulate their behaviors and self-calm in escalated situations (Carpenter, 2011). These challenges make it more likely that the population will "over-react" to their environment (Carpenter, 2011). Additionally, these individuals do not learn well from their mistakes and they often need multiple chances to re-try tasks they previously failed (McGregor, 2009). These individuals may also need more time to realize the value in rules and the importance of following them.

Self-realization and Psychological Empowerment. Adults with FASD have indicated that learning about their disability and how it impacts them has aided in understanding themselves and some of their challenges (e.g., increased vulnerability to additions) (McGregor, 2009). As children enter adulthood, they may choose not to volunteer that they have a disability with prospective employers or universities because of embarrassment or a strong will; they may attempt to independently cope with their struggles which could create problems in both of these environments and result in the lack of accommodations and supports necessary to be successful (McGregor, 2009). Developing a strong sense of self can help individuals with FASD be aware of their abilities and accept advice and assistance when needed.

Skill development can help promote a more positive sense of self. It is important to consider the abilities of individuals with FASD, because impairments do not exist in all areas (Jantzen et al., 1995). Intrapersonal strengths should be used to tailor instruction and adapt interventions so children with FASD can feel successful while improving in areas of weakness. One of the most important factors to help children with FASD understand is that they are capable of learning. Many individuals with FASD have prior school experiences that are negative (Duquette et al., 2006). Not only do educators face the challenge of teaching their students, but they also must help the students believe in themselves and be motivated learners; this can happen through continual successes in school. As professionals begin to shift their thinking about FASD, they are more likely to 
patiently instruct students instead of critically punishing them (Green, 2007). Table 1 provides a summary of specific development research for children with FASD and practices that have some research to support their efficacy.

\section{PLANNING FOR CAREGIVER INVOLVEMENT}

Early Years. Caregiver involvement needs to begin before pregnancy. Researchers have established numerous characteristics of mothers who are at the highest risk of birthing a child with FASD that can help guide the development of preventative programs (Cannon, Dominique, O'Leary, Sniezek, \& Floyd, 2012; May et al., 2009). A need exists for additional research exploring methods to improve the prevention of FASD and partnerships with community organizations so that education and resources can be disseminated to greater numbers of people and target the populations with the highest risk factors (Arendt $\&$ Farkas, 2007; Hanson, Winberg, \& Elliott, 2012). For example, since the majority of mothers who have a child with FASD are single or cohabitating, providing a support network could be especially helpful for meeting the unique needs of these mothers (Cannon et al., 2012).

School Age. Advocacy is the process of arguing in favor of something. Many individuals with FASD lack self-advocacy skills and rely on others to advocate for them (McGregor, 2009). Duquette and colleagues' (2006) found that caregiver advocacy is a protective factor increasing adolescent persistence to graduate from high school. Additionally, some successful interventions have involved parents and caregivers as facilitators for academic, social, and behavioral interventions (Bertrand, 2009). The majority of these programs have included caregiver workshops that teach parents about the effects of prenatal alcohol exposure and behavioral or cognitive strategies that could be useful when interacting with their child (Kabel et al., 2007). The use of parent facilitated strategies has helped parents act more responsively with their children (Lowe et al., 2006) and increased the children's learning over time (Bertrand, 2009).

Adulthood. Another factor adding to the importance of caregiver involvement is the dependence adults with FASD may have on their caregivers (McGregor, 2009). Seventy percent of adults with FASD live dependently and are unemployed (Spohr \& Steinhausen, 2008; Spohr, Willms, \& Steinhausen, 2007) with most being fired or resigning from numerous jobs (McGregor, 2009). If community integration is achieved, it is partially the result of emotional and financial support from friends and family (Clark et al., 2008). Providing these supports typically fall onto caregivers, who often take the responsibility of caring for their child longer than the societal norms of childrearing. In addition to these obligations, there is also added stress to families who try to plan for the care of their child in the event of their death (Clark et al., 2008). 
Table 1.

Methods to Support Children with FASD

\begin{tabular}{|c|c|c|}
\hline $\begin{array}{l}\text { Developmental } \\
\text { Area }\end{array}$ & $\begin{array}{l}\text { Developmental } \\
\text { Research }\end{array}$ & $\begin{array}{c}\text { Evidence-Based Practices } \\
\text { Research }\end{array}$ \\
\hline \multirow[t]{2}{*}{ Cognition } & $\begin{array}{l}\text { Children with FASD are more } \\
\text { likely to have cognitive impair- } \\
\text { ments than children who are typi- } \\
\text { cally developing. }\end{array}$ & \\
\hline & $\begin{array}{l}\text { Executive functioning and working } \\
\text { memory are central deficits. }\end{array}$ & $\begin{array}{l}\text { - Neurocognitive habili- } \\
\text { tation program }\end{array}$ \\
\hline $\begin{array}{l}\text { Intelligence } \\
\text { Comparison }\end{array}$ & $\begin{array}{l}\text { Children's performance in reading, } \\
\text { spelling, and communication are } \\
\text { comparable to levels expected for } \\
\text { their intelligence. }\end{array}$ & \\
\hline Pacing & $\begin{array}{l}\text { Development and learning occurs } \\
\text { in typical patterns for children with } \\
\text { FASD, compared to those who are } \\
\text { typically developing, but the rate of } \\
\text { learning is typically slower. }\end{array}$ & $\begin{array}{l}\text { - Teach and re-teach } \\
\text { content in smaller } \\
\text { amounts and at a } \\
\text { slower pace }\end{array}$ \\
\hline Acquisition & $\begin{array}{l}\text { When presented with the same } \\
\text { amount of information, children } \\
\text { with FASD usually acquire less } \\
\text { information than children who are } \\
\text { typically developing. }\end{array}$ & $\begin{array}{l}\text { - Semantic clustering } \\
\text { - Hands-on learning } \\
\text { - Teacher modeling } \\
\text { - Concrete examples }\end{array}$ \\
\hline $\begin{array}{l}\text { Retention } \\
\text { Generalization }\end{array}$ & $\begin{array}{l}\text { Retention and generalization of } \\
\text { information can be problematic. }\end{array}$ & - Rehearsal training \\
\hline Mathematics & $\begin{array}{l}\text { Mathematics is a limitation, even } \\
\text { when controlling for intelligence. }\end{array}$ & $\begin{array}{l}\text { - Neurocognitive habili- } \\
\text { tation program } \\
\text { - Socio-cognitive habili- } \\
\text { tation program } \\
\text { - Modified mathematics } \\
\text { curricula }\end{array}$ \\
\hline \multirow[t]{2}{*}{ Functional Skills } & $\begin{array}{l}\text { Adaptive skills are problematic and } \\
\text { parents sometimes fear for their } \\
\text { children's safety. }\end{array}$ & $\begin{array}{l}\text { - Virtual reality programs } \\
\text { - In vivo instruction }\end{array}$ \\
\hline & $\begin{array}{l}\text { Adolescents and adults need sup- } \\
\text { port with vocational skills, finding, } \\
\text { and keeping a job. }\end{array}$ & $\begin{array}{l}\text { - Vocational programs } \\
\text { - Post-secondary training } \\
\text { - Community outreach } \\
\text { programs }\end{array}$ \\
\hline
\end{tabular}


Table 1. (Continued)

\begin{tabular}{|c|c|c|}
\hline $\begin{array}{l}\text { Developmental } \\
\text { Area }\end{array}$ & $\begin{array}{l}\text { Developmental } \\
\text { Research }\end{array}$ & $\begin{array}{c}\text { Evidence-Based Practices } \\
\text { Research }\end{array}$ \\
\hline Social Emotional & $\begin{array}{l}\text { Deficits exist in social skills and } \\
\text { individuals usually have both inter- } \\
\text { nalizing, externalizing behavioral } \\
\text { challenges. }\end{array}$ & $\begin{array}{l}\text { - Social-behavioral } \\
\text { therapy } \\
\text { - Socio-cognitive habili- } \\
\text { tation program } \\
\text { - Self-monitoring } \\
\text { - Reinforcement } \\
\text { learning } \\
\text { - Consistency in } \\
\text { outcomes }\end{array}$ \\
\hline Hyperactivity & $\begin{array}{l}\text { Many children are hyperactive } \\
\text { and/or impulsive in their behaviors. }\end{array}$ & $\begin{array}{l}\text { - Social-behavioral } \\
\text { therapy } \\
\text { - Self-monitoring }\end{array}$ \\
\hline Attention & $\begin{array}{l}\text { Shifting attention and changes in } \\
\text { the routine are cumbersome. }\end{array}$ & $\begin{array}{l}\text { - Attention processing } \\
\text { training }\end{array}$ \\
\hline Friendships & $\begin{array}{l}\text { Individuals struggle forming } \\
\text { friendships and deeper relation- } \\
\text { ships. }\end{array}$ & $\begin{array}{l}\text { - Peer and caregiver } \\
\text { implemented social } \\
\text { skills training programs }\end{array}$ \\
\hline
\end{tabular}

Note: $\mathrm{FASD}=$ Fetal alcohol spectrum disorder; PAE $=$ Prenatal alcohol exposure

\section{DISCUSSION}

Effective practices to prevent FASD and intervene with the associated challenges are going to take the combined effort of policymakers, researchers, and communities (Kyskan \& Moore, 2005). The impact of these efforts could be screening and diagnostic procedures that identify more children with FASD earlier in life. This identification and intervention can assist children and families in a time of critical development for the child and promote healthy home environments and caregiving. These factors could substantially minimize later challenges and economic burdens for families and communities.

Now that a substantial data base has been acquired on the developmental characteristics of children with FASD, interventions need to be studied to determine the best methods to meet the needs of these individuals. It is imperative that this research covers the entire lifespan of the individual to ameliorate challenges at various stages of life, substantially improve the education for individuals with FASD, and improve the quality of life for them and their families. 


\section{Appendix}

Summary of Instructional Studies for Individuals with FASDs

\begin{tabular}{|c|c|c|c|}
\hline $\begin{array}{l}\text { Research Design } \\
\text { Bertrand (2009) }\end{array}$ & $\begin{array}{l}\text { Participant } \\
\text { Description }\end{array}$ & Research Focus & Results \\
\hline $\begin{array}{l}5 \text { randomized con- } \\
\text { trolled studies; } \\
\text { pre-post testing }\end{array}$ & $\begin{array}{l}\text { All had FASD } \\
\text { 1. } 100 \text { children } \\
\text { 6-12 years-old } \\
\text { Avg. IQ }-97 \\
\text { 2. } 61 \text { children } \\
\text { 3-10 years-old } \\
\text { Avg. IQ }-81 \\
\text { 3. } 78 \text { children } \\
\text { 6-11 years-old } \\
\text { Avg. IQ }-90 \\
\text { 4. } 58 \text { children } \\
\text { 3-7 years-old } \\
\text { Avg. IQ }-88 \\
\text { 5. 52 children } \\
\text { 5-11 years-old } \\
\text { Avg. IQ }-94\end{array}$ & $\begin{array}{l}\text { All projects included } \\
\text { pre/post testing } \\
\text { 1. Children's friend- } \\
\text { ship training; } \\
12 \text { weekly sessions } \\
\text { lasting } 90 \text { min.; } \\
3 \text { mo. follow-up } \\
\text { 2. Socio-cognitive } \\
\text { habilitation pro- } \\
\text { gram; } 2 \text { caregiver } \\
\text { workshops; } \\
6 \text { weeks of tutor- } \\
\text { ing using a modi- } \\
\text { fied math } \\
\text { curriculum } \\
\text { 3. Neuro-cognitive } \\
\text { habilitation, tar- } \\
\text { geting behavior } \\
\text { regulation; } \\
12 \text { weekly sessions } \\
\text { lasting } 75 \text { min. } \\
\text { 4. Comparison of } \\
\text { parent-child inter- } \\
\text { action and parent- } \\
\text { only therapy; } \\
14 \text { weekly sessions } \\
\text { lasting } 90 \text { min. } \\
\text { 5. Comparison of } \\
\text { Families Moving } \\
\text { Forward and stan- } \\
\text { dard community } \\
\text { care; } 9-11 \text { mo. } \\
\text { of training every } \\
\text { other week lasting } \\
90 \text { min. }\end{array}$ & $\begin{array}{l}\text { 1. Children in the } \\
\text { intervention group } \\
\text { significantly } \\
\text { improved in their } \\
\text { knowledge of social } \\
\text { behaviors and } \\
\text { actual social skills } \\
\text { \& decreased in } \\
\text { their problem } \\
\text { behaviors } \\
\text { 2. Caregivers were sat- } \\
\text { isfied with the pro- } \\
\text { gram and improved } \\
\text { in their knowledge } \\
\text { Children made } \\
\text { significant gains in } \\
\text { their math } \\
\text { knowledge } \\
\text { 3. Children made sig- } \\
\text { nificant improve- } \\
\text { ments in their } \\
\text { executive function- } \\
\text { ing, problem solv- } \\
\text { ing, \& behavior } \\
\text { regulation } \\
\text { 4. Children in both } \\
\text { groups improved } \\
\text { in their behaviors } \\
\text { Both groups of } \\
\text { caregivers found } \\
\text { their program } \\
\text { favorable } \\
\text { 5. Family needs were } \\
\text { better met and } \\
\text { children's behav- } \\
\text { iors significantly } \\
\text { improved in the } \\
\text { intervention group }\end{array}$ \\
\hline
\end{tabular}


Appendix. (Continued)

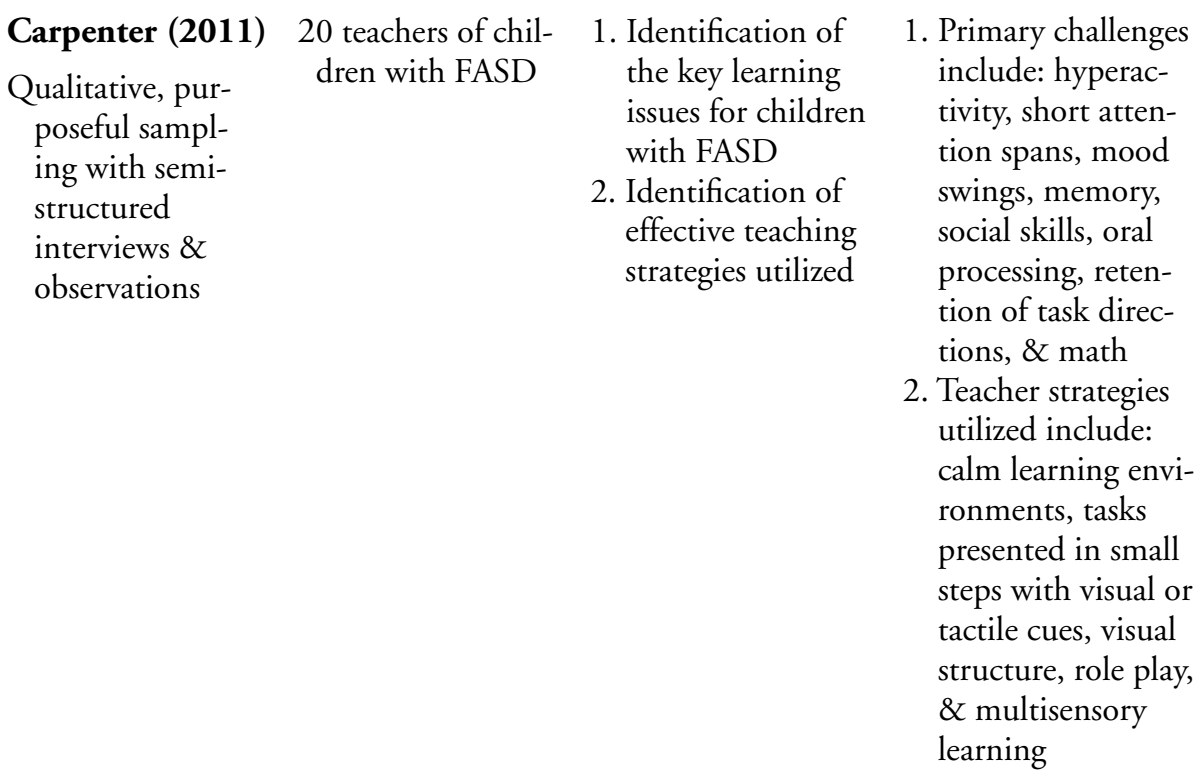

$\begin{array}{ll}\text { Coles, Kable, \& } & 54 \text { children } \\ \text { Taddeo (2009) } & \text { 3-10 years-old } \\ \text { Randomized } & \text { All had FASD } \\ \text { controlled study; } & \text { IQs }>50 \\ \text { pre-post testing } & \end{array}$

Duquette, Stodel, 8 adolescents with Fullarton, \& FASDs and their Hagglund (2006) adoptive parents Qualitative, case 15-20 years-old study

$\begin{array}{ll}\text { Edmunds \& } & 5 \text { adolescents } \\ \text { Crichton (2008) } & \text { 16-20 years-old } \\ \text { Qualitative, ethnog- } & \text { All had FASD } \\ \text { raphy } & \end{array}$
Parents' workshops
6 weeks of math intervention using a modified math curriculum
6 mo. later, post- test 2

Student Integration Model used to explore student dropout and persistence to graduate

The impact of a customized program on the learning, confidence, awareness, \& employment of individuals with FASD
At post-test 2, there were significantly greater scores on math performance and improvements in behaviors

Parental advocacy may be a protective factor for school dropout

Behavioral and learning challenges in school

None completed high school

All had been homeless

Individualized education with counseling and life support was effective 


\begin{tabular}{|c|c|c|c|}
\hline $\begin{array}{l}\text { Engle (2008) } \\
\text { Quasi-experimental } \\
\text { age \& sex matched }\end{array}$ & $\begin{array}{l}38 \text { children } \\
11-17 \text { years-old } \\
19 \text { FASD } \\
\text { Avg. IQ }-85 \\
19 \text { non-FASD } \\
\text { Avg. IQ }-107\end{array}$ & $\begin{array}{l}\text { Computerized task } \\
\text { with two stimuli of } \\
\text { differing reinforcing } \\
\text { values presented in } \\
120 \text { trials }\end{array}$ & $\begin{array}{l}\text { Both groups } \\
\text { improved } \\
\text { throughout the } \\
\text { task } \\
\text { Non-FASD group } \\
\text { learned reinforc- } \\
\text { ing concept faster }\end{array}$ \\
\hline $\begin{array}{l}\text { Grant, Huggins, } \\
\text { Connor, } \\
\text { Pedersen, } \\
\text { Whitney, \& } \\
\text { Streissguth, } \\
\text { (2004) } \\
\text { Qualitative, pilot } \\
\text { study }\end{array}$ & $\begin{array}{l}19 \text { women } \\
14-36 \text { years-old } \\
\text { FASD (11) Suspected } \\
\text { FASD (8) }\end{array}$ & $\begin{array}{l}12 \text { mo. community } \\
\text { intervention } \\
\text { Providers and advo- } \\
\text { cates trained on } \\
\text { FASD } \\
\text { Trained individuals } \\
\text { provided services } \\
\text { for the participants } \\
\text { in identified areas } \\
\text { of need }\end{array}$ & $\begin{array}{l}\text { Of the women } \\
\text { needing interven- } \\
\text { tions: } \\
5 \text { of } 8 \text { secured } \\
\text { housing } \\
11 \text { of } 16 \text { became } \\
\text { sober from } \\
\text { drugs/alcohol } \\
6 \text { of } 11 \text { began using } \\
\text { contraceptives }\end{array}$ \\
\hline $\begin{array}{l}\text { Kable, Coles, \& } \\
\text { Taddeo (2007) } \\
\text { Randomized con- } \\
\text { trolled study, pre- } \\
\text { post testing }\end{array}$ & $\begin{array}{l}61 \text { children } \\
3-10 \text { years-old } \\
\text { All had FAS }\end{array}$ & $\begin{array}{l}\text { Socio-cognitive } \\
\text { habilitative program } \\
\text { to improve } \\
\text { behavior and math } \\
\text { functioning } \\
\text { Caregivers' training } \\
\text { workshop } \\
6 \text { weeks of tutoring } \\
\text { services for both } \\
\text { children \& care- } \\
\text { givers in interven- } \\
\text { tion group } \\
\text { Posttest after 4-weeks }\end{array}$ & $\begin{array}{l}\text { Significant knowl- } \\
\text { edge gains in care- } \\
\text { givers } \\
\text { Significant reduc- } \\
\text { tion in problem } \\
\text { behaviors } \\
\text { Math gains in both } \\
\text { groups, but sig- } \\
\text { nificantly higher } \\
\text { gains in interven- } \\
\text { tion group }\end{array}$ \\
\hline $\begin{array}{l}\text { Keil, Paley, } \\
\text { Frankel, \& } \\
\text { O’Connor } \\
\text { (2010) } \\
\text { Randomized } \\
\text { control study }\end{array}$ & $\begin{array}{l}100 \text { children } \\
6-12 \text { years-old } \\
\text { FAS }(11) \text { pFAS } \\
(43) \text { ARND (46) } \\
\text { Verbal IQ > } 70\end{array}$ & $\begin{array}{l}\text { Group 1: CFT } \\
\text { Group 2: Delayed } \\
\text { treatment of CFT } \\
12 \text { weekly sessions } \\
\text { lasting } 90 \text { min. } \\
\text { Pre/Post testing }\end{array}$ & $\begin{array}{l}\text { The CFT group } \\
\text { had significant } \\
\text { decreases in } \\
\text { hostility for peer } \\
\text { group entry, but } \\
\text { not for peer } \\
\text { provocations }\end{array}$ \\
\hline $\begin{array}{l}\text { Kerns, Macsween, } \\
\text { vander Wekken, } \\
\text { \& Gruppuso } \\
(\mathbf{2 0 1 0 )}\end{array}$ & $\begin{array}{l}10 \text { children } \\
8-15 \text { years-old } \\
\text { All had FASD Avg. } \\
\text { IQ }-91\end{array}$ & $\begin{array}{l}\text { Computerized } \\
\text { Progressive } \\
\text { Attention Training } \\
\text { program }\end{array}$ & $\begin{array}{l}\text { Children signifi- } \\
\text { cantly improved } \\
\text { on measures of } \\
\text { sustained and } \\
\text { divided attention }\end{array}$ \\
\hline
\end{tabular}


Appendix. (Continued)

Quasi-experimental,
pre-post testing
(no control
group)

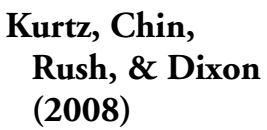

Single-case design: ABCAC \& Multielement designs

\section{2 children}

10-22 months

1 with prenatal alcohol, cocaine, $\&$ heroine exposure; 1 with prenatal heroine exposure

\section{4-11 years-old}

Manji, \&

Andrew (2008)
Randomized controlled trial, Pre-post testing

\section{McGregor (2009)}

Qualitative, Grounded Theory

\author{
16 hours of one-on- \\ one training \\ 3 types of attention
}

Functional assessments determined environmental factors maintaining challenging behaviors

Children were taught to request a preferred item or noncontingently reinforced with ignoring or time-out
Rehearsal training provided for the intervention group Post-test 2 about 10 days after post-test 1
Children significantly improved on meas- ures of distractibility
Children's math and reading fluency improved

Functional assessments effectively determined the reasons for challenging behaviors Instruction on requesting an item decreased challenging behaviors in 2 of 3 conditions

Non-contingent reinforcement with time-out decreased challenging behaviors

The intervention group showed significant improvement in memory performance, especially at post-test 2

No differences observed in the control group

In-depth interviews on the challenges

Self-awareness can aid living with FASD in accepting the supports and accommodations necessary for success

All adults had multiple experiences being fired or resigning from jobs Often others are needed to advocate for their needs 


\begin{tabular}{|c|c|c|c|}
\hline $\begin{array}{l}\text { O'Connor et al. } \\
\text { (2006a) }\end{array}$ & $\begin{array}{l}100 \text { children } \\
6-12 \text { years-old } \\
\text { FAS }(11) \text { pFAS }(43) \\
\text { ARND }(46) \\
\text { Verbal IQ }>70\end{array}$ & $\begin{array}{l}\text { Group 1: CFT } \\
\text { Group 2: Delayed } \\
\text { treatment of CFT } \\
12 \text { weekly sessions } \\
\text { lasting } 90 \text { min. } \\
\text { Pre/Post testing } \\
3 \text { mo. follow-up }\end{array}$ & $\begin{array}{l}\text { Improved knowledge } \\
\text { of appropriate social } \\
\text { behaviors } \\
\text { Improved social skills } \\
\text { Fewer Problem } \\
\text { behaviors } \\
\text { Outcomes main- } \\
\text { tained at } 3 \text { month } \\
\text { follow-up }\end{array}$ \\
\hline $\begin{array}{l}\text { O'Connor et al. } \\
\text { (2012) } \\
\text { Quasi-experimental } \\
\text { gender, ethnicity, } \\
\text { \& PAE matched }\end{array}$ & $\begin{array}{l}85 \text { children } \\
6-12 \text { years-old } \\
\text { With }(32) \text { and w/o } \\
\text { FASD }(53) \\
\text { Composite IQ > } 70\end{array}$ & $\begin{array}{l}\text { Group 1: CFT } \\
\text { Group 2: } \\
\text { Community stan- } \\
\text { dard of care } \\
12 \text { weekly sessions } \\
\text { lasting } 90 \text { min. } \\
\text { Pre/Post testing }\end{array}$ & $\begin{array}{l}\text { Children in the CFT } \\
\text { group made signifi- } \\
\text { cant improvements } \\
\text { in: knowledge of } \\
\text { social skills, self- } \\
\text { concept, and } \\
\text { parent-report of } \\
\text { social skills } \\
\text { CFT was equally } \\
\text { effective for chil- } \\
\text { dren with \& with- } \\
\text { out PAE }\end{array}$ \\
\hline $\begin{array}{l}\text { Padgett, } \\
\text { Strickland, \& } \\
\text { Coles (2006) }\end{array}$ & $\begin{array}{l}5 \text { children } \\
5-7 \text { years-old } \\
\text { FAS (3) pFAS (2) }\end{array}$ & $\begin{array}{l}\text { Virtual reality com- } \\
\text { puter game (fire } \\
\text { safety) }\end{array}$ & $\begin{array}{l}\text { All } 5 \text { mastered the } \\
\text { computer program } \\
4 \text { generalized all } 3\end{array}$ \\
\hline $\begin{array}{l}\text { Multiple-baseline; } \\
\text { multiple-probe; } \\
\text { pre-post testing }\end{array}$ & Varying IQs > 50 & $\begin{array}{l}3 \text { levels of instruction } \\
\text { with faded supports } \\
\text { and embedded } \\
\text { reinforcement }\end{array}$ & $\begin{array}{l}\text { steps } \\
3 \text { maintained the } \\
\text { skills after } 1 \text { week }\end{array}$ \\
\hline $\begin{array}{l}\text { Roebuck-Spencer } \\
\text { \& Mattson } \\
\text { (2004) } \\
\text { Quasi-experimental } \\
\text { age matched }\end{array}$ & $\begin{array}{l}69 \text { children } \\
\text { 9-16 years-old } \\
\text { FASD (35) \& } \\
\text { non FASD }(34) \\
\text { Avg. IQ }-78 \\
\text { (FASD) - } 105 \\
\text { (non FASD) }\end{array}$ & $\begin{array}{l}\text { Between and within } \\
\text { group comparisons } \\
\text { of children's verbal } \\
\text { learning with and } \\
\text { without the implicit } \\
\text { strategy of semantic } \\
\text { mapping }\end{array}$ & $\begin{array}{l}\text { Children with FASD } \\
\text { learned less infor- } \\
\text { mation, but } \\
\text { retained about the } \\
\text { same information } \\
\text { as children without } \\
\text { FASD } \\
\text { Children with FASD } \\
\text { did not differ from } \\
\text { children without } \\
\text { FASD on learning } \\
\text { and memory using } \\
\text { semantic clustering }\end{array}$ \\
\hline
\end{tabular}


Appendix. (Continued)

\begin{tabular}{|c|c|c|c|}
\hline $\begin{array}{l}\text { Ryan \& Ferguson } \\
\text { (2006) } \\
\text { Qualitative, } \\
\text { 3-year study; con- } \\
\text { textual compari- } \\
\text { son analysis }\end{array}$ & $\begin{array}{l}5 \text { Alaskan students, } \\
\text { their families, \& } \\
\text { professionals } \\
\text { 3-19 years-old } \\
\text { FAS (1) } \\
\text { Alcohol exposed (4) }\end{array}$ & $\begin{array}{l}\text { An evaluation of the } \\
\text { diagnostic team } \\
\text { process of identify- } \\
\text { ing individuals with } \\
\text { FASD \& meeting } \\
\text { student and family } \\
\text { needs }\end{array}$ & $\begin{array}{l}\text { Understanding the } \\
\text { effects of prenatal } \\
\text { alcohol exposure \& } \\
\text { functional abilities } \\
\text { are vital } \\
\text { Experienced teachers } \\
\text { use various methods } \\
\text { to educate students, } \\
\text { but novice teachers } \\
\text { do not differentiate } \\
\text { instruction } \\
\text { Families are frustrated } \\
\text { with the lack of sup- } \\
\text { ports \& services } \\
\text { Families are over- } \\
\text { whelmed with chal- } \\
\text { lenging behaviors }\end{array}$ \\
\hline $\begin{array}{l}\text { Timler, Olswang, } \\
\text { \& Coggins } \\
\text { (2005) } \\
\text { Single case design; } \\
\text { multiple-probe; } \\
\text { pre-post testing }\end{array}$ & $\begin{array}{l}1 \text { child with FASD } \\
9 \text { years-old } \\
2 \text { peers with FASD }\end{array}$ & $\begin{array}{l}\text { Social communication } \\
\text { intervention with } \\
\text { group role play \& } \\
\text { checklist questions } \\
\text { Two one-hour weekly } \\
\text { sessions for the } \\
\text { target child } \\
\text { Three two-hour } \\
\text { weekly sessions for } \\
\text { the group }\end{array}$ & $\begin{array}{l}\text { The specific child } \\
\text { produced more } \\
\text { mental state verbs } \\
\text { and provided alter- } \\
\text { native strategies to } \\
\text { social situations. }\end{array}$ \\
\hline $\begin{array}{l}\text { Vernescu (2007) } \\
\text { Randomized con- } \\
\text { trolled study; pre- } \\
\text { post testing }\end{array}$ & $\begin{array}{l}20 \text { children } \\
6-12 \text { years-old } \\
\text { All had FASD }\end{array}$ & $\begin{array}{l}\text { Attention process } \\
\text { training } \\
12 \text { daily } 30 \text { min. } \\
\text { training sessions } \\
\text { After } 3 \text { weeks, post- } \\
\text { test }\end{array}$ & $\begin{array}{l}\text { Significant improve- } \\
\text { ment on sustained } \\
\text { attention \& non- } \\
\text { verbal reasoning, } \\
\text { but not on executive } \\
\text { functioning for chil- } \\
\text { dren in the interven- } \\
\text { tion group }\end{array}$ \\
\hline $\begin{array}{l}\text { Wells, Chasnoff, } \\
\text { Schmidt, } \\
\text { Telford, \& } \\
\text { Schwartz } \\
\text { (2012) } \\
\text { Randomized } \\
\text { controlled study }\end{array}$ & $\begin{array}{l}78 \text { children } \\
6-11 \text { years-old } \\
\text { FAS or ARND } \\
\text { IQs } 45-138\end{array}$ & $\begin{array}{l}\text { The neurocognitive } \\
\text { habilitation cur- } \\
\text { riculum ( } 12 \text { weeks) } \\
\text { Group activity with } \\
\text { core concepts \& } \\
\text { review to promote } \\
\text { memory consolida- } \\
\text { tion }\end{array}$ & $\begin{array}{l}\text { Significant differences } \\
\text { in executive func- } \\
\text { tioning skills and } \\
\text { emotional problem- } \\
\text { solving scores } \\
\text { between treatment } \\
\text { and control group }\end{array}$ \\
\hline
\end{tabular}

Note: FASD = Fetal alcohol spectrum disorder; FAS = Fetal alcohol syndrome; ARND = Alcohol related neurodevelopmental disorder; CFT $=$ Children's Friendship Training 


\section{REFERENCES}

References marked with an asterisk indicate intervention studies that were examined for this research review.

Amendah, D. D., Grosse, S. D., \& Bertrand, J. (2011). Medical expenditures of children in the United States with fetal alcohol syndrome. Neurotoxicity and Teratology, 33, 322-324. doi: 10.1016/j.ntt. 2010.10.008

Aragon, A. S., Coriale, G., Fiorentino, D., Kalberg, W. O., Buckley, D., Gossage, J. P., Ceccanti, M., Mitchell, E. R., \& May, P. A. (2008a). Neuropsychological characteristics of Italian children with fetal alcohol spectrum disorders. Alcoholism: Clinical and Experimental Research, 32, 1909-1919. doi: 10.1111/j.1530-0277.2008.00775.x

Aragon, A. S., Kalberg, W. O., Buckley, D., Barela-Scott, L. M., Tabachnick, B. G., \& May, P. A. (2008b). Neuropsychological study of FASD in a sample of American Indian children: Processing simple versus complex information. Alcoholism: Clinical and Experimental Research, 32, 2136-2148. doi: 10.1111/j.1530-0277.2008.00802.x

Arendt, R. E. \& Farkas, K. J. (2007). Maternal alcohol abuse and fetal alcohol spectrum disorder: A life-span perspective. Alcoholism Treatment Quarterly, 25, 3-20. doi: 10.1300/J020v25n03_02

Bailey, B. N., Delaney-Black, V., Covington, C. Y., Ager, J., Janisse, J., Hannigan, J. H., \& Sokel, R. J. (2004). Prenatal exposure to binge drinking and cognitive and behavioral outcomes at age 7 years. American Journal of Obstetrics and Gynecology, 191, 1037-1043.

Bailey, D. B., Golden, R. N., Roberts, J., \& Ford, A. (2007). Maternal depression and developmental disability: Research critique. Mental Retardation and Developmental Disabilities Research Reviews, 13, 321-329. doi: $10.1002 /$ mrdd. 20172

Bart, O., Agam, T., Weiss, P. L., \& Kizony, R. (2011). Using video-capture virtual reality for children with acquired brain injury. Disability and Rehabilitation, 33, 1579-1586. doi: 10.3109/09638288. 2010.540291

Belcher, H. M. E., Butz, A. M., Wallace, P., Hoon, A., Reinhardt, E., Reeves, S. A., \& Pulsifer, M. B. (2005). Spectrum of early intervention services for children with intrauterine drug exposure. Infants \& Young Children, 18, 2-15.

* Bertrand, J. (2009). Interventions for children with fetal alcohol spectrum disorders (FASD): Overview of findings for five innovative research projects. Research in Developmental Disabilities, 30, 986-1006. doi: 10.1016/j.ridd.2009.02.003 
Bishop, S., Gahagan, S., \& Lord, C. (2007). Re-examining the core features of autism: a comparison of autism spectrum disorder and fetal alcohol spectrum disorder. Journal of Child Psychology and Psychiatry, 48, 1111-1121. doi: 10.1111/j.1469-7610.2007.01782.x

Blackburn, C. \& Whitehurst, T. (2010). Feotal alcohol spectrum disorders (FASD): raising awareness in early years settings, British Journal of Special Education, 37, 122-129. doi: 10.1111/j.1467-8578.2010.00471.x

Brown, C. W., Olson, H. C., \& Croninger, R. G. (2010). Alcohol consumption during pregnancy and infant social, mental, and motor development. Journal of Early Intervention, 32, 110-126. doi: 10.1177/ 1053815110366654

Burd, L. J. (2006). Interventions in FASD: We must do better. Child: Care, Health and Development, 33, 398-400. doi: 10.1111/j.1365-2214. 2006.00696.x

Burd, L., Cotsonas-Hassler, T. M., Martsolf, J. T., \& Kerbeshian, J. (2003). Recognition and management of fetal alcohol syndrome. Neurotoxicology and Teratology, 25, 681-688. doi: 10.1016/ j.ntt.2003.07.020

Burd, L., Klug, M. G., Li, Q., Kerbeshian, J., \& Martsolf, J. T. (2010). Diagnosis of fetal alcohol spectrum disorders: A validity study of the fetal alcohol syndrome checklist. Alcohol, 44, 605-614. doi: 10.1016/ j.alcohol.2009.08.010

Burden, M. J., Andrew, C., Saint-Amour, D., Meintjes, E. M., Molteno, C. D., Hoyme, H. E., ... Jacobson, S. W. (2009). The effects of fetal alcohol syndrome on response execution and inhibition: An event-related potential study. Alcoholism: Clinical and Experimental Research, 33, 1994-2004. doi: 10.1111/j.1530-0277.2009.01038.x

Burgess, D. M. \& Streissguth, A. P. (1992). Fetal alcohol syndrome and fetal alcohol effects: Principles for educators. Phi Delta Kappan, 74, 24-26, 28,30 .

Caley, L. M., Kramer, C., \& Robinson, L. K. (2005). Fetal alcohol spectrum disorder. The Journal of School Nursing, 21, 139-146.

Cannon, M. J., Dominique, Y., O’Leary, L. A., Sniezek, J. E., \& Floyd, R. L. (2012). Characteristics and behaviors of mothers who have a child with fetal alcohol syndrome. Neurotoxicity and Teratology, 34, 90-95. doi: 10.1016/j.ntt.2011.09.010

Caprara, D. L., Nash, K., Greenbaum, R., Rovet, J., \& Koren, G. (2007). Novel approaches to the diagnosis of fetal alcohol spectrum disorder. Neuroscience and Biobehavioral Reviews, 31, 254-260. doi: 10.1016/j.neubiorev.2006.06.015 
* Carpenter, B. (2011). Pedagogically bereft! Improving learning outcomes for children with foetal alcohol spectrum disorders. British Journal of Special Education, 38, 37-43.

Carr, J. L., Agnihotri, S., \& Keightley, M. (2010). Sensory processing and adaptive behavior deficits of children across the fetal alcohol spectrum disorder continuum. Alcoholism: Clinical and Experimental Research, 34(6), 1022-1032. doi: 10.1111/j.1530-0277.2010.01177.x

Centers for Disease Control and Prevention. (October 6, 2010a). Fetal alcohol spectrum disorders: Alcohol use in pregnancy. Retrieved from http://www.cdc.gov/ncbddd/fasd/alcohol-use.html

Centers for Disease Control and Prevention. (October 6, 2010b). Fetal alcohol spectrum disorders: Diagnosis. Retrieved from http://www.cdc.gov/ ncbddd/fasd/diagnosis.html

Centers for Disease Control and Prevention. (September 22, 2011). Fetal alcohol spectrum disorders: Facts about FASD. Retrieved from http://www. cdc.gov/ncbddd/fasd/facts.html

Center for Disabilities. (2008). Fetal alcohol spectrum disorders: Handbook. Sioux Falls, South Dakota: Sanford School of Medicine of the University of South Dakota. Retrieved from http://www.usd.edu/ medical-school/center-for-disabilities/upload/fasdhandbook.pdf

Chang, G. (2004). Screening and brief intervention in prenatal care settings. Alcohol Research and Health, 28, 80-84.

Clark, E., Minnes, P., Lutke, J., \& Ouellette-Kuntz, H. (2008). Caregiver perceptions of the community integration of adults with feotal alcohol spectrum disorder in British Columbia. Journal of Applied Research in Intellectual Disabilities, 21, 446-456. doi: 10.1111/j.1468-3148. 2007.00414.x

Coggins, T. E., Timler, G. R., \& Olswang, L. B. (2007). A state of double jeopardy: Impact of prenatal alcohol exposure and adverse environments on the social communicative abilities of school-age children with fetal alcohol spectrum disorder. Language Speech and Hearing Services in Schools, 38, 117-127.

Coles, C. D. \& Black, M. M. (2006). Introduction to the special issue: Impact of prenatal substance exposure on children's health, development, school performance, and risk behavior. Journal of Pediatric Psychology, 31, 1-4. doi: 10.1093/jpepsy/jsj036

* Coles, C. D., Kable, J. A., \& Taddeo, E. (2009). Math performance and behavior problems in children affected by prenatal alcohol exposure: Intervention and follow-up. Journal of Developmental and Behavioral Pediatrics, 30(1), 7-15. 
Coles, C. D., Platzman, K. A. Raskind-Hood, C. L., Brown, R. T., Falek, A., \& Smith, I. E. (1997). A comparison of children affected by prenatal alcohol exposure and attention deficit, hyperactivity disorder. Alcoholism: Clinical and Experimental Research, 21, 150-161. doi: 10.1111/j.1530-0277.1997.tb03743.x

Coles, C. D., Strickland, D. C., Padgett, L., \& Bellmoff, L. (2007). Games that "work": Using computer games to teach alcohol-affected children about fire and street safety. Research in Developmental Disabilities, 28, 518-530. doi: 10.1016/j.ridd.2006.07.001

Crocker, N., Vaurio, L., Riley, E. P., \& Mattson, S. N. (2011). Comparison of verbal learning and memory in children with heavy prenatal alcohol exposure or attention-deficit/hyperactivity disorder. Alcoholism: Clinical and Experimental Research, 35, 1114-1121. doi: 10.1111/j.1530-0277.2011.01444.x

Davis, K. M., Gagnier, K. R., Moore, T. E., \& Todorow, M. (2013). Cognitive aspects of fetal alcohol spectrum disorder. Wiley Interdisciplinary Reviews: Cognitive Science, 4(1), 81-92. doi: 10.1002/ wcs. 1202

Day, N. L., Helsel, A., Sonon, K., \& Goldschmidt, L. (2013). The association between prenatal alcohol exposure and behavior at 22 years of age. Alcoholism: Clinical and Experimental Research, 37, 1-8. doi: 10.1111/ acer. 12073

Dixon, D. R., Kurtz, P. F., \& Chin, M. D. (2008). A systematic review of challenging behaviors in children exposed prenatally to substances of abuse. Research in Developmental Disabilities, 29, 483-502. doi: 10.1016/j.ridd.2007.05.006

Drotar, D., Aylward, G., \& Beebe, D. (2012). Introduction to the special section: Psychological outcomes of pediatric conditions that affect the central nervous system. Journal of Pediatric Psychology, 37, 707-712. doi: $10.1093 /$ jpepsy/jsso79

Dumaret, A. C., Cousin, M., \& Titran, M. (2010). Two generations of maternal alcohol abuse: Impact on cognitive levels in mothers and their children. Early Child Development and Care, 180, 1311-1321. doi: 10.1080/03004430903040417

* Duquette, C., Stodel, E., Fullarton, S., \& Hagglund, K. (2006). Persistence in high school: Experiences with adolescents and young adults with fetal alcohol spectrum disorder. Journal of Intellectual and Developmental Disability, 31, 219-231. doi: 10.1080/13668250601031930

* Edmunds, K. \& Crichton, S. (2008). Finding ways to teach to students with FASD: A research study. International Journal of Special Education, 23, $54-73$. 
* Engle, J. A. (2008). Reinforcement learning in children and adolescents with fetal alcohol spectrum disorder (FASD) (Doctoral dissertation). Available from ProQuest Dissertations and Theses database.

Ens, C. D., Hanlon-Dearman, A., Millar, M. C., \& Longstaffe, S. (2010). Using Telehealth for assessment of fetal alcohol spectrum disorder: The experience of two Canadian rural and remote communities. Telemedicine and e-Health, 16, 872-877. doi: 10.1089/tmj. 2010.0070

Fagerlund, A., Heikkinen, S., Autti-Ramo, I., Korkman, M., Timonen, M., Kuusi, T., ... Lundbom, N. (2006). Brain metabolic alterations in adolescents and young adults with fetal alcohol spectrum disorders. Alcoholism: Clinical and Experimental Research, 30, 2097-2104. doi: 10.1111/j.1530-0277.2006.00257.x

Fryer, S. L., McGee, C. L., Matt, G. E., Riley, E. P., \& Mattson, S. N. (2007) Evaluation of psychopathological conditions in children with heavy prenatal alcohol exposure. Pediatrics, 119, 733-741.

Goodlett, C. R. (2010). Fetal alcohol spectrum disorders: New perspectives on diagnosis and intervention. Alcohol, 44, 579-582. doi: 10.1016/j.alcohol.2010.10.001

Graham, D. M., Crocker, N., Deweese, B. N., Roesch, S. C., Coles, C. D., Kable, J. A., ... Mattson, S. N. (2012). Prenatal alcohol exposure, attention-deficit/hyperactivity disorder, and sluggish cognitive tempo. Alcoholism: Clinical and Experimental Research, 37, 338-346. doi: 10.1111/j.1530-0277.2012.01886.x

* Grant, T., Huggins, J., Connor, P., Pedersen, J. Y., Whitney, N., \& Streissguth, A. (2004). A pilot community intervention for young women with fetal alcohol spectrum disorders. Community Mental Health Journal, 40, 499-511.

Green, J. H. (2007). Fetal alcohol spectrum disorders: Understanding the effects of prenatal alcohol exposure and supporting students. Journal of School Health, 77, 103-108.

Greenbaum, R. L., Stevens, S. A., Nash, K., Koren, G., \& Rovet, J. (2009). Social cognitive and emotion processing abilities of children with fetal alcohol spectrum disorders: A comparison with attention deficit hyperactivity disorder. Alcoholism: Clinical and Experimental Research, 33, 1656-1670. doi: 10.1111/j.1530-0277.2019.01003.x

Hamilton, D. A., Kodituwakku, P., Sutherland, R. J., \& Savage, D. D. (2003). Children with fetal alcohol syndrome are impaired at place learning but not cued-navigation in a virtual Morris water task. Behavioral Brain Research, 143, 85-94. doi: 10.1016/s0166-4328(03)00028-7

Hanson, J. D., Winberg, A., \& Elliott, A. (2012). Development of a media campaign on fetal alcohol spectrum disorders for Northern Plains 
American Indian communities. Health Promotion Practice, 13, 842-847. doi: 10.1177/1524839911404232

Hope for Women in Recovery Summit. (2005). Understanding and addressing the impact of prenatal alcohol exposure. Retrieved from http://fasdcenter.samhsa.gov/documents/WiR_Proceedings_Raleigh_V2.pdf

Hopkins, R. B., Paradis, J., Roshankar, T., Bowen, J., Tarride, J., Blackhouse, G., ... Longo, C. J. (2008). Universal or targeted screening for fetal alcohol exposure: A cost-effectiveness analysis. Journal of Studies on Alcohol and Drugs, 69, 510-519.

Howell, K. K., Lynch, M. E., Platzman, K. A., Smith, G. H., \& Coles, C. D. (2006). Prenatal alcohol exposure and ability, academic achievement, and school functioning in adolescence: A longitudinal follow-up. Journal of Pediatric Psychology, 31, 116-126. doi: 10.1093/jpepsy/ jsj029

Janzen, L. A., Nanson, J. L., \& Block, G. W. (1995). Neurophysiological evaluation of preschoolers with fetal alcohol syndrome. Neurotoxicity and Teratology, 17, 273-279.

Jirikowic, T., Gelo, J., \& Astley, S. (2010). Children and youth with fetal alcohol spectrum disorders: Summary of intervention recommendations after clinical diagnosis. Intellectual and Developmental Disabilities, 48, 330-344. doi: 10.1352/1934-9556-48.5.330

Johnson, M. K., Hashtroudi, S., \& Lindsay, D. S. (1993). Source monitoring. Psychological Bulletin, 114, 3-28.

Johnston, C., \& Mash, E. J. (1989). A measure of parenting satisfaction and efficacy. Journal of Clinical Child Psychology, 18, 167-175.

* Kable, J. A., Coles, C. D., \& Taddeo, E. (2007). Socio-cognitive habilitation using the math interactive learning experience program for alcoholaffected children. Alcoholism: Clinical and Experimental Research, 31, 1425-1434. doi: 10.1111/j.1530-0277.2007.00431.x

Kalberg, W. O. \& Buckley, D. (2007). FASD: What types of intervention and rehabilitation are useful? Neuroscience and Biobehavioral Reviews, 31, 278-285. doi: 10.1016.j.neubiorev.2006.06.014

* Keil, V., Paley, B., Frankel, F., \& O’Connor, M. J. (2010). Impact of social skills intervention on the hostile attributions of children with prenatal alcohol exposure. Alcoholism: Clinical and Experimental Research, 34, 231-241. doi: 10.1111/j.1530-0277.2009.01086.x

* Kerns, K. A., Macsween, J., vander Wekken, S. V., \& Gruppuso, V. (2010). Investigating the efficacy of an attention training programme in children with feotal alcohol spectrum disorder. Developmental Neurorehabilitation, 13, 413-422. doi: 10.318423.2010. 51142109/ 1751 
Kodituwakku, P. W. (2007). Defining the behavioral phenotype in children with fetal alcohol spectrum disorders: A review. Neuroscience Biobehavioral Reviews, 31, 192-201.

Kodituwakku, P. W. (2009). Neurocognitive profile in children with fetal alcohol spectrum disorders. Developmental Disabilities Research Reviews, 15, 218-224.

Kodituwakku, P. W. (2010). A neurodevelopmental framework for the development of interventions for children with fetal alcohol spectrum disorders. Alcohol, 44, 717-728.

Kodituwakku, P. W., Adnams, C. M., Hay, A., Kitching, A. E., Burger, E., Kalberg, W. O., ... May, P. A. (2006). Letter and category fluency in children with fetal alcohol syndrome from a community in South Africa. Journal of Studies on Alcohol, 67, 502-509.

Kodituwakku, P. W., Handmaker, N. S., Cutler, S. K., Weathersby, E. K., \& Handmaker, S. D. (1995). Specific impairments in self-regulation in children exposed to alcohol prenatally. Alcoholism: Clinical and Experimental Research, 19, 1558-1564.

Kodituwakku, P. W., Kalberg, W. O., \& May, P. A. (2001). The effects of prenatal alcohol exposure on executive functioning. Alcohol Research \& Health: The Journal of the National Institute on Alcohol Abuse and Alcoholism, 25, 192-198.

Kully-Martens, K., Denys, K., Treit, S., Tamana, S., \& Rasmussen, C. (2012). A review of social skills deficits in individuals with fetal alcohol spectrum disorders and prenatal alcohol exposure: Profiles, mechanisms, and interventions. Alcoholism: Clinical and Experimental Research, 36, 568-576. doi: 10.1111/j.1530-0277.2011.01661.x

Kully-Martens, K., Pei, J., Job, J. \& Rasmussen, C., (2012). Source monitoring in children with and without fetal alcohol spectrum disorders (FASD). Journal of Pediatric Psychology, 37, 725-735. doi: 10.1093/jpepsy/jsr123

* Kurtz, P. F., Chin, M. D., Rush, K. S., Dixon, D. R. (2008). Treatment of challenging behavior exhibited by children with prenatal drug exposure. Research in Developmental Disabilities, 29, 582-594. doi: 10.1016/j.ridd.2007.05.007

Kyskan, C. E. \& Moore, T. E. (2005). Global perspectives on fetal alcohol syndrome: Assessing practices, policies, and campaigns in four English-speaking countries. Canadian Psychology, 46(3), 153-165.

* Loomes, C., Rasmussen, C., Pei, J., Manji, S., \& Andrew, G. (2008). The effect of rehearsal training on working memory span of children with fetal alcohol spectrum disorder. Research in Developmental Disabilities, 29(2), 113-124. doi: 10.1016/j.ridd.2007.01.001 
Lotan, M., Yalon-Chamovitz, S., \& Weiss, P. L. (2010). Virtual reality as means to improve physical fitness of individuals at a severe level of intellectual and developmental disability. Research in Developmental Disabilities, 31, 869-874. doi: 10.1016/j.ridd.2010.01.010

Lowe, J., Handmaker, N., \& Aragon, C. (2006). Impact of mother interactive style on infant affect among babies exposed to alcohol in utero. Infant Mental Health Journal, 27, 371-382. doi: 10.1002/imhj.20098

Lupton, C., Burd, L., \& Harwood, R. (2004). Cost of fetal alcohol spectrum disorders. American Journal of Medical Genetics, 127C: 42-50. doi: 10.1002/ajmg.c.30015

Manji, S., Pei, J., Loomes, C., \& Rasmussen, C. (2010). A review of the verbal and visual memory impairments in children with foetal alcohol spectrum disorders. Developmental Neurorehabilitation, 12, 239-247.

Mattson, S. N., Calarco, K. E., \& Lang, A. R. (2006). Focused and shifting attention in children with heavy prenatal alcohol exposure. Neuropsychology, 20, 361-369. doi: 10.1037/0894-4105.20.3.361

Mattson, S. N., Goodman, A. M., Caine, C., Delis, D. C., \& Riley, E. P. (1999). Executive functioning in children with heavy prenatal alcohol exposure. Alcoholism: Clinical and Experimental Research, 23, 1808-1815.

Mattson, S. N. \& Riley, E. P. (2000). Parent ratings of behavior in children with heavy prenatal alcohol exposure and IQ-matched controls. Alcoholism: Clinical and Experimental Research, 24, 226-231.

Mattson, S. N., Riley, E. P., Gramling, L., Delis, D. C., \& Jones, K. L. (1998). Neuropsychological comparison of alcohol-exposed children with or without physical feathers of fetal alcohol syndrome. Neuropsychology, 12, 146-153.

Mattson, S. N. \& Roebuck, T. M. (2002). Acquisition and retention of verbal and nonverbal information in children with heavy prenatal alcohol exposure. Alcoholism: Clinical and Experimental Research, 26, $875-882$.

Mattson, S. N., Roesch, S. C., Glass, L., Deweese, B. N., Coles, C. D., Kable, J. A., ... Riley, E. P. (2013). Further development of a neurobehavioral profile of fetal alcohol spectrum disorders. Alcoholism: Clinical and Experimental Research, 37, 517-528. doi: 10.1111/j.1530-0277. 2012.01952.x

May, P. A., Grossage, J. P., Kalberg, W. O., Robinson, L. K., Buckley, D., Manning, M., \& Hoyme, H. E. (2009). Prevalence and epidemiologic characteristics of FASD from various research methods with an emphasis on recent in-school studies. Developmental Disabilities Research Reviews, 15, 176-192. doi: 10.1002/ddrr.68 
McGee, C. L., Bjorkquist, O. A., Riley, E. P., \& Mattson, S. N. (2009). Impaired language performance in young children with heavy prenatal alcohol exposure. Neurotoxicology and Teratology, 31, 71-75. doi: 10.1016/j.ntt.2008.09.004

* McGregor, D. L. (2009). Never say never: Struggle and determination in the lives of young adults with FASD (Doctoral dissertation). Available from ProQuest Dissertations and Theses database.

Niccols, A. (2007). Fetal alcohol syndrome and the developing socioemotional brain. Brain and Cognition, 65, 135-142. doi: 10.1016/ jbandc.2007.02.009

O'Connor, M. J. \& Kasari, C. (2000). Prenatal alcohol exposure and depressive features in children. Alcoholism: Clinical and Experimental Research, 24, 1084-1092. doi: 0145-6008/00/2407-1084\$03.00/0

* O'Connor, M. J., Frankel, F., Paley, B., Schonfeld, A. M., Carpenter, E., Laugeson, E. A., \& Marquardt, R. (2006). A controlled social skills training for children with fetal alcohol spectrum disorders. Journal of Consulting and Clinical Psychology, 74, 639-648. doi: 10.1016/j.alcohol.2009.10.009

* O'Connor, M. J., Laugeson, E. A., Mogil, C., Lowe, E., Welch-Torres, K., Keil, V., \& Paley, B. (2012). Translation of an evidence-based social skills intervention for children with prenatal alcohol exposure in a community mental health setting. Alcoholism: Clinical and Experimental Research, 36, 141-152. doi: 10.1111/j.1530-0277. 2011.01591.x

O'Connor, M. J. \& Paley, B. (2006). The relationship of prenatal alcohol exposure and the postnatal environment to child depressive symptoms. Journal of Pediatric Psychology, 31, 50-64. doi: 10.1093/jpepsy/jsj021

Olson H. C., Ohlemiller, M. M., O’Connor, M. J., Brown, C. W., Morris, C. A., Damus, K. (2009a). A call to action: Advancing essential services and research on fetal alcohol spectrum disorders. Washington, DC: National Task Force on Fetal Alcohol Syndrome and Fetal Alcohol Effect. Retrieved from http://www.cdc.gov/ncbddd/fasd/documents/calltoaction.pdf

Olson, H. C., Oti, R., Gelo, J., \& Beck, S. (2009b). "Family matters:” Fetal alcohol spectrum disorders and the family. Developmental Disabilities Research Reviews, 15, 235-249. doi: 10.1002/ddrr.65

* Padgett, L. S., Strickland, D., \& Coles, C. D. (2006). Case study: Using a virtual reality computer game to teach fire safety skills to children diagnosed with fetal alcohol syndrome. Journal of Pediatric Psychology, 31, 65-70. doi: 10.1093/jpepsy/jsj030 
Peadon, E., Rhys-Jones, B., Bower, C., \& Elliott, E. J. (2009). Systematic review of interventions for children with fetal alcohol spectrum disorders. BMC Pediatrics, 9, 35-44. doi: 10.1186/1471-2431-9-35

Pei, J., Job, J., Kully-Martens, K., \& Rasmussen, C. (2012). Executive function and memory in children with Fetal Alcohol Spectrum Disorder. Child Neuropsychology, 17, 290-309. doi: 10.1080/ 09297049.2010 .544650

Pei, J., \& Rinaldi, C. (2004). A review of the evolution of diagnostic practices for fetal alcohol spectrum disorder. Developmental Disabilities Bulletin, 32, 125-139.

Poitra, B.A., Marion, S., Dionne, M., Wilkie, E., Dauphinais, P., WilkiePepion, M., ... Burd, L. (2003). A school-based screening program for fetal alcohol syndrome. Neurotoxicology and Teratology, 25, 725-729. doi: 10.1016/j.ntt.2003.07.007

Rasmussen, C. (2005). Executive functioning and working memory in fetal alcohol spectrum disorder. Alcoholism: Clinical and Experimental Research, 29, 1359-1367.

Rasmussen, C. (2006). Mathematics and working memory development in children with fetal alcohol spectrum disorder (Doctoral dissertation). Available from ProQuest Dissertations and Theses database.

Rasmussen, C., Becker, M., McLennan, J., Urichuk, L., \& Andrew, G. (2010). An evaluation of social skills in children with and without prenatal alcohol exposure. Child: Care, Health, and Development, 37, 711-718. doi: 10.1111/j.1365-2214.2010.01152.x

Rasmussen, C. \& Bisanz, J. (2009). Exploring mathematics difficulties in children with fetal alcohol spectrum disorders. Child Development Perspectives, 3, 125-130.

Rasmussen, C., Talwar, V., Loomes, C., \& Andrew, G. (2008). Brief report: Lie-telling in children with fetal alcohol spectrum disorder. Journal of Pediatric Psychology, 33(2), 220-226. doi: 10.1093/jpepsy/jsm069

Riley, E. P. \& McGee, C. L. (2005). Fetal alcohol spectrum disorders: An overview view with emphasis on changes in brain and behavior. Experimental Biology and Medicine, 230, 357-365. Retrieved from http://ebm.rsmjournals.com/content/230/6/357.full

* Roebuck-Spencer, T. M. \& Mattson, S. N. (2004). Implicit strategy affects learning in children with heavy prenatal alcohol exposure. Alcoholism: Clinical and Experimental Research, 28, 1424-1431. doi: 10.1097/01.ALC.0000139826.25247.5B

Rowbottom, L., Merali, N., \& Pei, J. (2010). Interventions for non-biological caregivers of children with fetal alcohol spectrum disorder. Developmental Disabilities Bulletin, 38, 35-54. 
* Ryan, S. \& Ferguson, D. L. (2006). On, yet under, the radar: Students with fetal alcohol syndrome disorder. Exceptional Children, 72, 363-379.

Schonfeld, A. M., Paley, B., Frankel, F., \& O'Connor, M. J. (2006). Executive functioning predicts social skills following prenatal alcohol exposure. Child Neuropsychology, 12, 439-452. doi: 10.1080/ 09297040600611338

Simmons, R. W., Thomas, J. D., Levy, S. S., \& Riley, E. P. (2006). Motor response selection in children with fetal alcohol spectrum disorders. Neurotoxicology and Teratology, 28, 278-285. doi: 10.1016/ j.ntt.2006.01.008

Skinner, D. \& Weisner, T. S. (2007). Sociocultural studies of families of children with intellectual disabilities. Mental Retardation and Developmental Disabilities, 13, 302-312. doi: 10.1002/mrdd. 20170

Skogerbø, Å., Kesmodel, U., Wimberley, T., Støvring, H., Bertrand, J., Landrø, N., \& Mortensen, E. (2012). The effects of low to moderate alcohol consumption and binge drinking in early pregnancy on executive function in 5-year-old children. BJOG: An International Journal of Obstetrics and Gynecology, 119, 1201-1210. doi: 10.1111/ j.1471-0528.2012.03397.x

Sood, B., Delaney-Black, V., Covington, C., Nordstrom-Klee, B., Ager, J., Templin, T., ... Sokol, R. J. (2001). Prenatal alcohol exposure and childhood behavior at age 6 to 7 years: I. Dose-response effect. Pediatrics, 27, 108-134.

Spohr, H., Willms, J., \& Steinhausen, H. (2007). Fetal alcohol spectrum disorders in young adulthood. The Journal of Pediatrics, 150, 175-179. doi: 10.1016/j.peds.2006.11.044

Stephen, J. M., Kodituwakku, P. W., Kodituwakku, E. L., Romero, L., Peters, A. M., Sharadamma, N. M., ... Coffman, B. A. (2012). Delays in auditory processing identified in preschool children with FASD. Alcoholism: Clinical \& Experimental Research, 36, 1720-1727. doi: 10.1111/j.1530-0277.2012.01769.x

Streissguth, A. P., Barr, H. M., Kogan, J., \& Bookstein, F. L. (1996). Understanding the occurrence of secondary disabilities in clients with fetal alcohol syndrome and fetal alcohol effects: Final report to the Centers for Disease Control. Seattle, WA: University of Washington, Fetal Alcohol and Drug Unit.

Streissguth, A. P. (1997). Fetal alcohol syndrome: A guide to families and communities. Baltimore, MD: Guilford Press.

Streissguth, A. P., Bookstein, F. L., Barr, H. M., Sampson, P. D., O’Malley, K., \& Young, J. K. (2004). Risk factors for adverse life outcomes in fetal 
alcohol syndrome and fetal alcohol effects. Developmental and Behavioral Pediatrics, 25, 228-238. doi: 0196-206X/00/2504-0228

Strickland, D. C., McAllister, D., Coles, C. D., \& Osborne, S. (2007). An evolution of virtual reality training designs for children with autism and fetal alcohol spectrum disorders. Topics in Language Disorders, 27, 226-241.

Substance Abuse and Mental Health Services Administration. (2011). Results from the 2010 National Survey on Drug Use and Health: Summary of National Findings, NSDUH Series H-41, HHS Publication No. (SMA) 11-4658. Rockville, MD: Substance Abuse and Mental Health Services Administration.

* Timler, G. R., Olswang, L. B., \& Coggins, T. E. (2005). "Do I know what I need to do?" A social communication intervention for children with complex clinical profiles. Language, Speech, and Hearing Services in Schools, 36, 73-85.

* Vernescu, R. (2008). Sustained attention training in children with fetal alcohol spectrum disorder (Doctoral dissertation). Available from ProQuest Dissertations and Theses database.

Ware, A. L., O’Brien, J. W., Crocker, N., Deweese, B. N., Roesch, S. C., Coles, C. D., ... Mattson, S. N. (2012). The effects of prenatal alcohol exposure and attention-deficit/hyperactivity disorder on psychopathology and behavior. Alcoholism: Clinical and Experimental Research, 37, 507-516. doi: 10.1111/j.1530-0277.2012.01886.x

Watson, E., Finkelstein, N., Gurewich, D., \& Morse, B. (2011). The feasibility of screening for fetal alcohol spectrum disorders risk in early intervention settings: A pilot study of systems change. Infants \& Young Children, 24, 193-206. doi: 10.1097/IYC0b013e31820d97c9

* Wells, A. M., Chasnoff, I. J., Schmidt, C. A., Telford, E., \& Schwartz, L. D. (2012). Neurocognitive habilitation therapy for children with fetal alcohol spectrum disorders: An adaptation of the Alert Program. American Journal of Occupational Therapy, 66, 24-34. doi: 10.5014/ajot.111.002691

Whaley, S. E., O'Connor, M. J., \& Gunderson, B. (2001). Comparison of the adaptive functioning of children prenatally exposed to alcohol to a nonexposed clinical sample. Alcoholism: Clinical and Experimental Research, 25(7), 1018-1024.

Willford, J. A., Richardson, G. A., Leech, S. L., \& Day, N. L. (2004). Verbal and visuospatial learning and memory function in children with moderate prenatal alcohol exposure. Alcoholism: Clinical \& Experimental Research, 28(3), 497-507. 
Williams, B. F. \& Howard, V. R. (1994). Fetal alcohol syndrome: Developmental characteristics and directions for further research. Education and Treatment of Children, 17, 86-97.

Wozniak, J. R., Mueller, B. A., Muetzel, R. L., Bell, C. J., Hoecker, H. L., Nelson, M. L., Chang, P. N., \& Lim, K. O. (2011). Inter-hemispheric functional connectivity disruption in children with prenatal alcohol exposure. Alcoholism: Clinical and Experimental Research, 35, 849-861. doi: 10.1111/j.1530-0277.2010.01415.x

Yuen, E. K., Herbert, J. D., Forman, E. M., Goetter, E. M., Comer, R., \& Bradley, J. C. (2013). Treatment of social anxiety disorder using online virtual environments in second life. Behavior Therapy, 44, 51-61.

Zelner, I., Shor, S., Lynn, H., Roukema, H., Lum, L., Eisinga, K., \& Koren, G. (2012). Neonatal screening for prenatal alcohol exposure: Assessment of voluntary maternal participation in an open meconium screening program. Alcohol, 46, 269-276. doi: 10.1016/j.alcohol.2011.09.029 


\title{
BEYOND THE BRICK WALLS: HOMESCHOOLING STUDENTS WITH SPECIAL NEEDS
}

\author{
KATHLEEN B. COOK, KATIE E. BENNETT, JUSTIN D. LANE, \\ AND THEOLOGIA K. MATARAS
}

University of Georgia

\begin{abstract}
Author Note
Kathleen B. Cook, Department of Communication Sciences and Special Education, University of Georgia; Katie E. Bennett, Department of Communication Sciences and Special Education, University of Georgia; Justin D. Lane, Department of Communication Sciences and Special Education, University of Georgia; and Theologia K. Mataras, Department of Communication Sciences and Special Education, University of Georgia.

The authors wish to acknowledge the support and advisement of Dr. Kristin Sayeski in preparation of this manuscript.

Correspondence concerning this article should be addressed to Kathleen Cook, Department of Communication Sciences and Special Education, 570E Aderhold Hall, University of Georgia, Athens, GA 30602. E-mail: kcook1@uga.edu
\end{abstract}

\section{ABSTRACT}

The percentage of children with special needs receiving academic instruction at home has substantially increased since a resurgence of homeschooling during the 1990s. In light of this information, the purpose of this article was to provide an overview of the history and laws related to homeschooling, the characteristics of homeschool families, and the relevant issues that parents of children with disabilities encountered when choosing to homeschool. This is followed by a discussion of the reasons parents chose to homeschool their children with special needs, as well as the current state of research on homeschooling students with disabilities. Finally, suggestions related to 
homeschooling students with disabilities were made for future researchers, parents, and public school educators.

Over the past 15 years, data from the National Center for Education Statistics have shown an increasing trend in the numbers of children being educated within the home, including students with disabilities (Bielick, 2008). During the period from 1999 to 2007, the percentage of students with disabilities who were homeschooled increased from 1.8 to $2.6 \%$ (National Center for Education Statistics, 2010). The 2007 National Household Education Surveys Program found that approximately $21 \%$ of homeschooling parents reported "other special needs" and 11\% reported "physical or mental health problems" as important reasons for homeschooling (National Center for Education Statistics, 2007). According to these surveys, homeschooling has increasingly become an educational option for parents with exceptional children.

As more parents of children with disabilities consider homeschooling, this article provides information related to that decision-making process. First, an overview of homeschooling is provided, including a brief history of homeschools in the United States and a summary of laws related to homeschools and special education. Next, relevant issues for parents considering homeschooling are discussed, including characteristics of homeschool students and families, reasons that families have chosen to homeschool their children with disabilities, the benefits and challenges encountered, and the role of the public schools. Then, the current state of research on homeschool students with disabilities is explored. Finally, suggestions are made for future researchers, as well as for parents and public school educators, to consider when planning for the educational needs of children with disabilities at home.

\section{HISTORY OF HOMESCHOOLING IN THE UNITED STATES}

Throughout history, children have been educated at home. However, the industrial revolution of the late 1800s and early 1900s resulted in compulsory U.S. public school attendance legislation, and thus, homeschooling was no longer considered an option for most U.S. families for more than a half-century (Duffey, 1999; Wilhelm \& Firmin, 2009). Homeschool, however, made a resurgence in the 1960s. The rise in homeschools during that time was influenced by many different social and political influences 
including the passage of desegregation laws; removal of prayer from schools; and John Holt's book, How Children Fail, which blamed public schools for failing to educate (Wilhelm \& Firmin, 2009). The number of children being homeschooled steadily increased from the 1960s onward, and by 1993, homeschooling was legal in all 50 states (Wilhelm \& Firmin, 2009). Today's compulsory attendance laws stipulate attendance in public or nonpublic schools_-including homeschools_-and all K-12 programs must be approved by the state (Knickerbocker, 2001). In 2007, the National Household Education Surveys Program estimated that 1.5 million U.S. children, or almost $3 \%$ of school-aged children, received homeschooling (Bielick, 2008).

\section{LAWS AND REGULATIONS}

The U.S. Congress first passed legislation to provide funding for the education of students with disabilities in the 1970s. This legislation has been reauthorized several times over the years and is currently known as the Individuals with Disabilities Education Act (IDEA; Knickerbocker, 2001). Although making a distinction between public and private schools in the disbursement of funds, IDEA did not define what constituted a private school nor did it specifically address funding for students in homeschools. Therefore, decisions on whether to provide funding for special education services to students in homeschools were left to individual states, and many states considered IDEA rights to be forfeited for homeschool students (Knickerbocker, 2001; Lambert, 2001). The U.S. Supreme Court has supported the power of the individual states to make decisions about support of children with disabilities in homeschools. For example, in Hooks v. Clark County School District (1998), the U.S. Supreme Court upheld a Nevada school system's denial of speech therapy services for a homeschool child (as cited in Knickerbocker, 2001). The Supreme Court ruled that individual states have the power to treat a homeschool as either a private school or as a non-school; if categorized as a non-school, a student in a homeschool is not eligible for IDEA services (Knickerbocker, 2001; Lambert, 2001). However, some states such as Arizona, Iowa, North Dakota, and Pennsylvania have homeschool laws that include provisions for students with disabilities (Reinhiller \& Thomas, 1996). The state of Washington allows funding for special services for homeschool students who also attend public schools part time; other states or local education agencies provide special services for homeschool students on a case-by-case basis (Knickerbocker, 2001). Several authors (Duffey, 2002; Knickerbocker, 2001; Lambert, 2001) argued that IDEA should be 
amended to define homeschools as private schools so that services will be available for homeschool students with disabilities. It is notable that the U.S. Office of Special Education Programs has interpreted IDEA's Child Find provisions to be inclusive of children who are being homeschooled, even though services may not be available to eligible children who remain homeschooled (Duffey, 2002). In states that do allow IDEA funds to be used for homeschool students, two additional factors are typically in play: (a) in order to receive services, the parents must also agree to submit to evaluations for their children and work with a team to develop educational plans, thereby giving up some control of their children's educational management; and (b) IDEA funding for all eligible students in non-public schools is not guaranteed (Knickerbocker, 2001).

Whether or not a homeschool student has a disability, the homeschool must comply with its state's compulsory attendance laws (Reinhiller \& Thomas, 1996). Homeschool regulations vary from state-to-state, but most states stipulate that homeschools document some or all of the following: (a) specific qualifications of the home educator, (b) curriculum choices, (c) required number of hours per day and days per year of instructional time, (d) standardized testing, and (e) reports to local school systems (Reinhiller \& Thomas, 1996). The burden for compliance with state homeschool laws and regulations rests on the parents. In sum, parents need to know the local homeschool regulations and the accessibility of special education services for homeschools; a good place to start searching for information is the local school board.

\section{HOMESCHOOL CONSIDERATIONS}

\section{STUDENT AND FAMILY CHARACTERISTICS}

The research literature on homeschooling has shown that students with many different types of disabilities and with varying levels of need have participated in homeschools. Duffey (2002) conducted a national survey of parents who homeschooled their children with disabilities. The top diagnoses of homeschool children reported from 121 surveys were attention deficit hyperactivity disorder (ADHD), learning disabilities (LD), autism spectrum disorder (ASD), and speech-language impairment (Duffey, 2002). However, studies have also chronicled homeschool children with epilepsy (Arora, 2006; Reilly, Chapman, \& O’Donoghue, 2002), visual impairments (Arora, 2006; Parsons \& Lewis, 2010), intellectual disabilities (Kidd \& Kaczmarek, 2010; Parsons \& Lewis, 2010), hearing impairments and deafness (Parks, 2009), and physical disabilities (Loten, 2011; Parsons \& Lewis, 2010; Reilly et al., 2002). In addition, Obeng (2010) reported 
qualitative interviews with two parents of pre-adolescents with severe multiple health problems. Furthermore, a study by Duffey (2002) indicated that parents of students with disabilities tended to take a longer time deciding to remove their children from public school than other homeschool parents. However, once removed, the homeschool students with disabilities were also more likely to receive part time services from public schools than other homeschool students (Duffey, 2002). Another attribute of some homeschool families was that only their children with disabilities were homeschooled, while the siblings continued to attend public school (Olsen, 2008).

Homeschool children with disabilities come from families that are similar to all homeschool families. In a national survey of families who homeschooled children with disabilities, most families were described as white, two-parent (working father and stay-at-home mother), suburban, and with 3.5 children with 1.5 identified as having special needs (Duffey, 2002). In addition, most homeschool students with disabilities received the majority of instruction from their mothers (Arora, 2006; Duffey, 2002; Parks, 2009), even though fathers or other instructors have been reported (Arora, 2006). Duffey (2002) also found that $12 \%$ of mothers were certified teachers, $30 \%$ of which had some training in special education. Parents reported a wide range of educational levels, from high school through master's degrees (Parks, 2009; Parsons $\&$ Lewis, 2010). A very small number of homeschool parents reported having a physical or mental disability themselves (Rothermel, 2011). Collectively, these studies provided a picture of homeschoolers with disabilities and their families; nevertheless, there are many homeschool students and families that will not fall under these broad descriptors.

\section{REASONS FOR HOMESCHOOLING}

Two main philosophical perspectives for homeschooling have traditionally been described as ideological and pedagogical (Higgins, 2008). Initially categorized by Van Galen in 1988 (as cited in Higgins, 2008), Higgins attempted to verify whether homeschool parents could be divided into Van Galen's two discrete groups: ideologues, homeschooling because of religious reasons; or pedagogues, homeschooling to provide different methods of instruction than the schools. Higgins concluded that the philosophical position for most homeschool families indicated an overlap between the two constructs-more often, both principles played a part in the decision to homeschool. The results of studies of homeschool students with disabilities aligned with Higgins' findings: many parents expressed a desire to teach their children from religious 
perspectives (Arora, 2006; Parks, 2009; Parsons \& Lewis, 2010), but more often, the main decision to homeschool was related to a desire to provide better instruction or individualization for their children (Arora, 2006; Duffey, 2002; Hurlbutt, 2011; Loten, 2011; Olsen, 2008; Parks, 2009; Parsons \& Lewis, 2010; Reilly et al., 2002).

Parents with deep philosophical differences with public education may choose to homeschool regardless of the services their children with disabilities could be offered in public school. However, other reasons for homeschooling, frequently rooted in pedagogy, include the perception that the public school has failed to meet a child's needs. That is, the main motivation for many parents to homeschool was that their children's special education needs simply were not being met (Arora, 2006; Duffey, 2002; Hurlbutt, 2011; Olsen, 2008; Parks, 2009; Parsons \& Lewis, 2010; Reilly et al., 2002). For example, a chief concern of parents of children with ASD was that schools were either unwilling or unable to provide therapies or treatments that parents considered effective (Hurlbutt, 2011). In addition, parents also attributed negative experiences with public schools as a deciding factor in choosing to homeschool (Duffey, 2002; Parsons $\&$ Lewis 2010). Other reasons for homeschooling included escape from bullying (Arora, 2006; Parsons \& Lewis, 2010) and avoiding the stigma of a labeled disability (Ensign, 2000; Olsen, 2008). The salient point is that some parents, frustrated with their child's services, choose to homeschool and figure out how to deliver those services on their own. These findings suggest that, especially in school systems that do not have official policies and programs to support homeschool families, public schools could do a better job of outreach, connection, and communication with families to prevent much of the dissatisfaction that has led many parents to choose homeschooling over public schools.

\section{BENEFITS AND CHALLENGES OF HOMESCHOOLING}

A majority of parents across several studies reported satisfaction with their children's progress in homeschools (Duffey, 2002; Kidd \& Kaczmarek, 2010; Rothermel, 2011). Parents specified the benefits of freedom in selecting curriculum, pace of instruction, and daily routines that met their family's and individual children's needs (Ensign, 2000; Hurlbutt, 2011; Loten, 2011). In this era of increased access to technology, many parents reported reliance on Internet sources for instructional support (Parsons and Lewis, 2010). In addition, educational consultants were often used at some point in the homeschool planning process, especially when the child had special needs (Ensign, 2000). Some students were unschooled, meaning they had an unstructured schedule guided by the student's day-to-day learning interests (Loten, 2011). 
However, Arora (2006) found that most of the interviewed families followed a structured daily routine for their children with disabilities. Furthermore, Higgins (2008) related that parents of children with disabilities were significantly more likely to use traditional teaching methods (i.e., parent directed) in homeschooling rather than more loosely structured instruction. Although there has been some indication that homeschool families shift from original values and attitudes over time, becoming more nontraditional the longer they homeschooled (Rothermel, 2011), it is unclear whether families whose children have special needs follow this progression. However, no matter the degree of structure or the method of instruction, parents reported enjoying much more control over their children's education when they homeschooled.

Although parents tended to give high ratings to the overall homeschool experience, many reported challenges with homeschooling students with disabilities. Some families described a lack of emotional, social, and moral support from outside sources (Arora, 2006; Obeng, 2010). When support was found, it was more likely to be from other homeschool families and organized homeschool groups than from public schools (Arora, 2006; Parsons \& Lewis, 2010). In interviews with two parents who homeschooled their children with severe multiple health problems, Obeng (2010) found that parents did not receive enough professional and social support, and as a result, the parents were feeling overwhelmed with sadness and frustration. While many other factors may influence the intensity of homeschooling challenges, certainly the severity of the child's needs and the amount of support available to the family are two major components that will affect the success of the homeschool program.

Although a commonly stated concern related to homeschooling was that students might have limited social interactions, most parents reported feeling satisfied with the socialization opportunities afforded their children from homeschool groups, sports, and religious services (Kidd \& Kaczmarek; 2010; Loten, 2011; Parks, 2009; Parsons \& Lewis, 2010). However, very few researchers gathered information directly from the homeschool students with disabilities about their perspectives on socialization. In one study that included interviews with homeschool adolescent females with LD, all three participants reported feeling uncomfortable in social situations (Loten, 2011). The first participant, an adolescent girl who also had a physical disability, reported struggling to make friends even though she had plenty of opportunities to socialize. The second adolescent reported not feeling a part of her peer group because of her learning deficits, and the third adolescent reported feelings of peer isolation because her family lived in a rural area. While it is possible that these teens would have felt the same awkwardness or isolation in a public school setting, socialization might remain an area of legitimate concern for many homeschool students and their parents. 


\section{ROLE OF PUBLIC SCHOOLS}

Unfortunately, there often seems to be disconnect between public schools and homeschools. For example, an interview of educators in Canadian schools indicated mostly negative opinions about students that had been removed from their schools for homeschooling (Olsen, 2008). Administrators reported being aware that parents probably did not share their real reasons for choosing to homeschool, but also expressed frustration with parents for not working with the school to resolve problems. Conversely, parents reported not feeling genuinely welcomed to ask for support from schools, even though some administrators offered part time classes and the opportunity to reenroll students. In addition, teachers reported feeling personally offended when parents removed their children from school. Teachers' perceptions were that students tended to reenter public schools after a period of homeschooling with greater academic and social deficits (Olsen, 2008). Overall, most of the educators reported negative views on homeschooling (Olsen, 2008). Such negative attitudes about homeschooling seem to be pervasive across many educators and educational groups, including the National Education Association. An organization supporting public education, the National Education Association has issued resolutions over the past several years stating that homeschools with parents as instructors are inadequate educational programs (National Educational Association, 2013).

As noted earlier, parents reported many reasons for choosing to educate children with disabilities at home, but frequently, unhappiness with the schools was a main motivation. In a personal account of her experiences homeschooling her son with an ASD, Sofia (2010) described her frustrations with her son's fourth grade teachers. Sofia felt that the teachers expected all students to have normal behavior and placed inordinately high value on student compliance as a measure of success. Rather than providing differentiated instruction, teachers blamed her son's inappropriate behavior for his lack of progress. After removing her son from school, Sofia employed the services of a certified teacher for curriculum advice, based homeschool lessons on her son's areas of interest, and provided her son explicit instruction on social rules. Sofia reported that her son successfully reentered the public school system the following school year.

It is important to note that not all school systems fail to support of homeschools. One example of a school system providing homeschooling services is the Des Moines Public Schools Home Instruction Program (Des Moines Public Schools, 2013). The Des Moines Public School System was one of the first in the United States to offer a cooperative home-school partnership for homeschooling families (Duffey, 1999). There are other home-school partnerships in existence, and it seems that they may present a viable solution to 
support children with disabilities in homeschools. Funding special education services for homeschool students can offer support for families as well as special education services for students, and can potentially provide a seamless reentry for students who elect to return after a year or two of homeschooling. Even though parents of children with disabilities may have high expectations of the educational system, schools might prevent families from withdrawing due to dissatisfaction by developing a better understanding of student and family needs, and promoting stronger outreach.

\section{CURRENT STATE OF HOMESCHOOLING RESEARCH}

A recent comprehensive literature review evaluated homeschooling in general (Kunzman \& Gaither, 2013). Results of the review indicated that most research on homeschooling was qualitative in design (e.g., surveys, case studies, and personal interviews) and conducted within the United States. Kunzman and Gaither (2013) attributed the dearth of quantitative research to varying state regulations and recordkeeping requirements, which created difficulties in comparing existing state databases. Kunzman and Gaither also contended that, although a few large group studies have reported high academic achievement in homeschool students, the validity of experimental research results may be questionable. For example, in studies by Home School Legal Defense Association and the National Home Education Research Institute, research designs did not employ random sampling methods, and homeschool volunteers provided self-reports of achievement test scores (Kunzman \& Gaither, 2013).

As in the Kunzman and Gaither (2013) review on homeschools, most of the existing research on homeschool students with disabilities used qualitative or mixed method research designs. In addition, the most common method for gathering data was parent interview or survey. The qualitative and mixed method research design studies largely reported on parent motivation and rationale for homeschooling; many also discussed other homeschool issues such as the level of education of the instructor-parent, the structure of the school day and teaching methods used, opportunities to socialize, and overall perception of whether the homeschool experience was successful. Only two studies collected information directly from homeschool students (see Ensign, 2000; Loten, 2011).

It is notable that there have not been any studies using true experimental research designs that examine the efficacy of homeschooling students with disabilities. However, two quasi-experimental exploratory studies supported the effectiveness of parents as instructors of their children with disabilities in a 
homeschool setting. The first exploratory study was conducted with children with LD (Duvall, Ward, Greenwood, \& Delquadri, 1997). Participating students were comprised of one middle school and three elementary level students who were paired with counterpart peers of similar ages, demographic descriptions, and abilities in public school. The duration of student engagement in academic tasks was collected over seven observations in both settings, and pretest-posttest standardized achievement tests were administered to both groups of students. Duvall et al. (1997) determined that homeschool students with LD were on task and engaged in work activities approximately two-anda-half times more than their counterparts in a general education classroom. Pretest to posttest comparisons also indicated that homeschool students made more progress in reading and written language than their public school peers, and made equivalent progress in math. Duvall et al. (1997) attributed the progress of the homeschool students to the higher rate of interaction with the parent-instructor and the greater degree of individualized attention provided in the homeschool setting.

Several years later, Duvall, Delquadri, and Ward (2004) replicated the earlier exploratory study with students with ADHD instead of LD. Two homeschool students with ADHD were paired with two similar students in the public school setting. Both groups of students were observed once a month for five months to collect academic engagement time data. Results indicated that the homeschool students with ADHD were academically engaged at higher rates than their counterparts, and their reading and math gains were greater or equal to their public school peers. Overall, Duvall et al. (2004) posited that study results supported the effectiveness of untrained parents as homeschool instructors of their children with disabilities; however, the parents of children with ADHD reported doubts about their effectiveness as instructors (Duvall et al., 2004).

\section{CONCLUSION}

\section{FUTURE RESEARCH}

Considering the limited research on the efficacy of homeschool students with disabilities - physical disabilities, in particular - there is a need for further study on the effects of homeschooling on the academic, social, and quality of life of students with disabilities. Although there may be challenges to conducting true experimental research, more research using systematic and tightly controlled quasi-experimental designs is warranted. Valuable information can be gleaned from evaluating homeschool variables such as student disabilities, level of parent education and training, curriculum, online programs, 
and professional supports (e.g., tutors, therapists) on student outcomes. More qualitative and quantitative research is warranted to describe and evaluate programs such as the Des Moines Public Schools Home Instruction Program (Des Moines Public Schools, 2013), including the participating students, the services offered, parent satisfaction, and student progress. A comprehensive list of states and local systems that offer services to homeschool students with disabilities would be also be of value to parents of students with disabilities. Furthermore, more research is needed on student perspectives and on longterm academic and social outcomes. (Arora, 2006; Duvall et al., 2004; Duvall et al., 1997; Parks, 2009). Lastly, more research is necessary on homeschool children with specific disabilities, such as children who are deaf or hard of hearing (Parks, 2009), and children with physical, health, and multiple disabilities.

\section{PERSPECTIVES OF PARENTS WHO HOMESCHOOL CHILDREN WITH DISABILITIES}

Many parents reported success homeschooling their children with disabilities, but others described the difficulties and the lack of support from the schools and the community. Some school systems provide part time services for students with disabilities, but many states do not support students that are in a homeschool setting. Parents need to be aware of the regulations and services available in their locales, and they need to explore the benefits and challenges of homeschooling before making the decision to homeschool a student with disabilities.

A common conclusion among studies was that a collaborative relationship between homeschools and school systems would be beneficial for students with disabilities (Arora, 2006; Duffey, 2002; Olson, 2008; Parks, 2009; Parsons \& Lewis, 2010; Reilly et al., 2002; Stevens \& Blair, 1997). Other researchers concluded that public schools might prevent some loss of students to homeschools by increasing individualized instruction (Loten, 2011; Parsons $\&$ Lewis, 2010). Of special concern are families whose children have severe disabilities. Obeng (2010) concluded that parents who homeschool children with extensive medical needs would also benefit from psychotherapy and other supports to maintain their own health. Kunzman and Gaither (2013), in their review of homeschools, reported that the trend seems to be moving in favor of greater access to public schools, with 22 states reporting some accommodations for homeschoolers and only six states refusing to support homeschools. Offering part time special education services might facilitate connection with the homeschool community, and may result in the decreased exodus of students with disabilities due to parental dissatisfaction. 
In conclusion, making the decision to homeschool a child with a disability requires thoughtful deliberation. Some of the many benefits of homeschooling are greater parent involvement, a strengthening of the family unit, opportunities for more natural learning experiences, increased self esteem in students with disabilities, increased individualization and student paced learning, and increased flexibility with family schedules (Peterson, 2009; Romanowski, 2001). However, the challenges include making curriculum decisions, managing finances, accessing special education services, facilitating socialization opportunities, and finding connections with other parents for support. In light of the increasing number of families choosing to homeschool, increased support in the form of special education services from the public schools would serve to improve the homeschooling experiences of many students with disabilities. In addition, if quality research begins to indicate that homeschooling can be done effectively, our legal and educational systems may become more willing to provide a continuum of special education support services. Furthermore, with improved relationships between public schools and families of children with disabilities, parents will choose to homeschool for the right reasons-not as an escape from the school system. The end result will be considered a win for both sides, and more importantly, for the children.

\section{REFERENCES}

Arora, T. (2006). Elective home education and special educational needs. Journal of Research in Special Educational Needs, 6(1), 55-66.

Bielick, S. (2008). 1.5 million homeschooled students in the United States in 2007. National Center for Education Statistics Institute of Education Sciences. http://nces.ed.gov/pubsearch/pubsinfo.asp?pubid=2009030

Des Moines Public Schools. (2013). Home Instruction Program. Retrieved from http://www.dmschools.org/departments/teaching-learning/ home-instruction/

Duffey, J. (1999). Home schooling and students in special education: Sorting out the options for parents. Preventing School Failure, 43(2), 57-63.

Duffey, J. (2002). Home schooling children with special needs. Journal of Special Education Leadership, 15, 25-32.

Duvall, S. F., Delquadri, J. C., \& Ward, D. L. (2004). A preliminary investigation of the effectiveness of homeschool instructional environments for students with attention-deficit/hyperactivity disorder. School Psychology Review, 33, 140-158.

Duvall, S. F., Ward, D. L. Greenwood, C. R., \& Delquadri, J. C. (1997). An exploratory study of home school instructional environments and 
their effects on the basic skills of students with learning disabilities. Education \& Treatment of Children, 20, 150-72.

Ensign, J. (2000). Defying the stereotypes of special education: Homeschool students. Peabody Journal of Education, 75, 147-158.

Higgins, C. (2008). Pilot study: Homeschooling parents' motivations and pedagogy. Unpublished manuscript. Department of Sociology, Humboldt State University, Arcata, California. Retrieved from http://www.humboldt.edu/sociology/downloads/senior_projects/2008_Higgins.pdf

Hurlbutt, K. (2011). Experiences of parents who homeschool their children with autism spectrum disorders. Focus on Autism and Other Developmental Disabilities, 26, 239-249.

Kidd, T. \& Kaczmarek, E. (2010). The experiences of mothers home educating their children with autism spectrum disorders. Issues in Educational Research, 20, 257-275.

Knickerbocker, L. R. (2001). The education of all children with disabilities: Integrating home-schooled children into the Individuals with Disabilities Education Act. Ohio State Law Journal, 62, 1515-1542.

Kunzman, R. \& Gaither, M. (2013). Homeschooling: A comprehensive survey of the research. Other Education: The Journal of Educational Alternatives, 2, 4-59.

Lambert, S. A. (2001). Finding the way back home: Funding for home school children under IDEA. Columbia Law Review, 101, 1709-1729.

Loten, S. (2011). Melissa, Trisha, and Ruth: Hearing the voices of three home schooled adolescents with learning disabilities (Master's thesis). Retrieved from http://hdl.handle.net/1974/6693

National Center for Education Statistics. (2007). Parent and Family Involvement in Education Survey of the 2007 National Household Education Surveys Program (NHES). U.S. Department of Education. Retrieved from http://nces.ed.gov/programs/coe/tables/table-hsc-2.asp

National Center for Education Statistics. (2010). Digest of education statistics: Table 41. Retrieved from http://nces.ed.gov/programs/digest/ d11/tables/dt11_041.asp

National Educational Association. (2013). 2012-1013 NEA resolutions: Home Schooling (Resolution No. B-82). Retrieved from http://www.nea.org/ resolutions

Obeng, C. (2010). A study of the experiences of parents with home-schooled pre-adolescent children with severe multiple health problems. International Journal of Special Education, 25, 80-86.

Olsen, N. B. (2008). Understanding parental motivation to home school: A qualitative case study. Dissertation Abstracts International Section A: Humanities and Social Science, 69(5-A), 1623. 
Parks, E. S. (2009). Deaf and hard of hearing homeschoolers: Sociocultural motivation and approach. Work Papers of the Summer Institute of Linguistics, University of North Dakota Session, 49. Retrieved from http://www.und.edu/dept/linguistics/wp/2009Parks.PDF

Parsons, S. \& Lewis, A. (2010). The home-education of children with special needs or disabilities in the UK: Views of parents from an online survey. International Journal of Inclusive Education, 14, 67-86.

Peterson, D. (2009). You can homeschool your child with special needs. Exceptional Parent, 39(5), 38-39.

Reilly, L., Chapman, A., \& O'Donoghue, T. (2002). Home schooling of children with disabilities. Queensland Journal of Educational Research, 18. Retrieved from http://www.iier.org.au/qjer/qjer18/reilly.html

Reinhiller, N. \& Thomas, G. J. (1996). Special education and home schooling: How laws interact with practice. Rural Special Education Quarterly, 15(4), 11-17.

Romanowski, M. H. (2001). Common arguments about the strengths and limitations of home schooling. Clearing House, 75, 70-83.

Rothermel, P. (2011). Setting the record straight: Interviews with a hundred British home educating families. Journal of Unschooling and Alternative Learning, 5, 20-57.

Sofia, C. A. (2010). Bringing lessons from homeschool to the writing classroom. English Journal, 100, 98-104.

Stevens, S. H. \& Blair, J. F. (1997). Homeschooling LD/ADD children: Great idea or big mistake? LDonline. Retrieved from http://www.ldonline.org/ article/Homeschooling_LD/ADD_Children\%3A_Great_Idea_or_Big _Mistake\%3F?theme=print

Wilhelm, G. M. \& Firmin, M. W. (2009). Historical and contemporary developments in home education. Journal of Research on Christian Education, 18, 303-315. 


\section{Important Notice}

The Division of Physical, Health and Multiple Disabilities is planning to convert its journal, Physical Disabilities: Education and Related Services, to an all-electronic format. In that case, this is the last hard copy of the journal that you will receive. Look for more information about this change soon. 